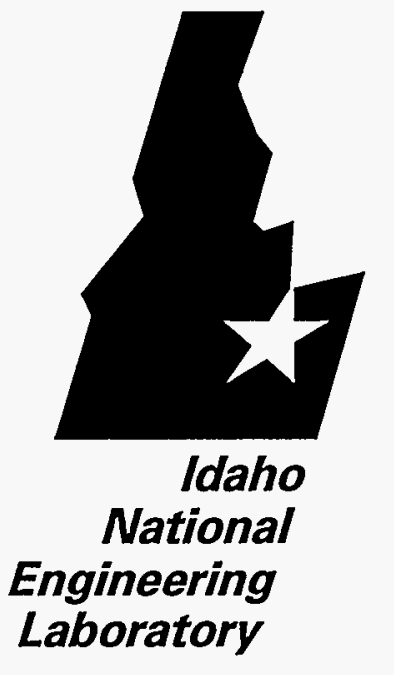

December 1995
Dig-face Monitoring during Excavation of a Radioactive Plume at Mound Laboratory, Ohio
N. E. Josten

R. J. Gehrke

M. V. Carpenter

\author{
PECCUPS \\ FEB 23 任了 \\ OSTI
}

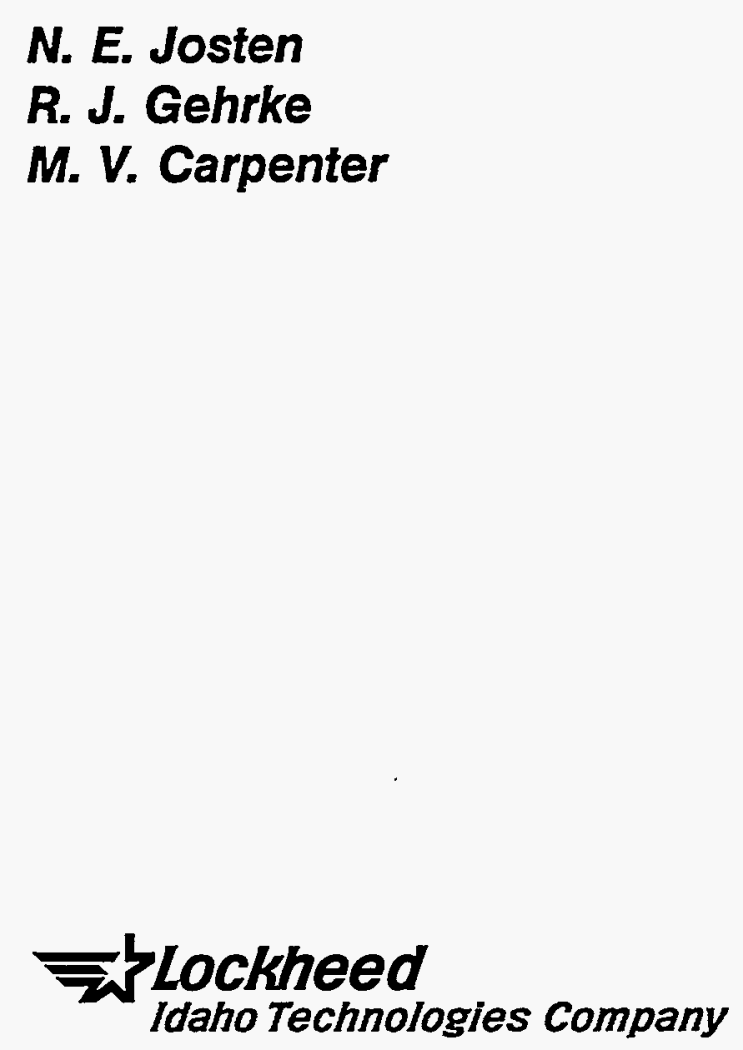


, 
INEL-95/0633

\title{
Dig-face Monitoring during Excavation of a Radioactive Plume at Mound Laboratory, Ohio
}

\author{
N. E. Josten \\ R. J. Gehrke \\ M. V. Carpenter \\ Published December 1995 \\ Idaho National Engineering Laboratory \\ Integrated Earth Sciences \\ Lockheed Idaho Technologies Company \\ Idaho Falls, Idaho 83415
}

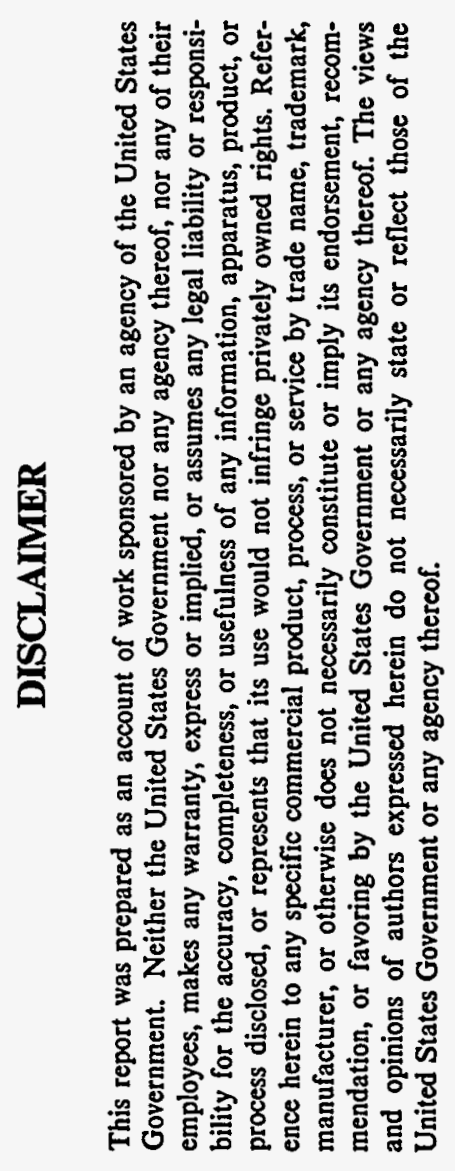

Prepared for the

U.S. Department of Energy

Assistant Secretary for Environmental Management

Under DOE Idaho Operations Office

Contract DE-AC07-94ID13223 


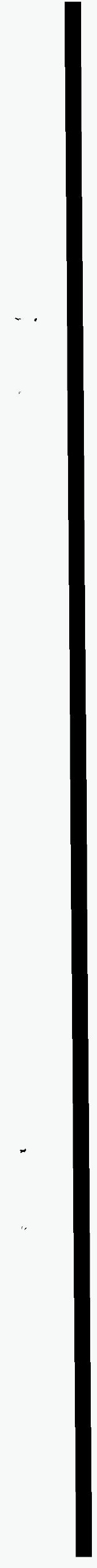




\section{ABSTRACT}

Dig-face characterization is a concept for improving the safety and efficiency of hazardous waste retrieval. A dig-face characterization system consists of onsite hardware for collecting detailed information on the changing chemical, radiological, and physical conditions in the subsurface soil during the entire course of a hazardous site excavation. The dig-face characterization concept originated at the Idaho National Engineering Laboratory and has been under development there since 1992. During August 1995, a prototype dig-face system was taken to Mound Laboratory, Ohio, for a first attempt at monitoring a hazardous excavation. Mound Area 7 was the site of historical disposals of ${ }^{232} \mathrm{Th},{ }^{227} \mathrm{Ac}$, and assorted debris. The dig-face characterization system was used to monitor a $20-\mathrm{ft} x$ 20 -ft $\times 5$-ft-deep excavation aimed at removing ${ }^{227}$ Ac-contaminated soils. Radiological, geophysical, and topographic sensors were used to scan across the excavation dig-face at four successive depths as soil was removed in 1-ft to 2-ft lifts. The geophysical and topographic sensors mapped the dig-face topography and the location of metallic debris in great detail as the excavation advanced. The radiation sensors produced high-fidelity images showing the location of radioactive contaminants and clearly identified and delineated separate ${ }^{232} \mathrm{Th}$ and ${ }^{227} \mathrm{Ac}$ plumes. By combining the radiation data from all four levels, a three-dimensional image of the contamination plumes was developed. The radiation sensor data indicated that only a small portion of the excavated soil volume was contaminated. This conclusion could not be verified by routine sample collection procedures because it was impossible to reconstruct the spatial position of the collected samples. The spatial information produced by the dig-face system was used to direct the excavation activities into the area containing the ${ }^{227} \mathrm{Ac}$ and to evaluate options for handling the separate ${ }^{232} \mathrm{Th}$ plume. 


\section{ACKNOWLEDGEMENTS}

The authors wish to acknowledge the Mound managers, scientists, technicians, and workers who welcomed us to work alongside them during this valuable study. Besides assisting and encouraging us, they also accomplished their own impressive demonstration of safe and complete remediation of a radioactively hazardous site under difficult conditions. Thanks to them for reclaiming Area 7 for future public use. 


\section{CONTENTS}

ABSTRACT $\ldots \ldots \ldots \ldots \ldots \ldots \ldots \ldots \ldots \ldots \ldots \ldots \ldots \ldots \ldots \ldots \ldots \ldots \ldots \ldots$

ACKNOWLEDGEMENTS $\ldots \ldots \ldots \ldots \ldots \ldots \ldots \ldots \ldots \ldots \ldots \ldots \ldots \ldots \ldots \ldots \ldots \ldots$

INTRODUCTION $\ldots \ldots \ldots \ldots \ldots \ldots \ldots \ldots \ldots \ldots \ldots \ldots \ldots \ldots \ldots \ldots \ldots \ldots \ldots$

1. BACKGROUND $\ldots \ldots \ldots \ldots \ldots \ldots \ldots \ldots \ldots \ldots \ldots \ldots \ldots \ldots \ldots \ldots \ldots \ldots \ldots$

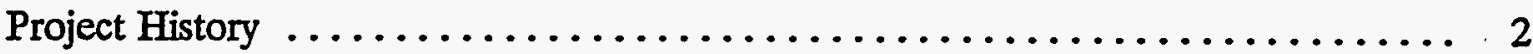

Selection of a Hot Demonstration Site $\ldots \ldots \ldots \ldots \ldots \ldots \ldots \ldots \ldots \ldots \ldots$

Mound Laboratory Area $7 \ldots \ldots \ldots \ldots \ldots \ldots \ldots \ldots \ldots \ldots \ldots \ldots \ldots \ldots \ldots$

Overview of the Mound Area 7 Operation $\ldots \ldots \ldots \ldots \ldots \ldots \ldots \ldots \ldots \ldots$

Description of the Dig-face Characterization System $\ldots \ldots \ldots \ldots \ldots \ldots \ldots \ldots \ldots$

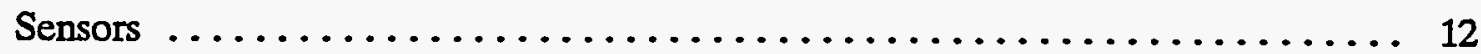

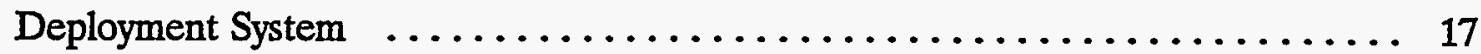

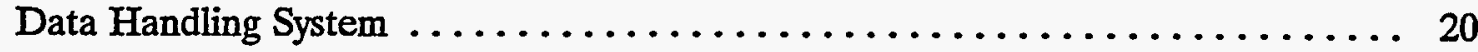

2. $\quad$ RESULTS $\ldots \ldots \ldots \ldots \ldots \ldots \ldots \ldots \ldots \ldots \ldots \ldots \ldots \ldots \ldots \ldots \ldots \ldots$

Laser Rangefinder Measurements $\ldots \ldots \ldots \ldots \ldots \ldots \ldots \ldots \ldots \ldots \ldots \ldots \ldots \ldots$

Level 1-4 Laser Rangefinder Measurements . . . . . . . . . . . . . . . . . . . 24

Magnetometer Measurements: The Benefit of Changing Viewpoints . . . . . . . . 24

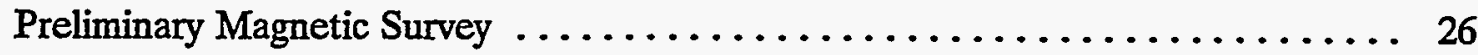

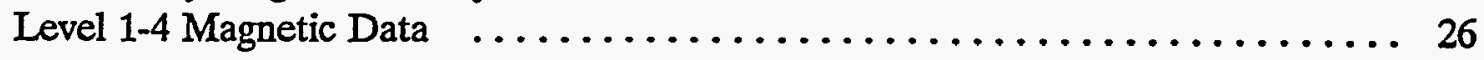

Radiation Measurements: Detecting and Mapping Radioactive Contamination ..... 34

Level 1 Radiation Measurements: Ground Elevation $=0.0 \mathrm{ft} \ldots \ldots \ldots \ldots \ldots$

Level 2 Radiation Measurements: Ground Elevation $=-1.5 \mathrm{ft} \ldots \ldots \ldots \ldots \ldots 34$

Level 3 Radiation Measurements: Ground Elevation $=-3.5 \mathrm{ft} \ldots \ldots \ldots \ldots \ldots 40$

Level 4 Radiation Measurements: Ground Elevation $=-5.6 \mathrm{ft} \ldots \ldots \ldots \ldots \ldots 40$

Interpretation of the ${ }^{232} \mathrm{Th}$ Contamination Area $\ldots \ldots \ldots \ldots \ldots \ldots \ldots \ldots$

Quantifying Radiation Measurements: In Situ Radionuclide Concentrations . . . . . 41

Conversion of Data to Activity Concentrations ................. 43 
A Comparison of Dig-face Radiation Data with Sampling and Analysis Plan

Sampling Results

Potential for Waste Minimization and Cost Savings

Operations Issues

Trolley Scan Footprint $\ldots \ldots \ldots \ldots \ldots \ldots \ldots \ldots \ldots \ldots \ldots \ldots \ldots \ldots \ldots \ldots$

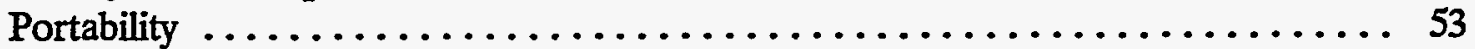

Trolley Function $\ldots \ldots \ldots \ldots \ldots \ldots \ldots \ldots \ldots \ldots \ldots \ldots \ldots \ldots \ldots$

Projected Cost for a Routine Dig-Face Characterization Operation ......... 55

3. SOME COMMENTS FROM USERS $\ldots \ldots \ldots \ldots \ldots \ldots \ldots \ldots \ldots \ldots \ldots$

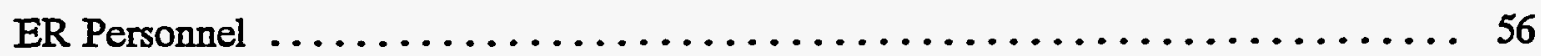

Health Physics $\ldots \ldots \ldots \ldots \ldots \ldots \ldots \ldots \ldots \ldots \ldots \ldots \ldots \ldots \ldots \ldots \ldots$

Remediation Workers $\ldots \ldots \ldots \ldots \ldots \ldots \ldots \ldots \ldots \ldots \ldots \ldots \ldots \ldots$

Regulators $\ldots \ldots \ldots \ldots \ldots \ldots \ldots \ldots \ldots \ldots \ldots \ldots \ldots \ldots \ldots \ldots \ldots \ldots$

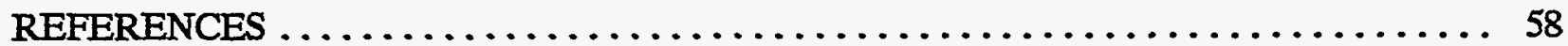

Appendix A-Radiation Sensor Calibration $\ldots \ldots \ldots \ldots \ldots \ldots \ldots \ldots \ldots \ldots \ldots \ldots \ldots \ldots$

FIGURES

1. Dig-face characterization system components shown in overall context of a

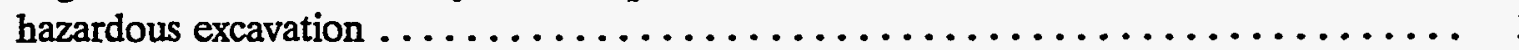

2. Drawing of site layout for the Area 7 excavation (left) and detail of excavation (right)

3. Photograph of trolley after initial assembly of the support structure at the INEL LBC facility

4. Photograph of trolley during full function testing at the INEL WRRTF facility ..... 9

5. Photograph showing construction of gravel foundations for the trolley $x$-axis tracks $\ldots 10$

6. Photograph showing placement of the bridge-mast assembly onto the track carriages .. 11 
7. Schematic summary of the excavation sequence at Area 7 during the dig-face characterization support phase $\ldots \ldots \ldots \ldots \ldots \ldots \ldots \ldots \ldots \ldots \ldots \ldots \ldots \ldots \ldots$

8. Photograph of the gamma/neutron mapper (GNM) mounted on the trolley $\ldots \ldots \ldots 15$

9. Photograph of the Ge-spectrometer mounted on the trolley $\ldots \ldots \ldots \ldots \ldots \ldots \ldots$

10. Photograph of the magnetometer/laser rangefinder (MLR) mounted on the trolley ... 18

11. Scale drawings of the Mound trolley viewed along each of the three principal axes ... 19

12. Photograph showing coupling between a bridge beam C-channel and pipe on track carriages $\ldots \ldots \ldots \ldots \ldots \ldots \ldots \ldots \ldots \ldots \ldots \ldots \ldots \ldots \ldots, 21$

13. Photograph of the sensor and trolley control workstation $\ldots \ldots \ldots \ldots \ldots \ldots \ldots 22$

14. Perspective net drawings of the Area 7 pit topography at each dig-face scan level ... 25

15. Magnetic map of the Area 7 site from data collected several months prior to beginning the excavation. Anomalies $\mathrm{D}$ and $\mathrm{E}$ are also shown in $2 \ldots \ldots \ldots \ldots 27$

16. Magnetic data from dig-face scan Levels 1 through $4 \ldots \ldots \ldots \ldots \ldots \ldots \ldots$

17. Photograph of concrete debris removed during the second excavation lift. The debris was thought to be a remnant of the concrete septic tank $\ldots \ldots \ldots \ldots \ldots \ldots . . . .33$

18. Gamma radiation data from dig-face scans Levels 1 through $4 \ldots \ldots \ldots \ldots \ldots \ldots$

19. Summary of dig-face characterization data for Level 1-4 dig-face scans (1-d). Magnetic object trends are shown by heavy lines

20. Interpreted geometry of ${ }^{232} \mathrm{Th}$ plume at Area 7. Lines in (a) show the location of peak radiation for each Level. The interpreted depth distribution is shown in (b) ...... 42

21. Contamination levels for various compartments of the Area 7 excavation based on

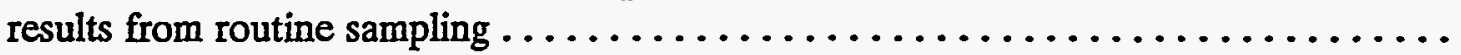

22. Comparison between ${ }^{227} \mathrm{Ac}$ contamination geometry as reconstructed from routine

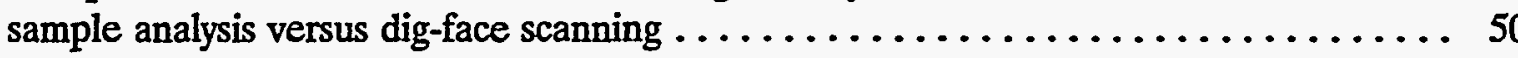

23. Comparison between ${ }^{232} \mathrm{Th}$ contamination geometry as reconstructed from routine sample analysis versus dig-face scanning $\ldots \ldots \ldots \ldots \ldots \ldots \ldots \ldots \ldots \ldots \ldots, 51$

24. Diagram of the effective scan area for the trolley-based dig-face characterization

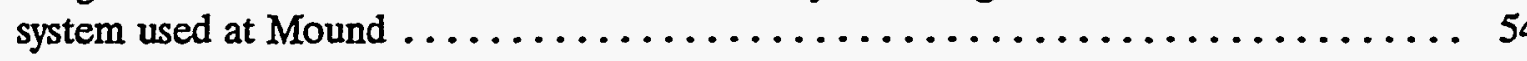


A-1. Drawing of the Ge-spectrometer detector/shield assembly showing the removable cover plate and window

A-2. Photograph of sample container used for measuring activity concentration in $20-\mathrm{g}$ grab samples

\section{TABLES}

1. Summary of Dig-face Characterization Project activities and key personnel .3

2. Summary of estimated radionuclide activity concentrations based on dig-face radiation sensor measurements ............................. 45

3. Cost estimate for operation of a dig-face characterization system as a commercial venture 


\section{Dig-face Monitoring during Excavation of a Radioactive Plume at Mound Laboratory, Ohio}

\section{INTRODUCTION}

This report describes the results from a demonstration of the Idaho National Engineering Laboratory (INEL) dig-face characterization system during excavation of radioactively contaminated soil at Mound Laboratory, Miamisburg, Ohio, in August 1995. In Section 1, the context for the demonstration is presented through brief descriptions of the dig-face characterization project history, the dig-face system hardware, and the historical conditions at the Mound demonstration site. Section 2 presents the unique Mound dig-face data sets and discusses their perceived significance. Section 3 summarizes comments and discussion offered by the four major players in the Mound remediation effort: regulators, Mound Environmental Restoration managers, health physicists, and the remediation workers.

The Mound effort produced many interesting results. The dig-face system captured detailed images of in situ radioactive contamination areas within the remedial excavation, which were observed to change with each excavation step. Contaminants were identified within minutes after scans were begun, in most cases hours or days before they were identified through sample analysis. Perhaps most interesting was the observation that contamination geometries interpreted from the dig-face scan images were in some ways quite different than the geometries interpreted from manual sampling results. The complementary relationship between the view of contamination pieced together from sample analysis, and the view based on dig-face scan data, offers promise for establishing true economic incentive to operate a dig-face characterization system. 


\section{BACKGROUND}

Dig-face characterization is a concept for improving the safety and efficiency of hazardous waste retrieval. Incomplete knowledge of hazards during waste retrieval can compromise worker safety or lead to spreading or mixing of hazardous materials, creating higher downstream waste processing and storage costs. A dig-face characterization system functions to identify and monitor the changing make-up of the dig during waste excavation as a means to avoid the undesirable consequences of incomplete knowledge. The system consists of on-site sensors and hardware for collecting detailed information on the changing chemical, radiological, and physical conditions in the subsurface during the entire course of hazardous waste excavation (Figure 1). Site managers use this information to recognize and correct potentially dangerous or inefficient operations.

\section{Project History}

The dig-face characterization concept has been under development since 1992 by the U.S. Department of Energy's (DOE's) Office of Technology Development (OTD) through the Landfill Stabilization Focus Area (LFSA) at the Idaho National Engineering Laboratory (INEL). The Dig-face Characterization Project began with a conceptual design effort, completed in 1992 (Josten 1992). Based on this conceptual design, several parallel development efforts were launched in FY-93. These efforts, which included sensor development and simulated site testing, were continued with some modifications in FY-94. In FY-95, the project performed a hot site demonstration. Table 1 summarizes project activities since inception.

\section{Selection of a Hot Demonstration Site}

The Mound demonstration culminated three years of dig-face characterization system development at simulated waste sites. The step from simulated demonstrations to a hot site demonstration was taken in order to shift the focus of the project from envisioned to practical technology and to obtain insights and criticisms from such end users as remediation managers, health physicists, workers, and regulators. The benefits of a dig-face characterization system arise chiefly from the safety and economic factors inherent in the actual handling of hazardous materials. It had become increasingly difficult to evaluate true benefit under nonhazardous conditions.

Beginning in early FY-95, INEL project personnel began contacting environmental restoration groups at other National Laboratories and defense facilities. They sought collaboration opportunities on impending remedial actions having size, complexity, and schedule commensurate with prototype dig-face characterization hardware. Several opportunities emerged. The simplest of these was an EPA approved Removal Action at Mound Laboratory Area 7 scheduled for Summer 1995.

A program for dig-face characterization support at Area 7 was outlined in a letter to Mound in late December 1994. System design began in late January 1995, and the new system was functional by May. The Area 7 excavation with dig-face characterization support was conducted in August. 


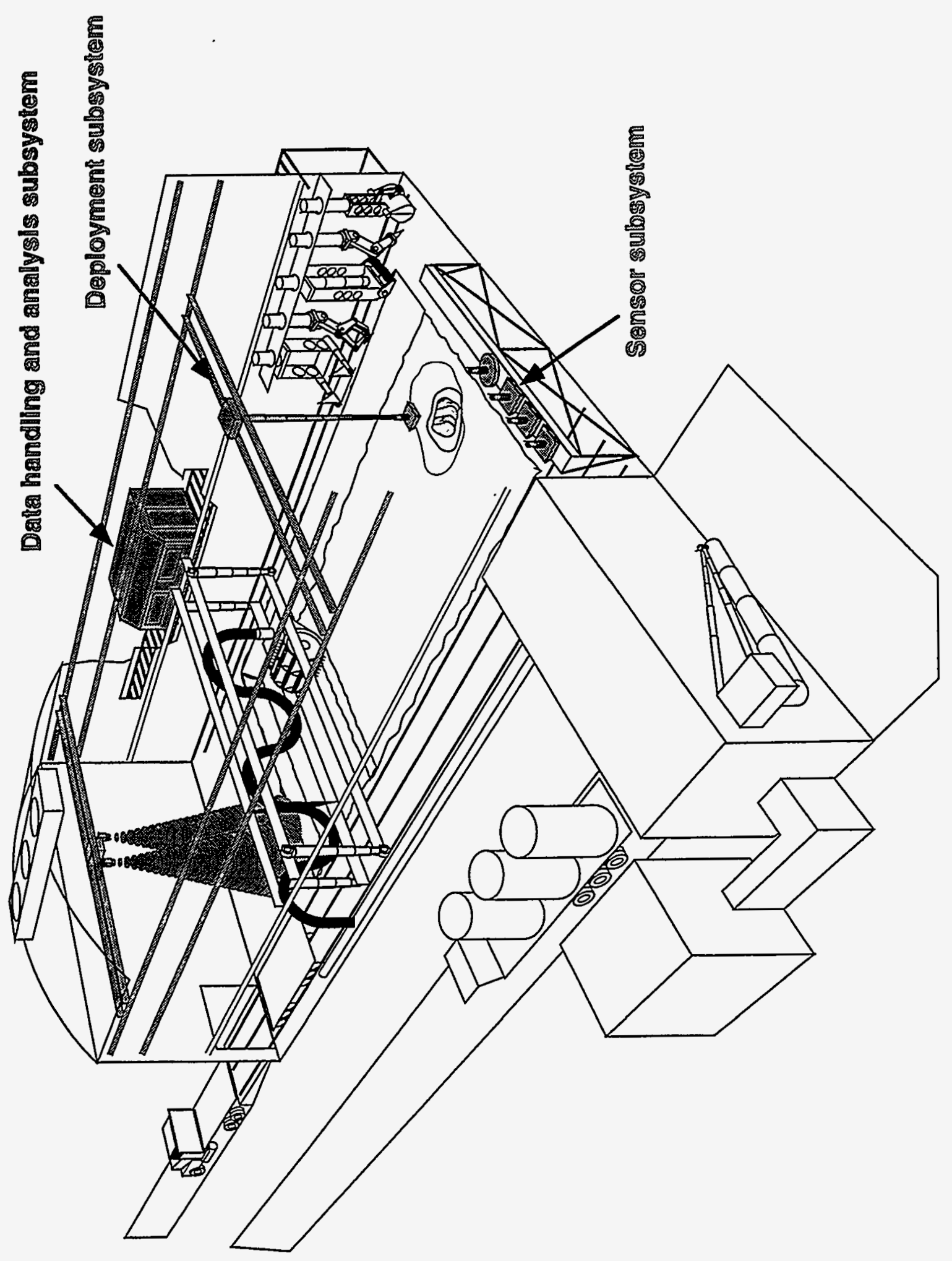

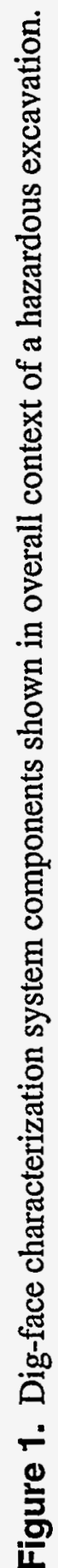


Table 1. Summary of Dig-face Characterization Project activities and key personnel.

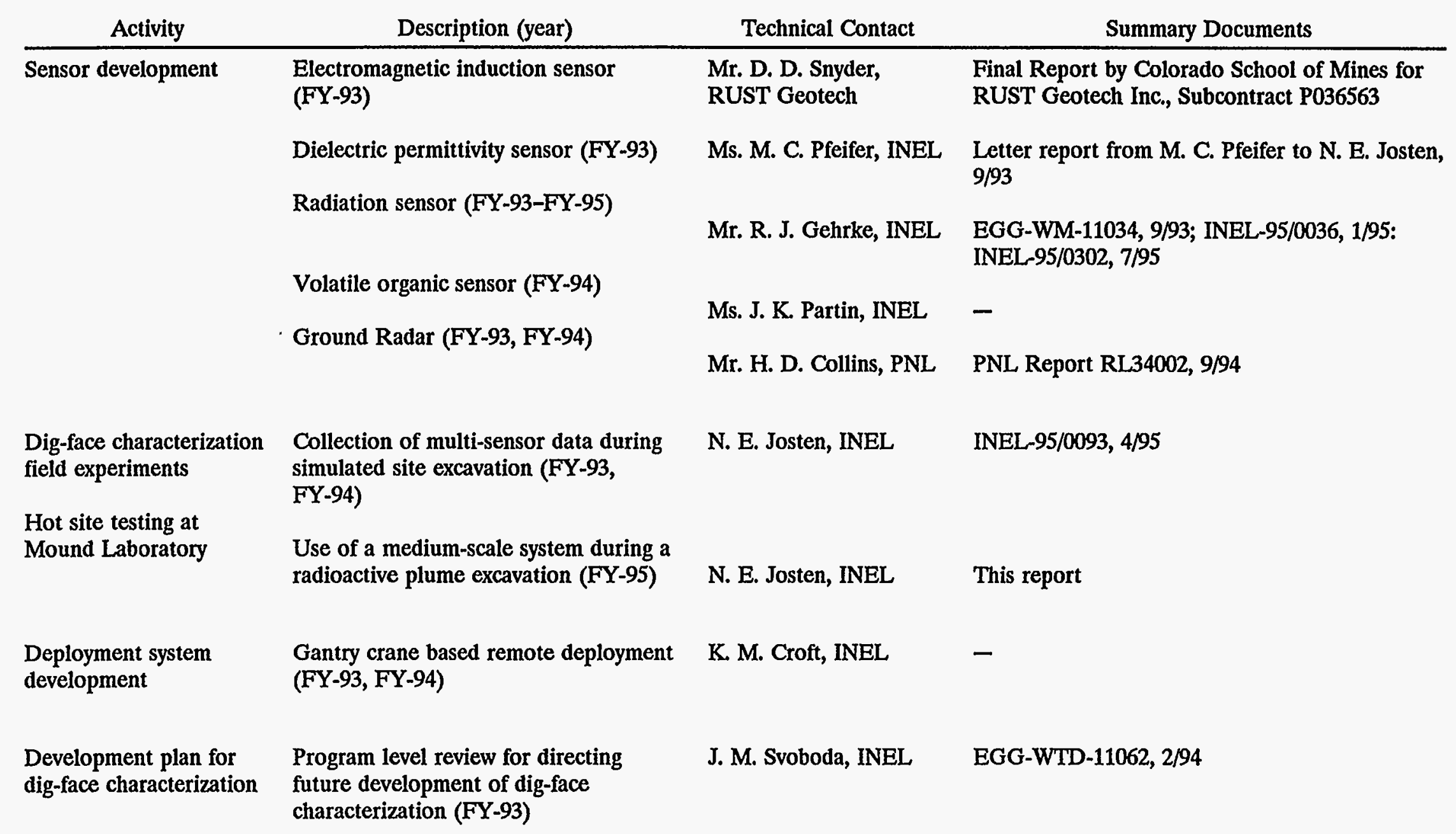


Table 1. (continued).

\begin{tabular}{llll}
\multicolumn{1}{c}{ Activity } & \multicolumn{1}{c}{ Description (year) } & \multicolumn{1}{c}{ Technical Contact } & \multicolumn{1}{c}{ Summary Documents } \\
\hline General & $\begin{array}{l}\text { Conceptual design considerations } \\
\text { (FY-92, FY-93, FY-94) }\end{array}$ & N. E. Josten, INEL & EGG-EELS-002, 9/92 \\
& & $\begin{array}{l}\text { Consultant report by P. Graebner and } \\
\text { N. Harthill for EG\&G Idaho, Inc., Subcontract } \\
\end{array}$ \\
& & C92-120383, 9/92 \\
& & Consultant report by P. Graebner for EG\&G \\
& & Idaho Inc., Subcontract C93-120493, 9/93 \\
& & Consultant report by P. Graebner for EG\&G \\
& & Idaho Inc., Subcontract C93-120493, 4/94 \\
\hline
\end{tabular}




\section{Mound Laboratory Area 7}

Soil borings at Area 7 in the mid-80s and 1994 indicated the presence of Actinium-227 $\left({ }^{227} \mathrm{Ac}\right)$, Thorium-232 ( $\left.{ }^{232} \mathrm{Th}\right)$, and Radium-226 $\left({ }^{226} \mathrm{Ra}\right)$ in the subsurface soils. Mound historical records linked the contamination to a building demolition in about 1960 . Debris was disposed of in a steep ravine alongside (possibly inside) a concrete septic tank. The ravine was later backfilled and turned into a parking lot. Figure 2 shows the layout of Area 7. Regulators approved a time critical removal action for a portion of Area 7 under the Comprehensive Environmental Response, Compensation, and Liability Act (CERCLA). The ${ }^{227} \mathrm{Ac}$ and ${ }^{232} \mathrm{Th}$ cleanup levels were set at $5 \mathrm{pCi} / \mathrm{g}$ and $15 \mathrm{pCi} / \mathrm{g}$, respectively.

The original excavation plan targeted a 20 -ft $\times 20$-ft by 17 -ft-deep volume centered on the highest detected ${ }^{227} \mathrm{Ac}$ from sample borings. A high-resolution magnetic survey conducted by INEL in April 1995 detected two possible septic tank locations in the vicinity of the sample borings. The depth of these objects was estimated at 4 to $8 \mathrm{ft}$, significantly shallower than previously expected. The magnetic results supplied a basis to modify the removal action for shallower target depths, eliminating the need for shoring and dewatering systems.

${ }^{227}$ Ac posed a significant radiological health hazard. The inhalation annual limit of intake (ALI) for ${ }^{227} \mathrm{Ac}$ is 20 times more restrictive than for Plutonium-238 $\left({ }^{238} \mathrm{Pu}\right)$. The ingestion ALI is almost 5 times more restrictive than for ${ }^{238} \mathrm{Pu}$. Consequently, the removal action work plan stipulated respiratory protection for excavation workers.

The principal objective for dig-face characterization support during the Removal Action was to establish the location and in situ geometry of ${ }^{227} \mathrm{Ac}$ as soon as it was encountered.

\section{Overview of the Mound Area 7 Operation}

Dig-face characterization system hardware for the Mound project was designed based on the project objectives and anticipated conditions. The major components of the system were a set of radiation and geophysical sensors, a trolley-type scanning structure, and a computer based data acquisition and trolley control system. The projected excavation size and ${ }^{227} \mathrm{Ac}$ cleanup levels were critical design drivers. All aspects of the system were built, assembled, and tested at INEL prior to shipping (Figures 3 and 4).

The system was shipped to Mound in mid-August and staged in the parking lot adjacent to the excavation site. After removal of an overburden layer, gravel foundations were prepared for the trolley $x$-axis track (Figure 5). The trolley bridge-mast assembly was then hoisted onto the track (Figure 6), components were connected, and the system was tested.

The portion of the Area 7 site excavation under dig-face characterization support followed a regular, repetitive sequence of activities. Each cycle began with a topographic scan of the current dig-face. The acquired digital topography data were used to determine the maximum dig-face elevation within the scan area. After setting sensor elevation to maintain an optimal average clearance above terrain (approximately 3 to 9 inches), geophysical and radiation sensor scans were conducted to examine subsurface conditions. Following data review, the dig-face system was 


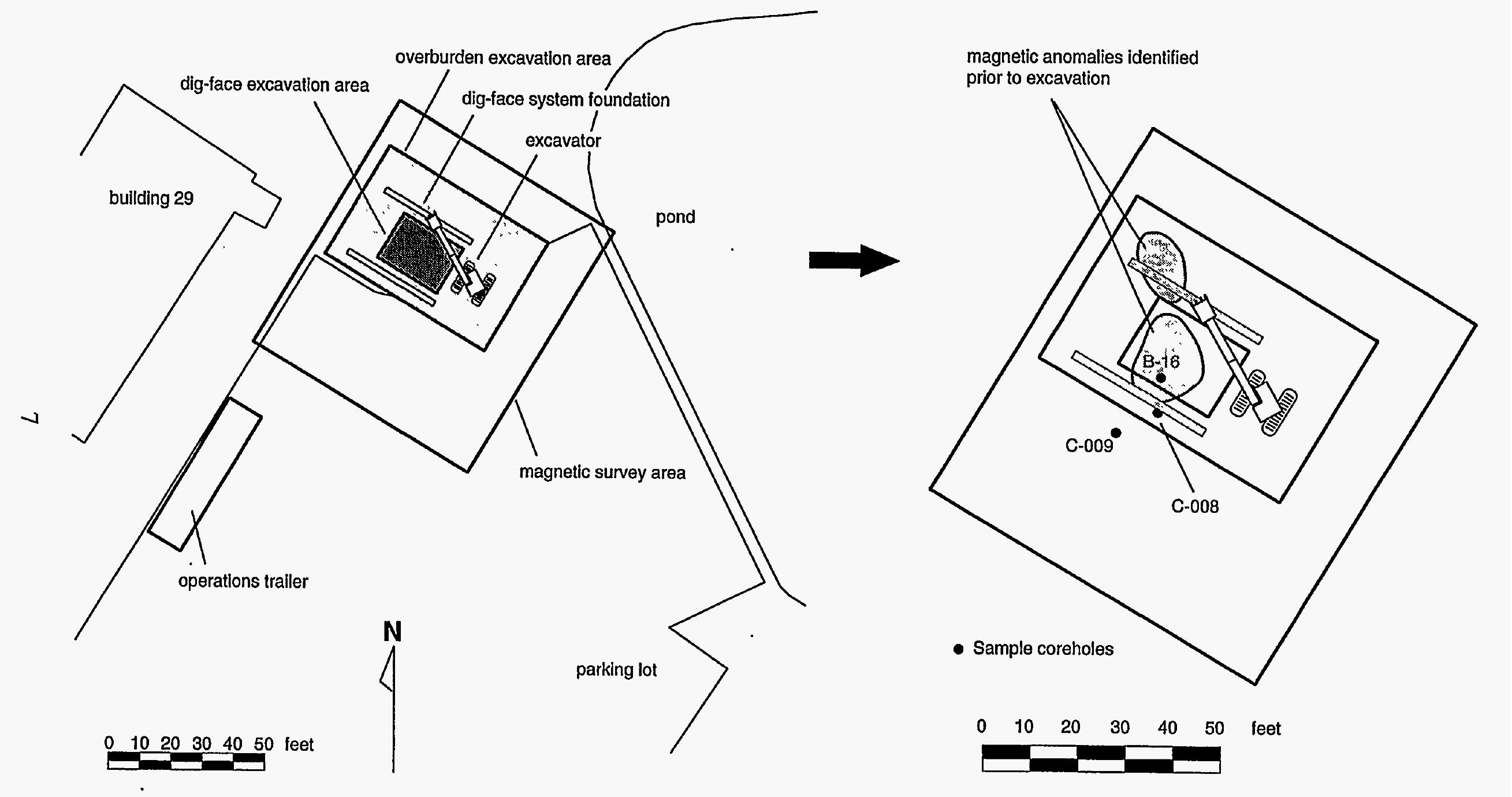

Figure 2. Drawing of site layout for the Area 7 excavation (left) and detail of excavation (right). 


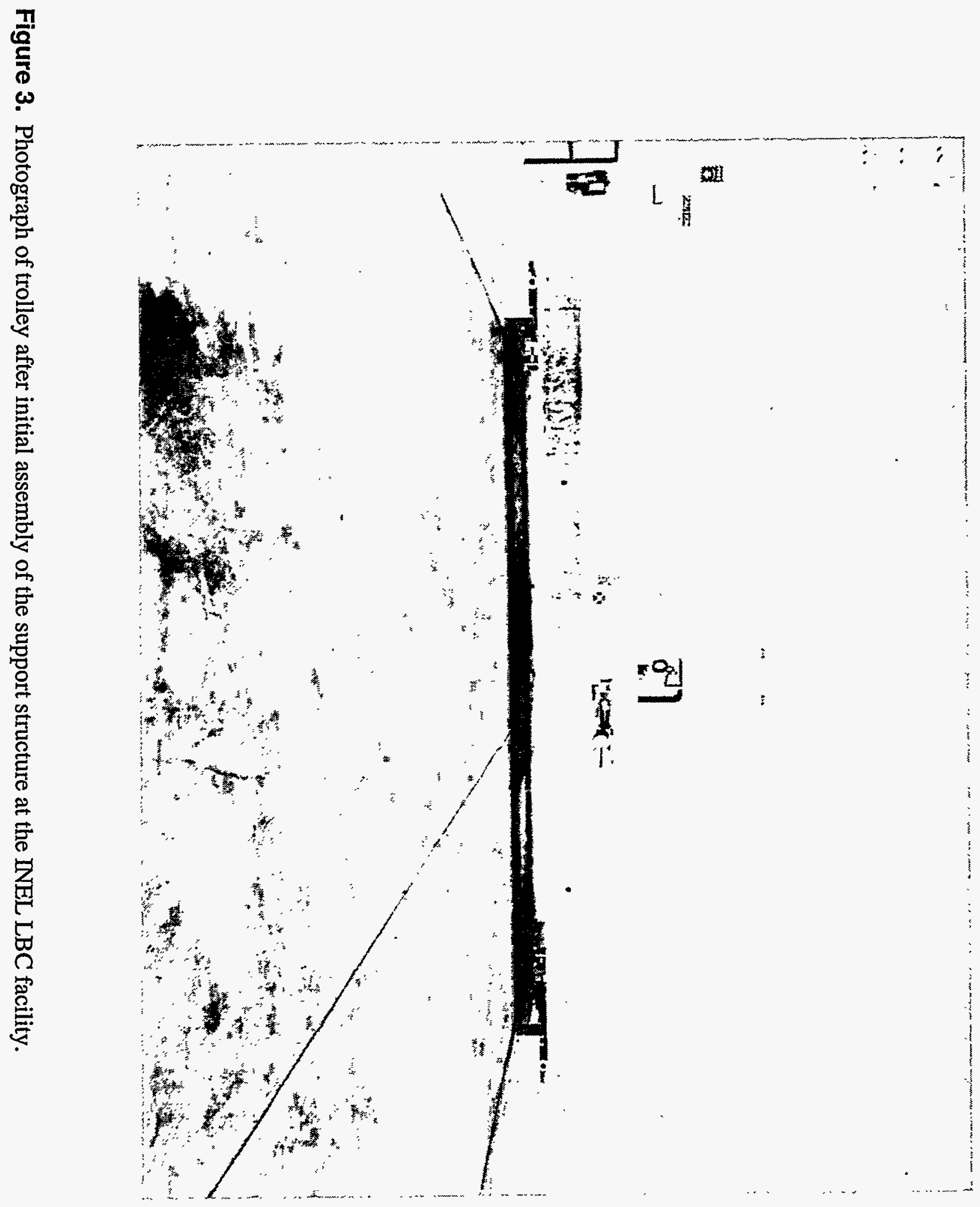




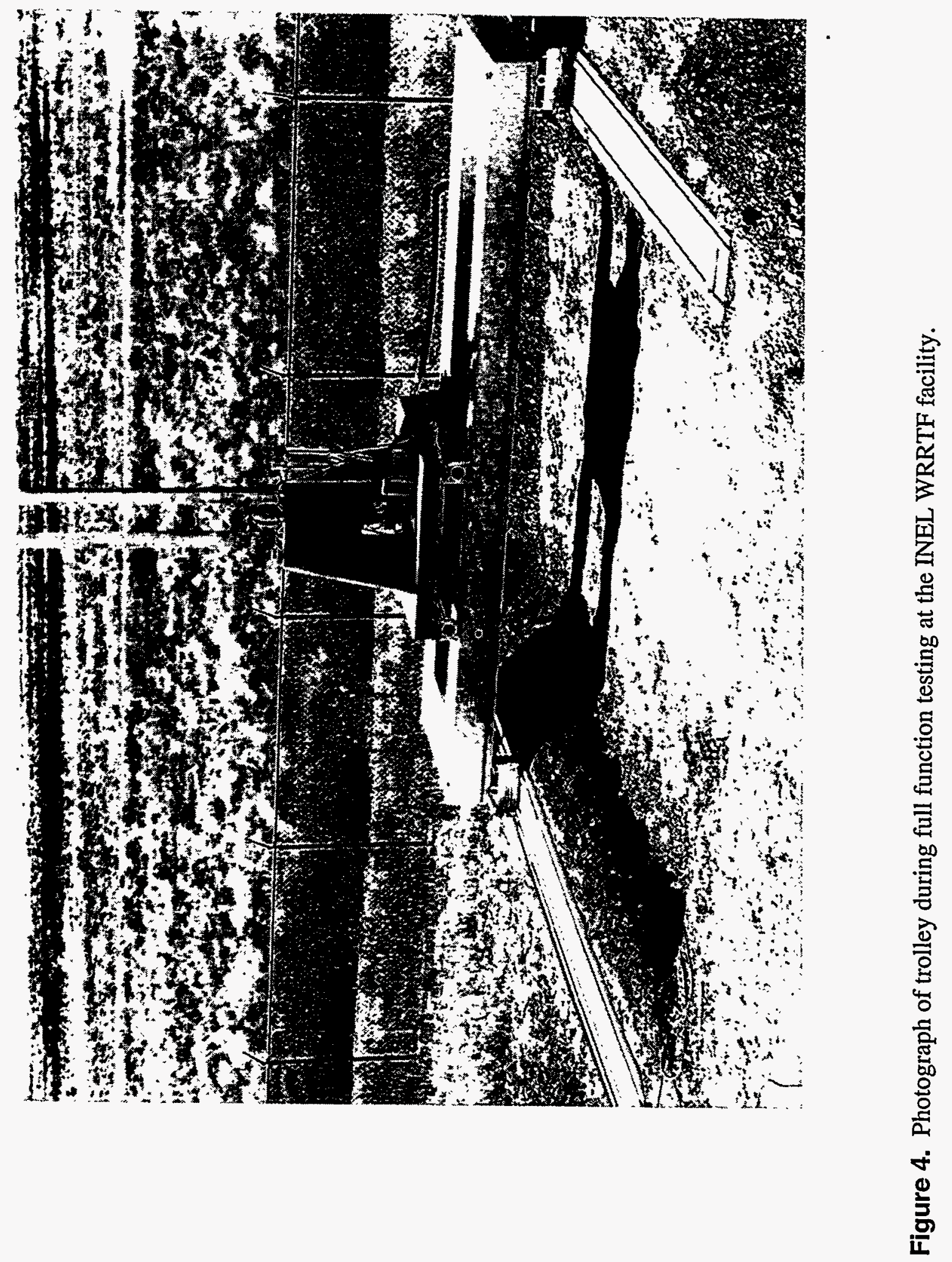




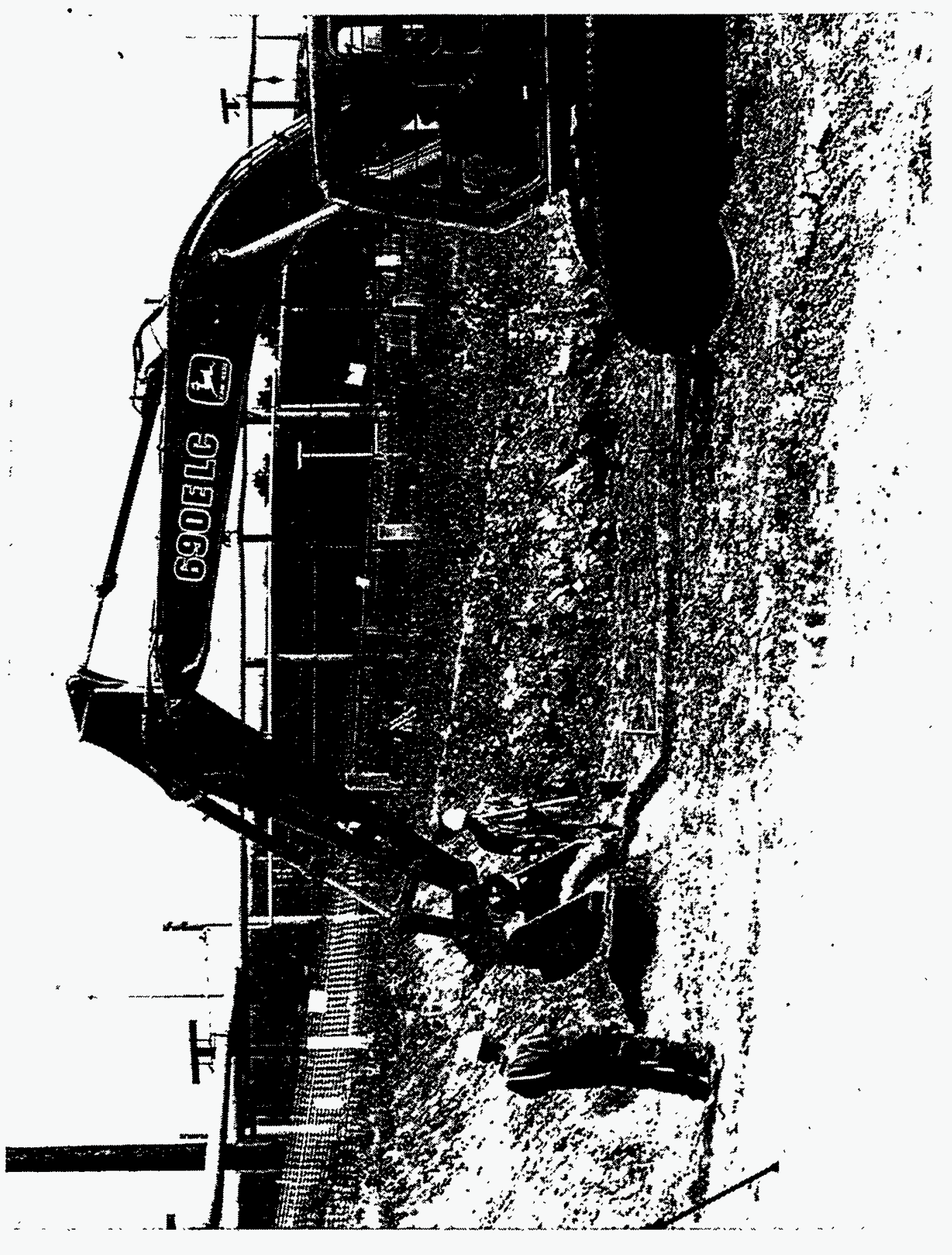

0. 


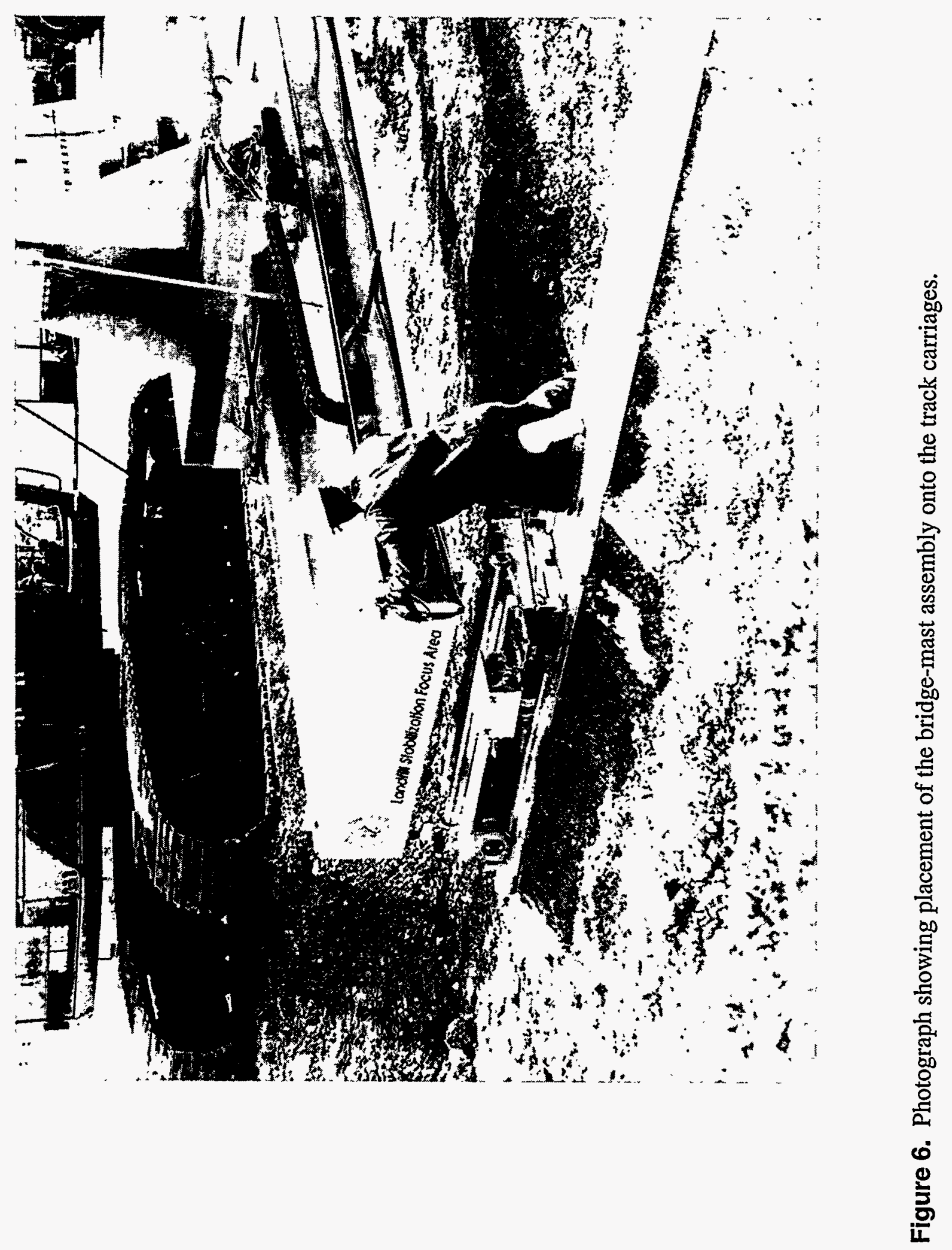


rolled back off the pit and excavation resumed, initiating the next cycle. Figure 7 summarizes the full sequence of activities supported by the dig-face characterization system.

\section{Description of the Dig-face Characterization System}

The Mound dig-face characterization system incorporates three technologies: a sensor subsystem, a deployment subsystem, and a data handling subsystem. In general, the combination of these subsystems may have many forms, depending on the nature of the application. In all cases, these subsystems supply the basic capability to (a) detect the particular subsurface conditions of interest at the site, (b) collect these data anywhere on the waste excavation dig-face, and (c) analyze the data in near real time to provide information feedback for managing the waste retrieval effort.

The sensor system consists of a sensor suite matched to the conditions of interest during the retrieval operation. These conditions may be of general interest at many sites (e.g., mapping solid waste boundaries, volatile chemical plumes, and radiation fields), or they may be highly site-specific (e.g., tracking a mercury plume or locating a specific object such as a reactor core). The deployment system delivers the sensors to points where measurements are desired. Deployment technology may vary substantially, depending on many factors. The most important factors are the scan mode requirements for each sensor, the overall site dimensions, the expected topography of the excavation face, and the need to avoid impeding excavation equipment functions. The data handling system incorporates technology for transmitting data from sensors to a control station, validating and storing these data, analyzing the data, and communicating results to decision makers.

\section{Sensors}

At Mound, the targets of interest were radioactively contaminated soil zones (specifically ${ }^{232} \mathrm{Th}$ and $\left.{ }^{227} \mathrm{Ac}\right)$ and the suspected septic tank. The low action levels for ${ }^{227} \mathrm{Ac}(5 \mathrm{pCi} / \mathrm{g})$ and the high potential for non- ${ }^{227}$ Ac radioactive contamination were additional considerations in sensor suite development. Three sensors were taken to Mound. The first, a gamma/neutron mapper (GNM) performed high sensitivity detection of nonspecific gamma fields at relatively high speed. The second, a germanium gamma-ray spectrometer (Ge-spectrometer) provided the capability to identify mixtures of radionuclides on a point by point basis. The third, a magnetometer/laser rangefinder (MLR) provided metal detection capabilities and topographic mapping, the latter enabling adjustment of sensor height for optimal sensitivity.

Gamma/Neutron Mapper. The GNM was specifically built for high-speed, high-sensitivity detection of low-level gamma fields. Design of the GNM was based on the goal of detecting $5 \mathrm{pCi} / \mathrm{g}{ }^{227} \mathrm{Ac}$ at a $1 \mathrm{ft} / \mathrm{s}$ scan speed, assuming a six-inch standoff distance from the ground. 


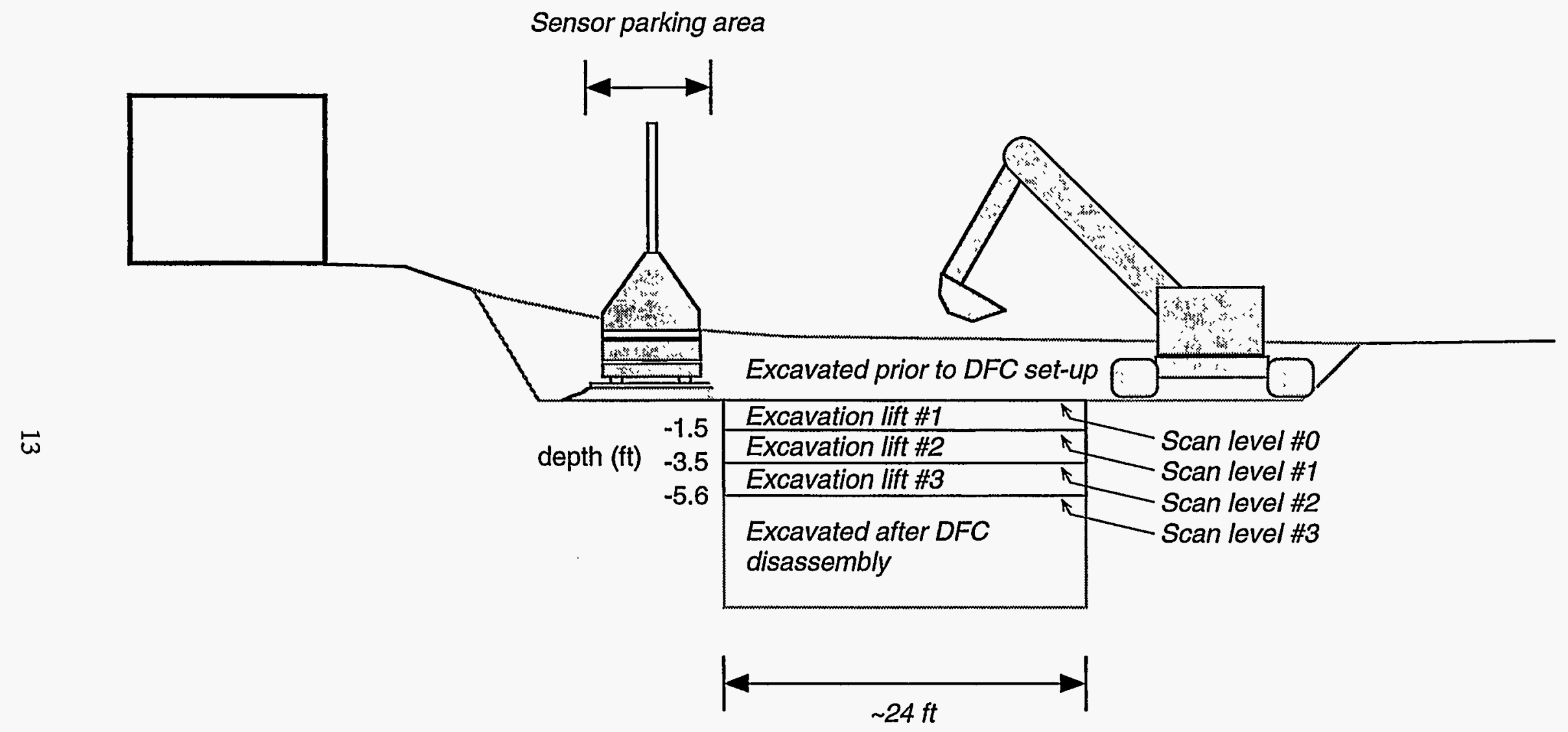

Figure 7. Schematic summary of the excavation sequences at Area 7 during the dig-face characterization support phase. 
The gamma-neutron mapper consists of two large 25.4-cm x 48.26-cm x 3.81-cm-thick plastic scintillators located in front of two ${ }^{3} \mathrm{He}$ chambers of the same length and width. ${ }^{\mathrm{a}}$. These four detectors are located inside a protective stainless steel box, as shown in Figure 8. A 1.0-mm-thick titanium window is located directly over the plastic scintillators to reduce the attenuation of low-energy gamma-rays (e.g., the $60-\mathrm{keV}$ gamma-ray of ${ }^{241} \mathrm{Am}$ ). Data acquisition electronics are integral to the GNM. The data acquisition module includes $A / D$ hardware and the radio frequency (RF) ethernet electronics used to communicate with the data acquisition system.

The efficiency of the GNM was calibrated with a set of ${ }^{227} \mathrm{Ac}$ sources distributed evenly over an area of $9548 \mathrm{~cm}^{2}$. The ${ }^{227} \mathrm{Ac}$ sources were used to measure the intrinsic efficiency of the plastic scintillation detectors because ${ }^{227} \mathrm{Ac}$ was understood to be the radionuclide of primary interest. Calibration is discussed in more detail in Appendix A.

As configured for Mound, the GNM counting range had to be set at a fixed value. The proper range was estimated prior to each scan, beginning with 5000 counts/sec (cps) for the initial scan. When the actual gamma fields exceeded the preset range, the electronics become effectively saturated. The GNM reported the maximum range value throughout these high field areas. This arrangement was unfortunate because it meant that peak radiation field strength was not captured for some of the observed contamination areas.

Ge-spectrometer. The Ge-spectrometer measures the energy of each incident gamma-ray and keeps count of the number of gamma rays detected at each energy. The resulting gamma ray spectrum accumulated by the Ge-spectrometer consists of a series of peaks representing the number of gamma-rays observed at each energy. Specific gamma emitters are identifiable based on their unique pattern of spectral peaks. At Area 7, where ${ }^{227} \mathrm{Ac}$, ${ }^{232} \mathrm{Th}$, and ${ }^{226} \mathrm{Ra}$ were all expected to occur, the Ge-spectrometer provided a means to identify the specific contaminant associated with high gamma fields measured by the GNM.

The Ge-spectrometer consists of a $41.5 \%$ n-type coaxial germanium detector with an energy resolution of $1.94 \mathrm{FWHM}$ at $1332 \mathrm{keV}$ (Figure 9). The spectrometer is equipped with a dual-energy pulser developed at the INEL. The pulser provides a means to observe spectral drift and is used as a check on the quality of the spectral data. A bismuth shield covers the detector housing on all but the back side, with removable portions of the shield allowing for different "fields of view." At present, the spectral data are accumulated, analyzed, and stored on a dedicated VAX 4000 workstation, which functions independently of the dig-face characterization system's data acquisition computer.

The Ge-spectrometer was efficiency-calibrated with 20 -g soil samples containing a homogeneous distribution of mixed standardized radionuclides $\left({ }^{109} \mathrm{Cd},{ }^{57} \mathrm{Co},{ }^{139} \mathrm{Cd},{ }^{113} \mathrm{Sn},{ }^{54} \mathrm{Mn}\right.$, ${ }^{88} \mathrm{Y},{ }^{65} \mathrm{Zn}$, and ${ }^{60} \mathrm{Co}$ ). This calibration configuration was used during the Area 7 excavation to measure contamination in $20 \mathrm{~g}$ grab samples. The Ge-spectrometer was also calibrated using an

a. Although neutron data were automatically acquired, no neutron fields were anticipated or measured above background at Area 7. 


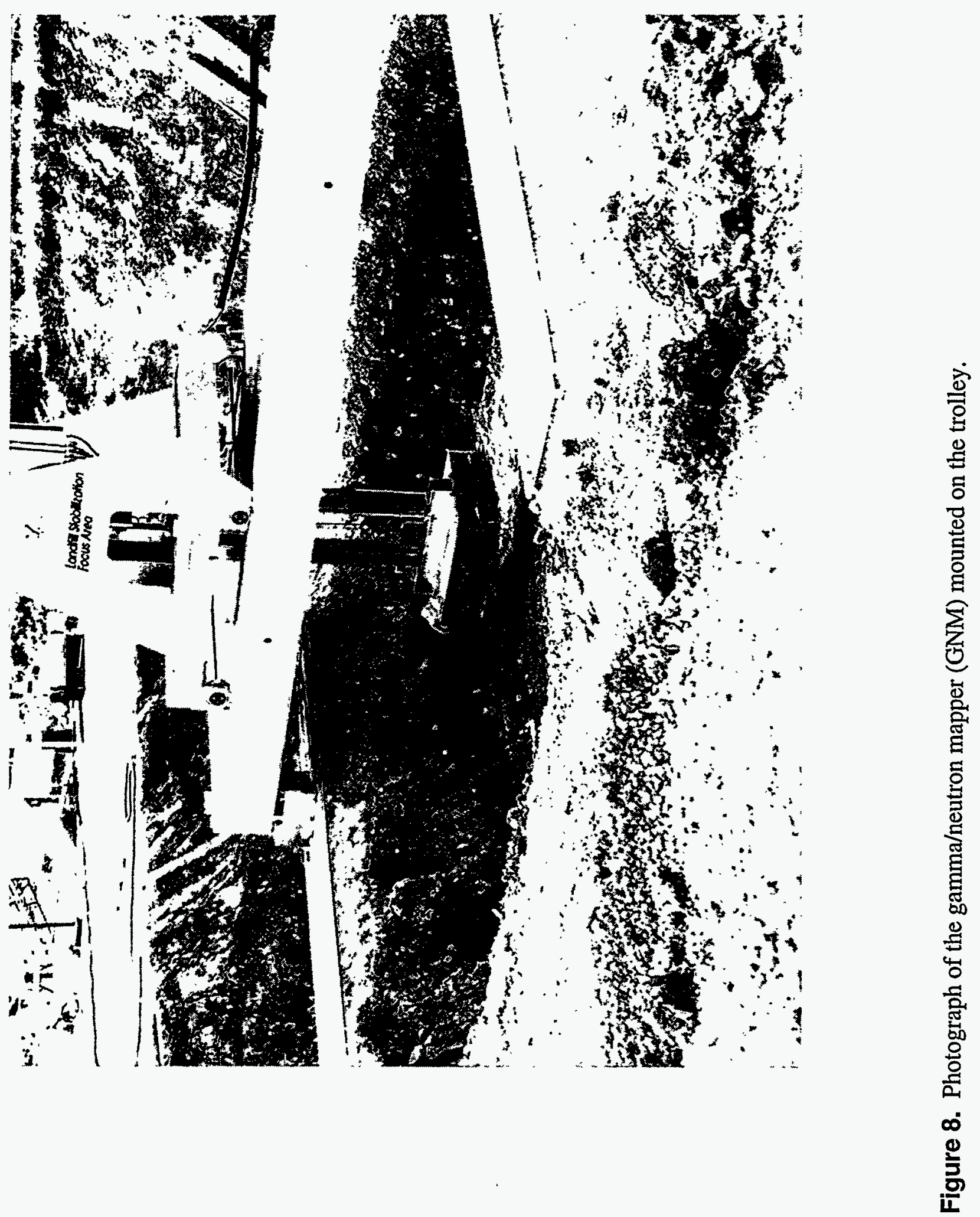




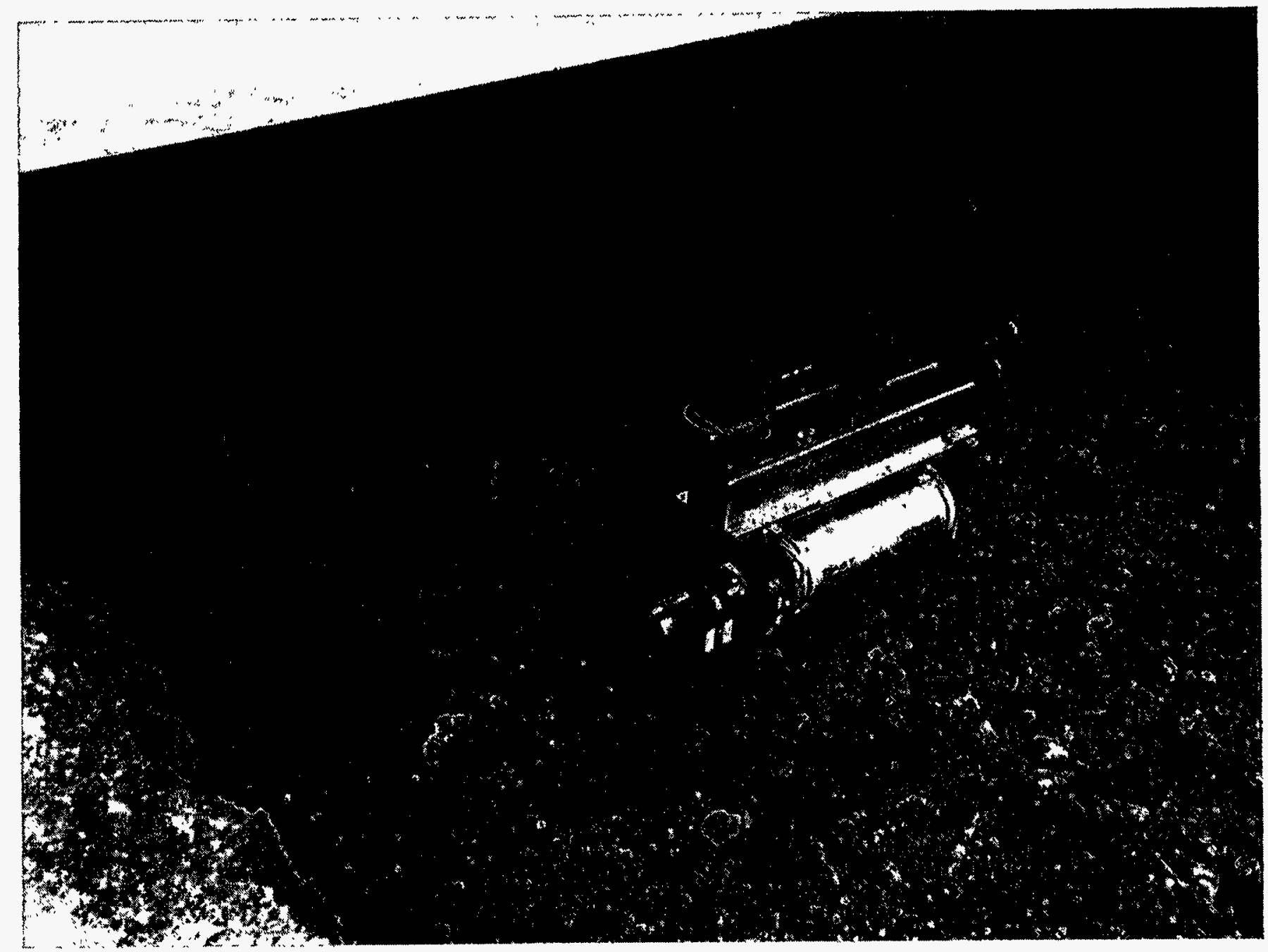

Figure 9. Photograph of the Ge-spectrometer mounted on the trolley. 
evenly distributed set of point sources of these mixed standardized radionuclides covering an area of $800 \mathrm{~cm}^{2}$ at a standoff distance of $15 \mathrm{~cm}$. See Appendix A for more details on calibration.

Quantifying Radiation Sensor Results. Both the Ge-spectrometer and GNM measure gamma-ray fields in counts/sec. To convert count values to estimates of radionuclide concentration in $\mathrm{pCi} / \mathrm{g}$, it is necessary to know the detector efficiency and to estimate the effective area and depth of soil contributing counts to the acquired data. Since contaminant concentrations form the basis for many decisions during a radioactive site cleanup, this conversion is of fundamental importance for a dig-face operation such as Area 7. Appendix A discusses several approaches that were tested using the Area 7 GNM and Ge-spectrometer data sets.

Magnetometer/Laser Rangefinder. The magnetometer/laser rangefinder is a combination sensor used to detect buried metallic debris and to map the topography of the dig-face (Figure 10). The magnetic sensor in the MLR is a high-speed fluxgate magnetic gradiometer mounted in the plastic stinger affixed to the bottom of the sensor housing. Magnetic gradiometers are common metal detection sensors that measure magnetic disturbances caused by the presence of iron or steel objects. At Area 7, the magnetometer was used to search for evidence of the suspected septic tank historically associated with the radioactive soil disposal.

The laser rangefinder operates by measuring the travel time of laser pulses transmitted from the sensor, reflected off the ground surface, and returned through the sensor lens. Topography measurements are made by scanning the MLR across the ground surface from a fixed height. The sensor is calibrated by setting a zero distance at a fixed calibration point with known elevation.

\section{Deployment System}

Figure 11 shows engineering drawings for the trolley based sensor deployment system that was built for the Mound operation. The design incorporates several features aimed at making the trolley both highly adaptable and inexpensive. The main components of the trolley are (a) the main beam or track ( $x$-axis), (b) the bridge (y-axis), (c) the mast (z-axis), and (d) the motor drive system.

Main Beam. The main or $\mathrm{x}$-axis beam of the trolley has wheeled carriages or trucks that run on simple track. These assemblies allow the trolley to support excavations of unlimited length through use of additional sections of inexpensive track. The carriages are constructed primarily from aluminum with steel axles.

For the Mound work, four 8-ft track sections were used, providing $32 \mathrm{ft}$ of $\mathrm{x}$-axis motion. This allowed for complete access to the 20 - $\mathrm{ft}$ excavation plus a 10 -ft parking area. The track rested on gravel foundations to ensure stability and provide for a level track. The trolley was moved to the parking area during digging operations and for changing or servicing sensors.

Bridge Beam. The bridge or $\mathrm{y}$-axis assembly is constructed primarily from plywood and TJI joists formed into box beams. The bridge incorporates a set of rails to guide $y$-axis motion. The design establishes standard dimensions for bridge components that guarantee compatibility with the main beam and the mast assembly. The bridge length determines a maximum span for the 


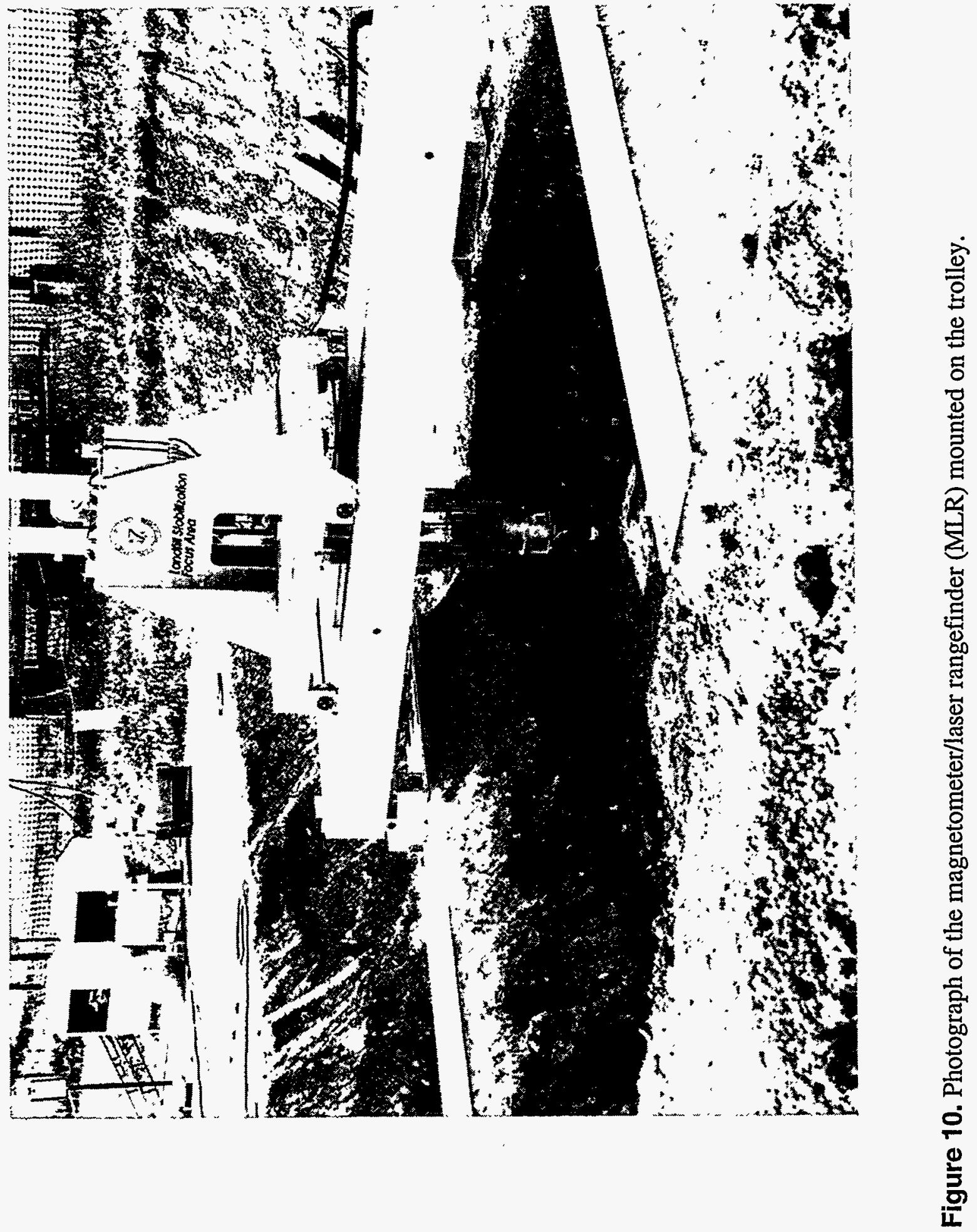



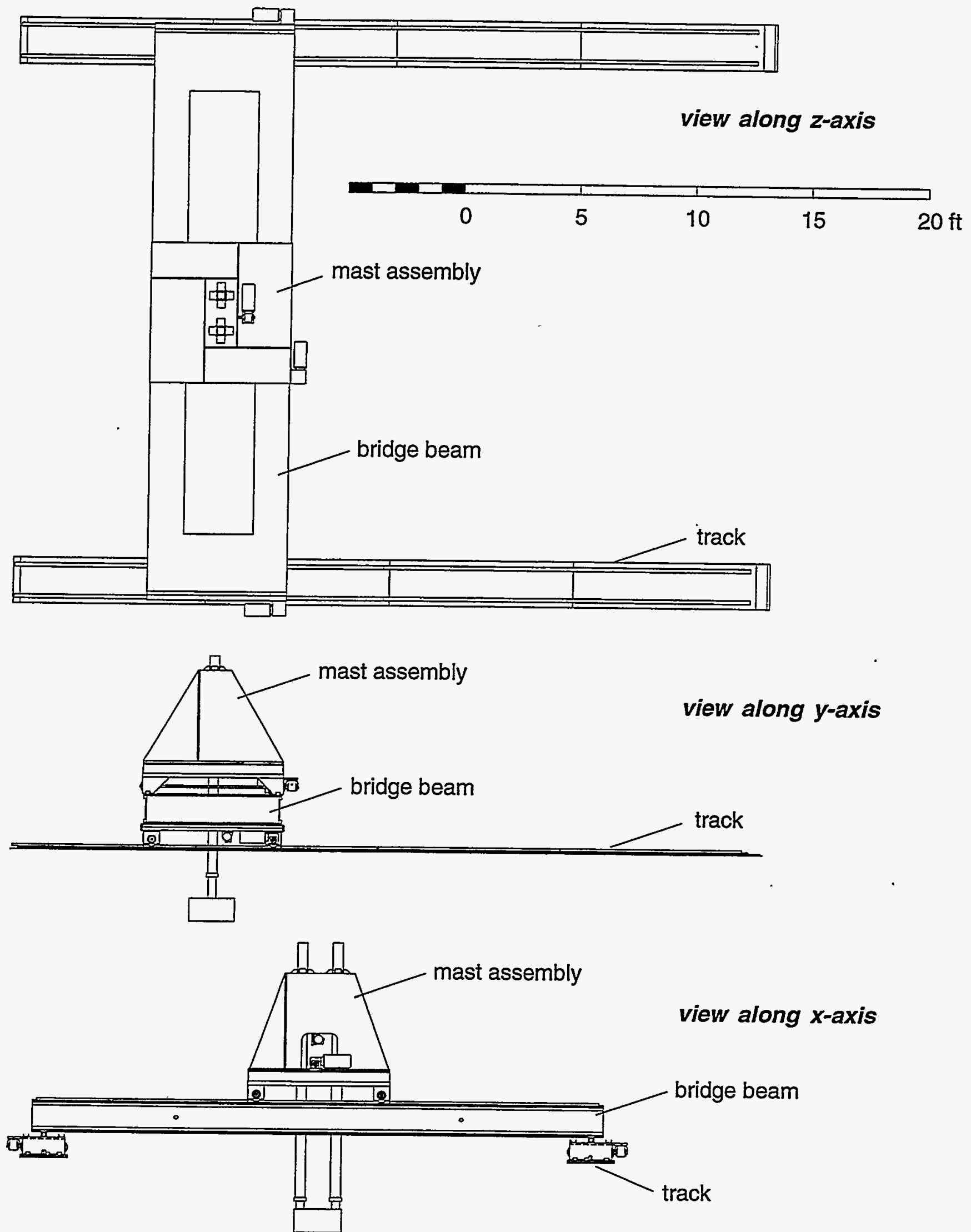

Figure 11. Scale drawing of the Mound trolley viewed along each of the three principal axes. 
trolley, but the design makes it possible to adjust the bridge to lesser spans. Greater spans are possible by constructing longer bridge assemblies, which are relatively simple and inexpensive structures. Coupling between the bridge and the main beam carriages involves fitting a pipe into a box channel, making this operation very easy to accomplish with a small crane (Figure 12).

A 24-foot bridge was built for the Mound work. This provided the required 20 feet of $y$-axis motion to span the pit. The bridge supports loads up to $400 \mathrm{lbs}$ with a deflection less than 1/8 inch. The bridge assembly weighs approximately $800 \mathrm{lbs}$.

Mast Assembly. The mast assembly (Z-axis) incorporates a horizontal rolling frame carrying a retractable vertical mast. The frame sets on the rails fixed atop the $y$-axis bridge beam and has motor driven wheels for traversing back and forth across the bridge during sensor scans. The mast can be extended about 10 feet below the base of the bridge and retracted to a point near the base of the bridge. This allows for scans to be conducted at the bottom of a 10-ft pit while retaining the capability to retract the sensor and park the bridge completely off the pit. Sensors mount to the mast end plate using 6-in. pins.

Motor Drives. The trolley incorporates four separate motors to generate motion of the three axes. The two main beam carriages each have an integral motor. These drive the carriage wheels in tandem to provide $\mathrm{x}$-axis translation. The other two motors mount to the mast assembly. One motor propels the mast assembly drive wheels to translate the assembly across the bridge in the $y$-direction. The fourth motor raises and lowers the mast and sensor by spooling and unspooling a cable. The motors are of the stepper variety, which allow precise control over the amount of motion and supply feedback of distance traveled to the control computer. The trolley also employs radial encoders to track distance traveled on each axis.

\section{Data Handling System}

During the Area 7 operation, the trolley motors, the GNM, and the MLR were operated from a control station located approximately $100 \mathrm{ft}$ from the trolley in the site operations trailer (see Figure 2). A data handling system provided the operator interface with the trolley and sensors (Figure 13). To accommodate remote operations, the data handling system uses radio (RF) links for communication between the computer workstation console and the trolley/sensors.

Sensor Control. The GNM and MLR have integral sensor control modules that perform analog-to-digital conversion (if necessary) and provide one end of the two-way RF link. A communication antenna located outside the excavation exclusion zone provided the other end of the RF link. The communication station connects to the operator workstation by way of coaxial cable. By this arrangement, sensor on/off commands were transmitted to the sensors, and digital sensor output was transmitted to the operator workstation. Incoming data were displayed on the workstation console in real time as they were acquired, and were stored in files for postprocessing.

The Ge-spectrometer was controlled by a separate data acquisition system. This system has not yet been adapted for remote operations and requires coaxial line connections to the sensor. 


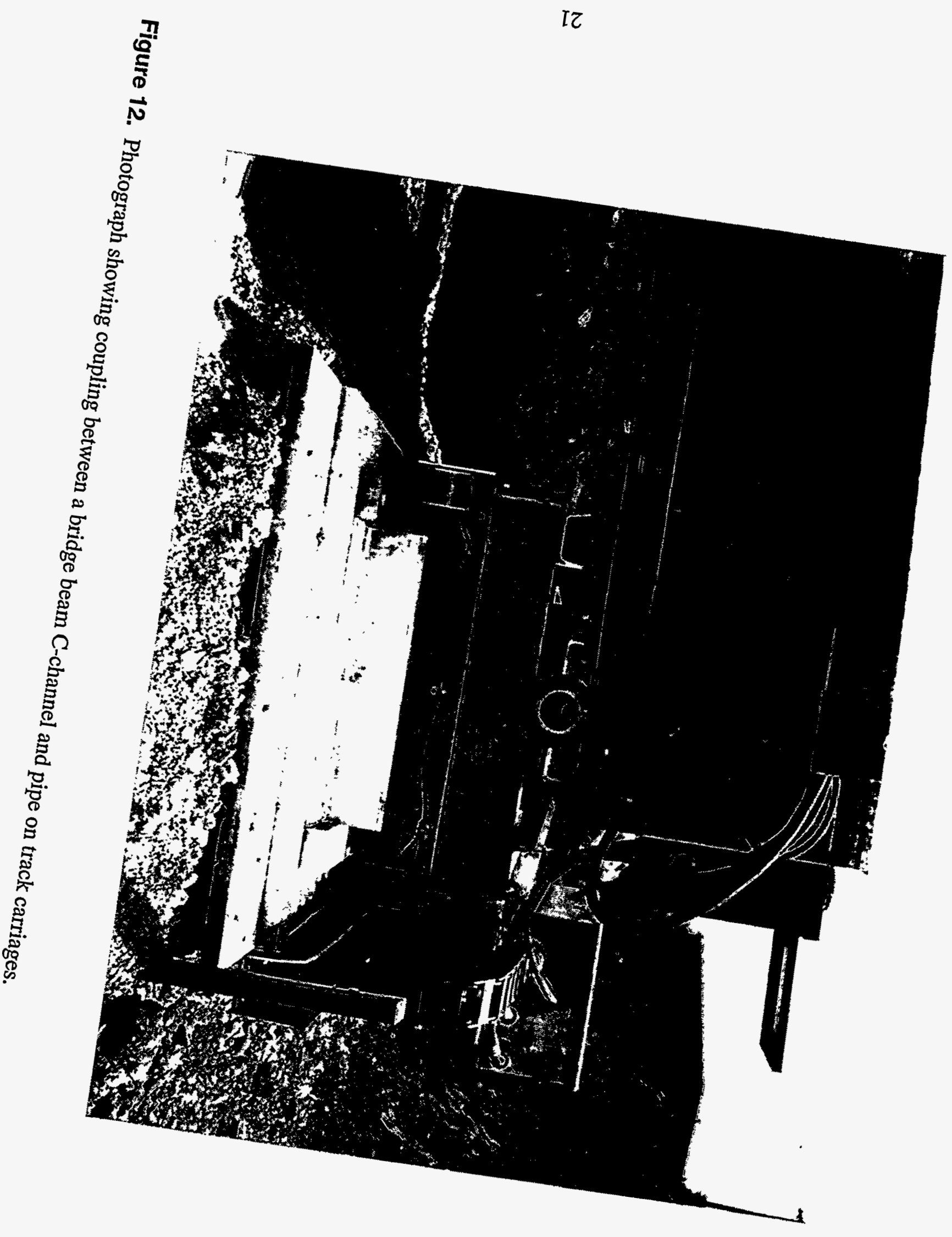




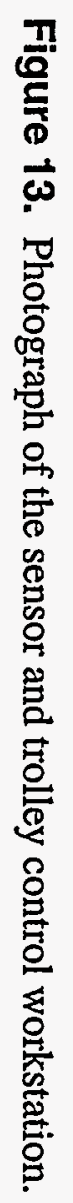

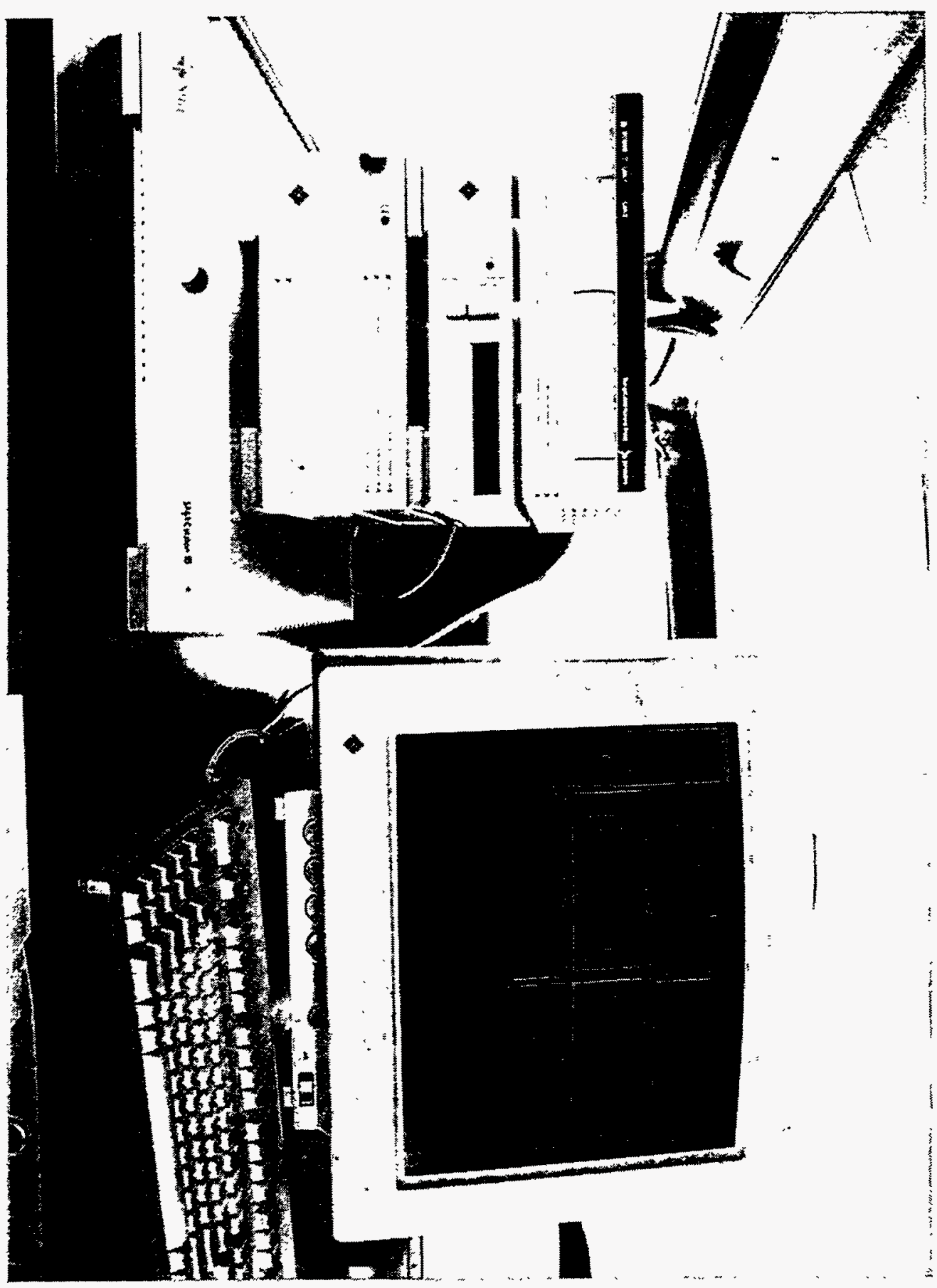


Motor Control. A motor controller located on the trolley mast assembly and connected to the operator workstation by an RF link (identical to the sensor communication links) receives operator commands and energizes the motors as needed. The workstation computer monitors and records sensor position at all times. The sequence of motions required to make simple translations along each axis and to perform a complete area scan are preprogrammed and available to the operator through simple menu commands. Scan speeds and data spacing are also set by the operator. 


\section{RESULTS}

It was necessary to develop the specially adapted sensors, deployment system, and data acquisition equipment to investigate the dig-face characterization concept under hazardous site conditions. Together, the prototype dig-face characterization equipment constitute an admirable engineering feat, but accomplish nothing toward proving the value of the concept. On the other hand, data acquired during the Area 7 excavation, the information concerning site conditions portrayed by these data, and the relation of this information to the ongoing decision-making process associated with the removal action are highly relevant to discovering the practical value of dig-face characterization. This section presents these data.

\section{Laser Rangefinder Measurements}

The laser rangefinder offered a simple solution to the basic problem of mapping dig-face topography. The dig-face topography forms a boundary of the dig-face characterization mapping domain and is important for several reasons. First, the changing shape and depth of the dig-face record the progress of the excavation. Excavated soil volumes may be accurately calculated, and benchmark depths are straightforwardly documented. Objects, debris, or contamination discovered during the course of the dig may be referenced to the dig-face depth at the time of their detection. Accurate depth information permits site operators to more easily envision the subsurface in three dimensions and becomes valuable in attempting to predict conditions at greater depth. Topography data are also used to control the motion of sensors. Sensor elevation may be set to achieve an optimum offset from the ground surface while avoiding collisions.

\section{Level 1-4 Laser Rangefinder Measurements}

Figure 14 shows the excavation sequence at Area 7 as reconstructed from the MIR topography data. The MLR acquired the topographic data at a 0.5 -ft x 1.0 -ft data spacing. All topographic data were collected relative to the height of a calibration block located in the sensor parking area. The data illustrated in Figure 14 represent operation of the MLR over laser path lengths ranging from 3 to $10 \mathrm{ft}$. Laser reflectivity data indicate that the sensor operated very comfortably in this range, and that significantly greater depths could be mapped.

Note the irregularities in the pit bottom topography at each stage. These resulted from the dragging action of the backhoe excavator, which caused rocks, concrete and other debris being removed to leave drag marks and voids. These detailed topographic features were very reliably captured by the MLR data, though some of the smaller features were aliased at the $0.5-\mathrm{ft} \times 1.0-\mathrm{ft}$ sampling interval. The MLR showed some tendency to lose reflections in the bottom of these drag features. In such cases, the MLR reported erroneously deep depths.

\section{Magnetometer Measurements: The Benefit of Changing Viewpoints}

The role of the magnetometer in the Area 7 Removal Action began with a high-precision magnetic survey conducted on the original ground surface several months before excavation began. This preliminary survey and the magnetic scans collected during the actual excavation focused on the problem of detecting and recognizing the concrete septic tank presumed to be 

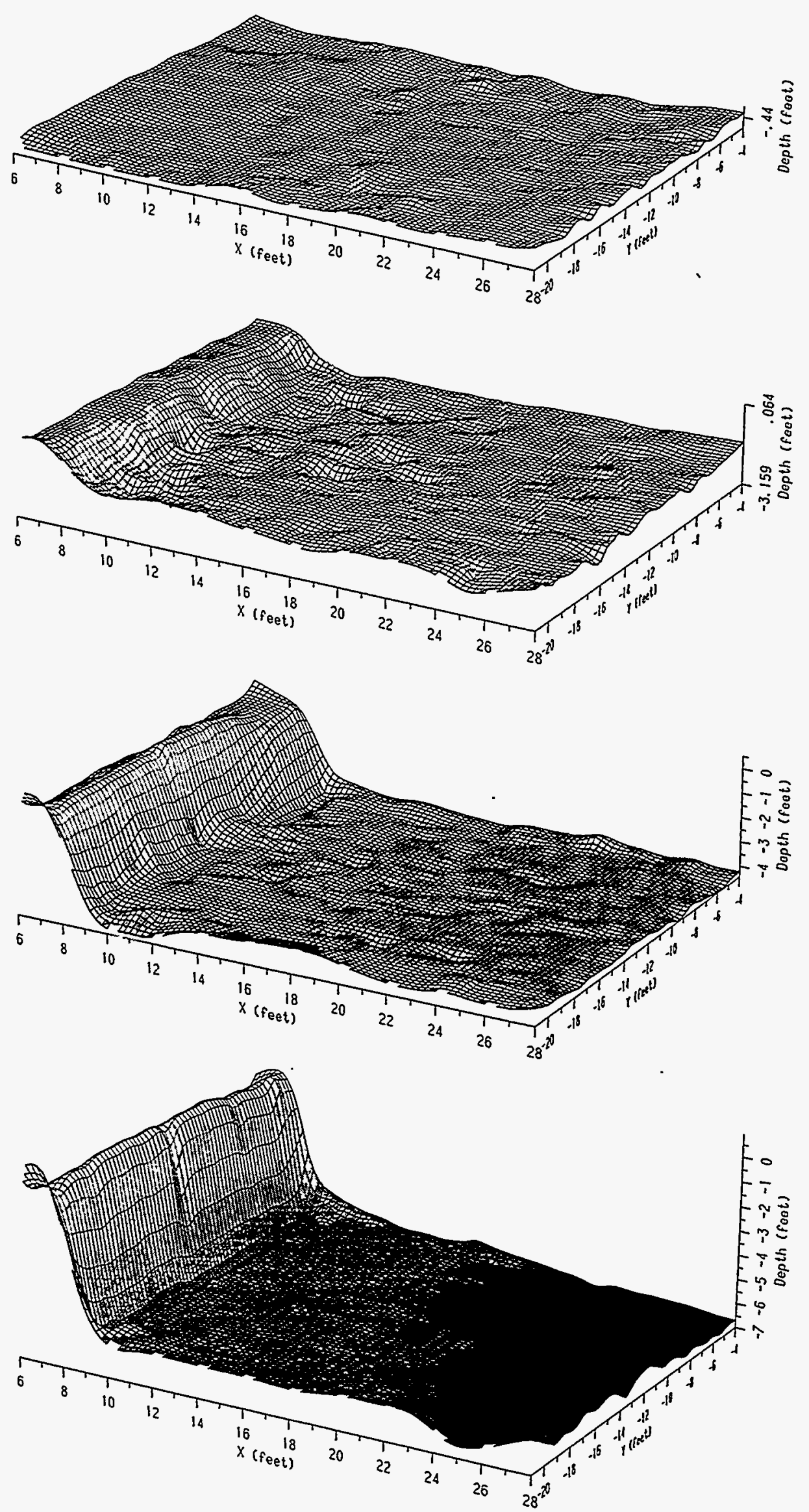

Figure 14. Perspective net drawings of the Area 7 pit topography at each dig-face scan level. 
buried near the ${ }^{227} \mathrm{Ac}$ plume. In the end, the magnetic data had only minor influence on the outcome of the removal action. However, the general case of searching for specific objects believed to be markers of contamination is well illustrated by the Mound magnetic data.

\section{Preliminary Magnetic Survey}

Figure 15 shows the surface magnetic data collected in April 1995 in an effort to locate the buried septic tank. (The approximate location of the Area 7 excavation and the dig-face characterization system within the magnetic survey area is shown in Figure 2.) The magnetic data were interpreted to show two possible locations for the septic tank (D and E), as well as a number of smaller buried metal objects. Small test excavations were conducted to evaluate the magnetic anomalies. These excavations encountered reinforced concrete and construction debris at 5 to $7 \mathrm{ft}$ below the ground surface. The debris areas were assumed to be the sources for the magnetic anomalies. Although the concrete septic tank was not positively located, the presence of debris tended to support the conclusion that this area was a former disposal site.

\section{Level 1-4 Magnetic Data}

The Level 1 and Level 2 magnetic data are shown in Figure 16a,b. In the left plots, magnetic field intensity is indicated by colors superimposed on a grid representing the pit topography. Conventional contour plots are presented to the right of the perspective plots. Figure 16c,d presents the Level 3 and Level 4 data in the same fashion.

The elliptical pattern of magnetic anomalies observed in the Level 1 data result from the same group of sources that produced Anomaly D in Figure 15. The discrete sources were unresolvable in the surface data, which was collected from a position 5 to $6 \mathrm{ft}$ above the sensor position for the Level 1 dig-face scan. In the Level 1 data, the existence of discrete, small magnetic sources is clearly evident.

It became immediately apparent based on the Level 1 data that a large metal structure such as the reinforced concrete tank would not be encountered in the excavation area. Instead, the subsurface appeared to be littered with small metal debris. Level 1 through Level 4 data show the progressive excavation and removal of this debris. Some of the excavated material appeared to be remnants of a concrete structure (Figure 17), possibly the suspected tank.

The emergence of a second area of debris is also traceable in the Level 1 through Level 4 data sets. This second area is evident as a yellow-colored anomalous zone near $\mathrm{x}=23, \mathrm{y}=-10$ in the Level 1 data. This zone becomes more evident at each successive level. The general appearance of this anomaly progression mimics the progression of the first anomaly zone. The debris encountered and removed from this second anomaly zone after the Level 4 scan was quite similar to the debris seen within the first zone.

It was never possible to predict the detailed characteristics of the magnetic sources encountered during the excavation, i.e., sections of rebar were not distinguishable from a drum lid based on the magnetic patterns. However, the general conclusion that none of the magnetic anomalies were caused by large or massive objects, though vague, proved useful. The progressive 


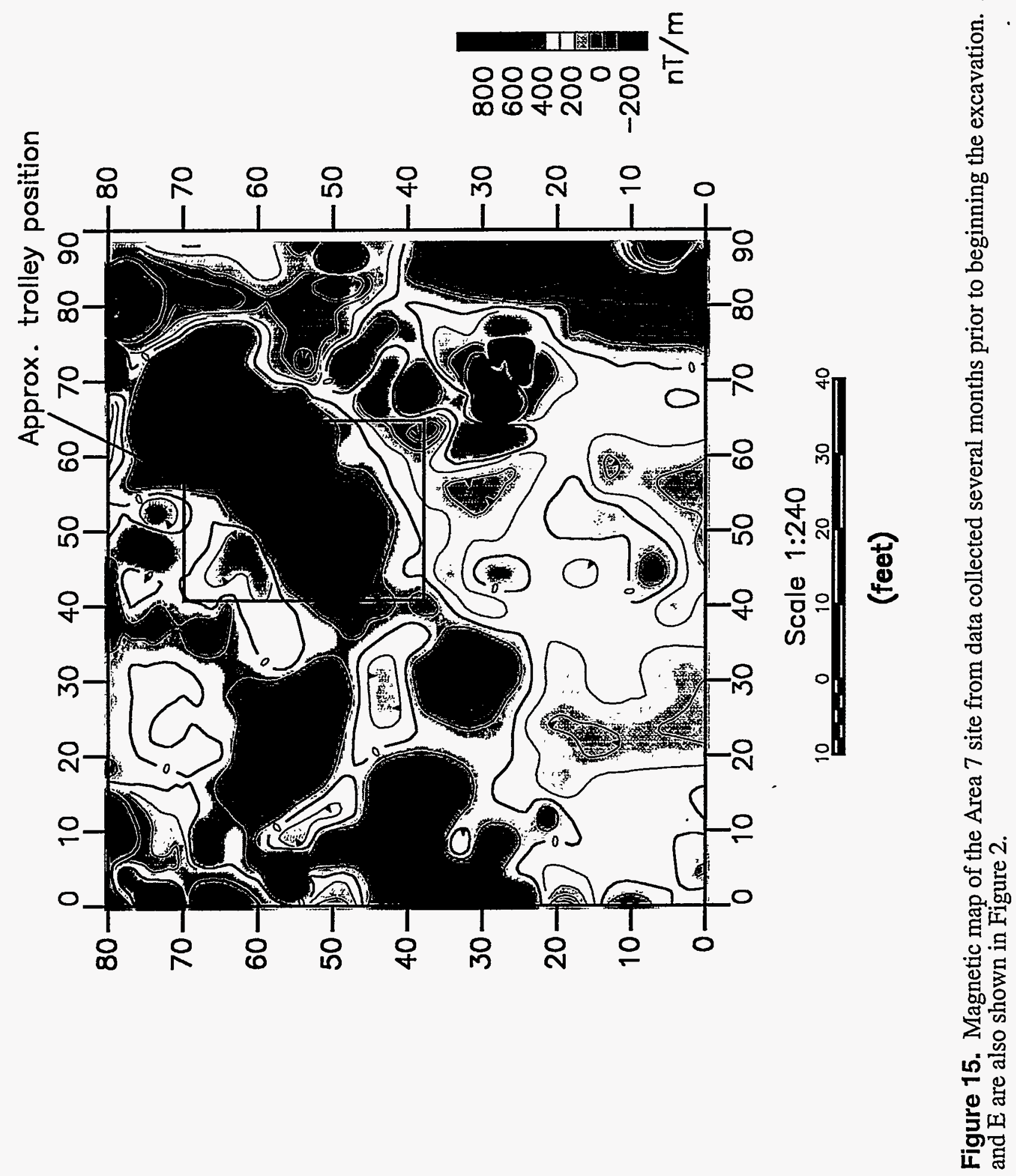


Level 1

dig-face elevation: $0.0 \mathrm{ft}$

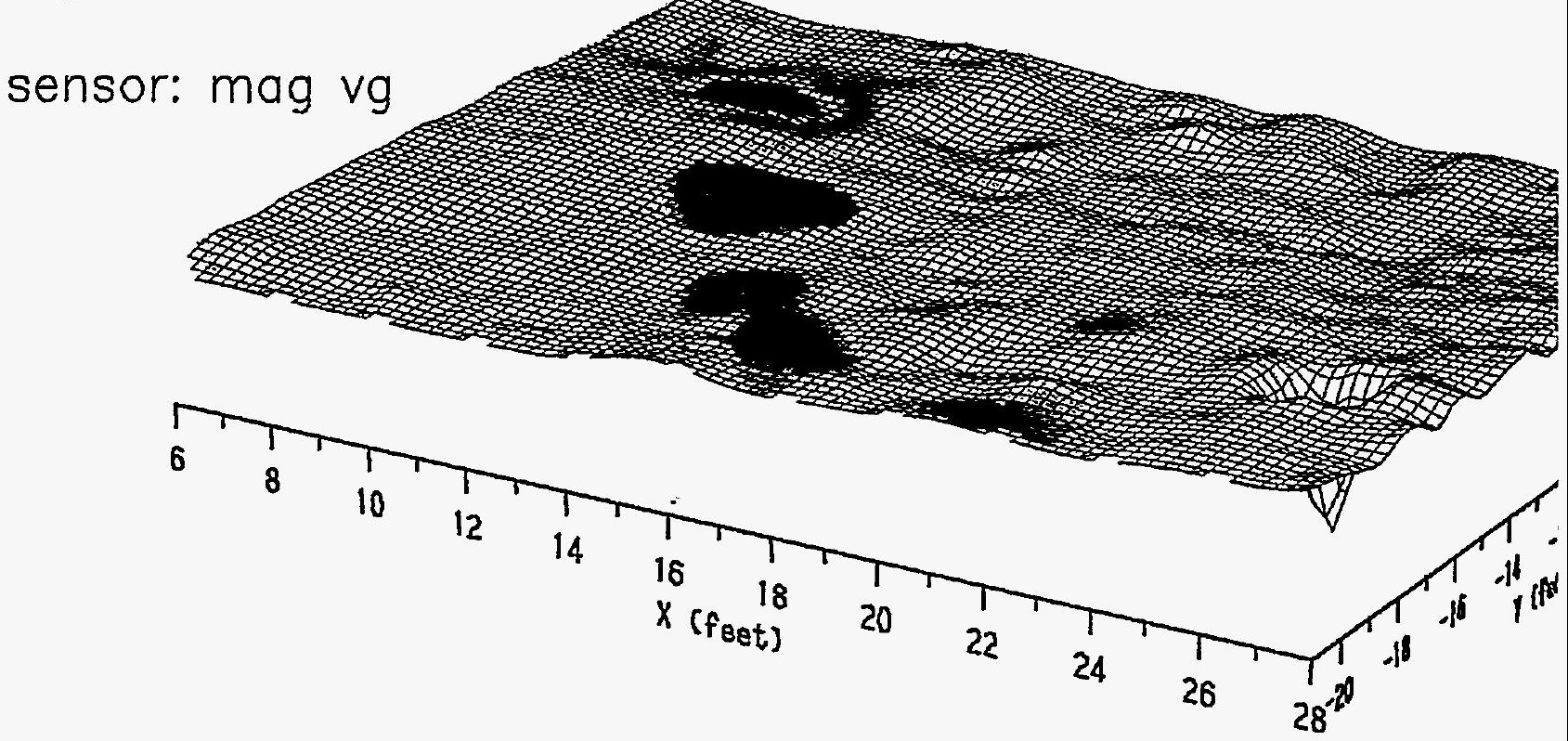

Level 2

dig-face elevation: $-1.5 \mathrm{ft}$

sensor: mag vg

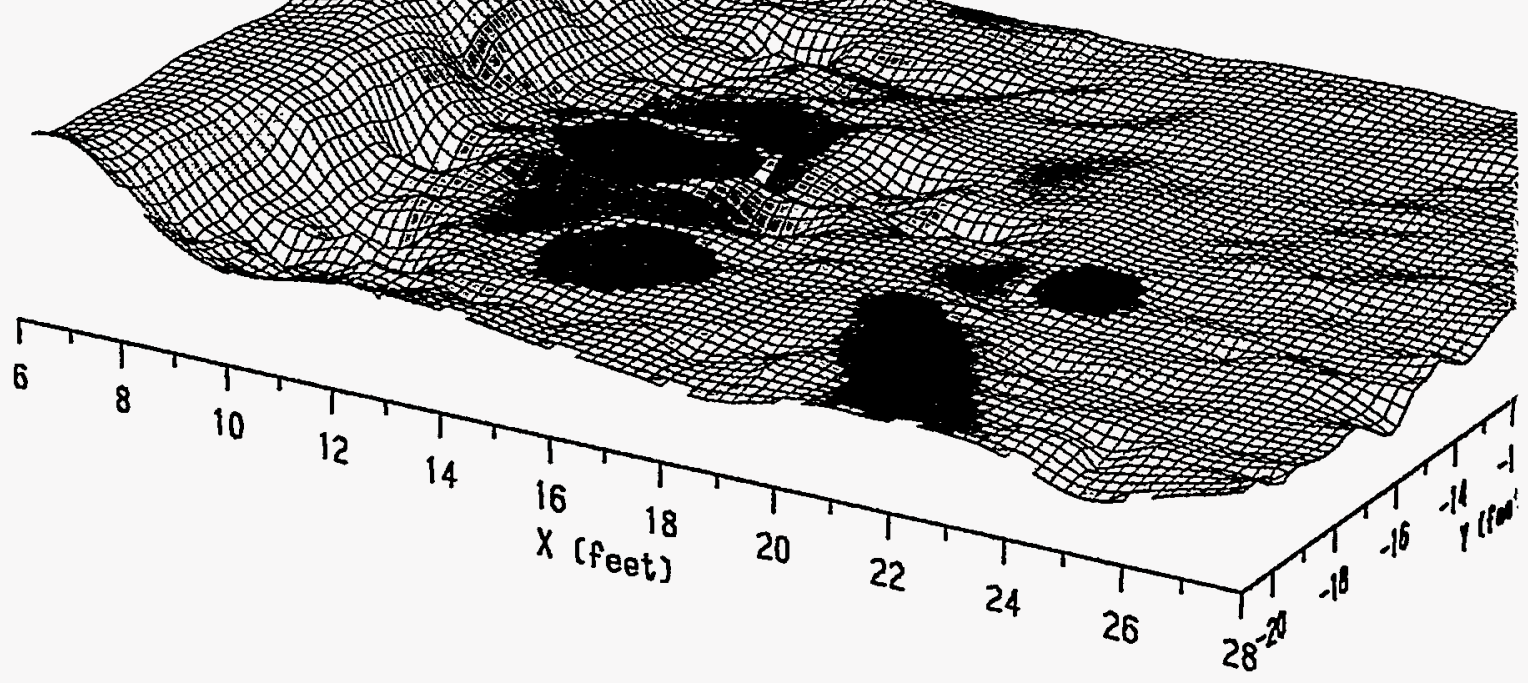

Figure 16. Magnetic data from Levels 1-4 (a-d) digface scans. See text for discussion. 

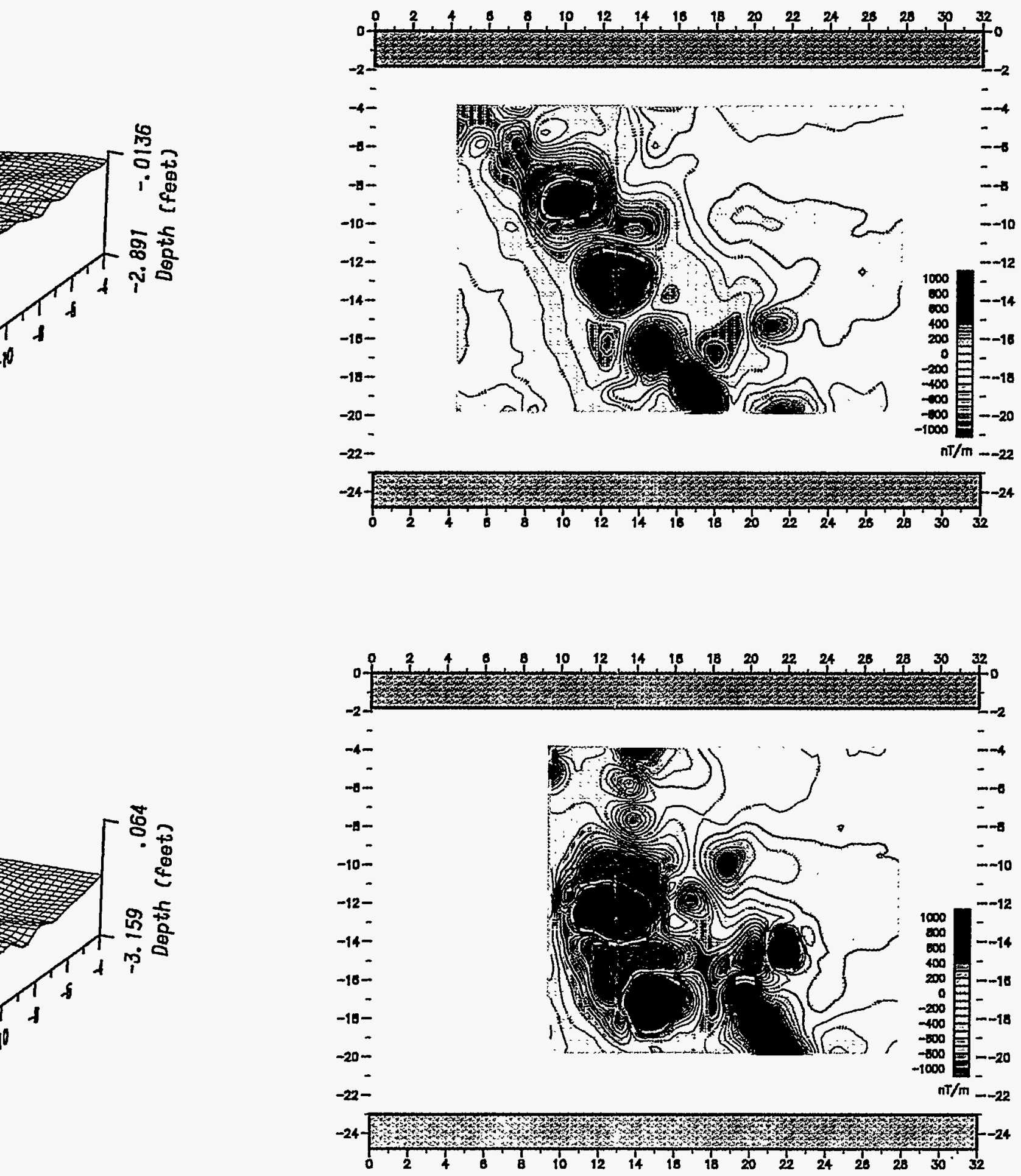
Level 3

dig-face elevation: $-3.5 \mathrm{ft}$

sensor: mag vg

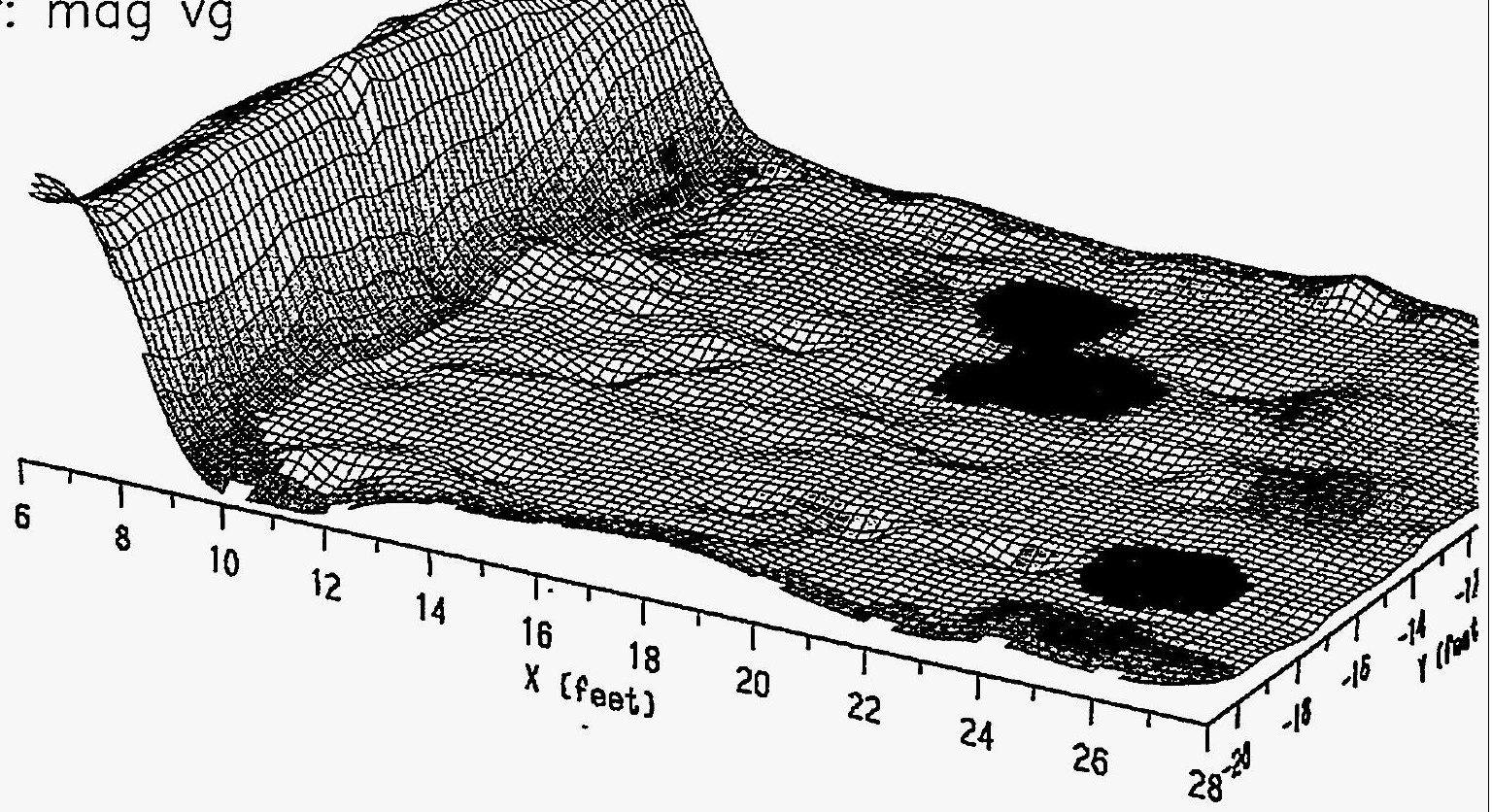

Level 4

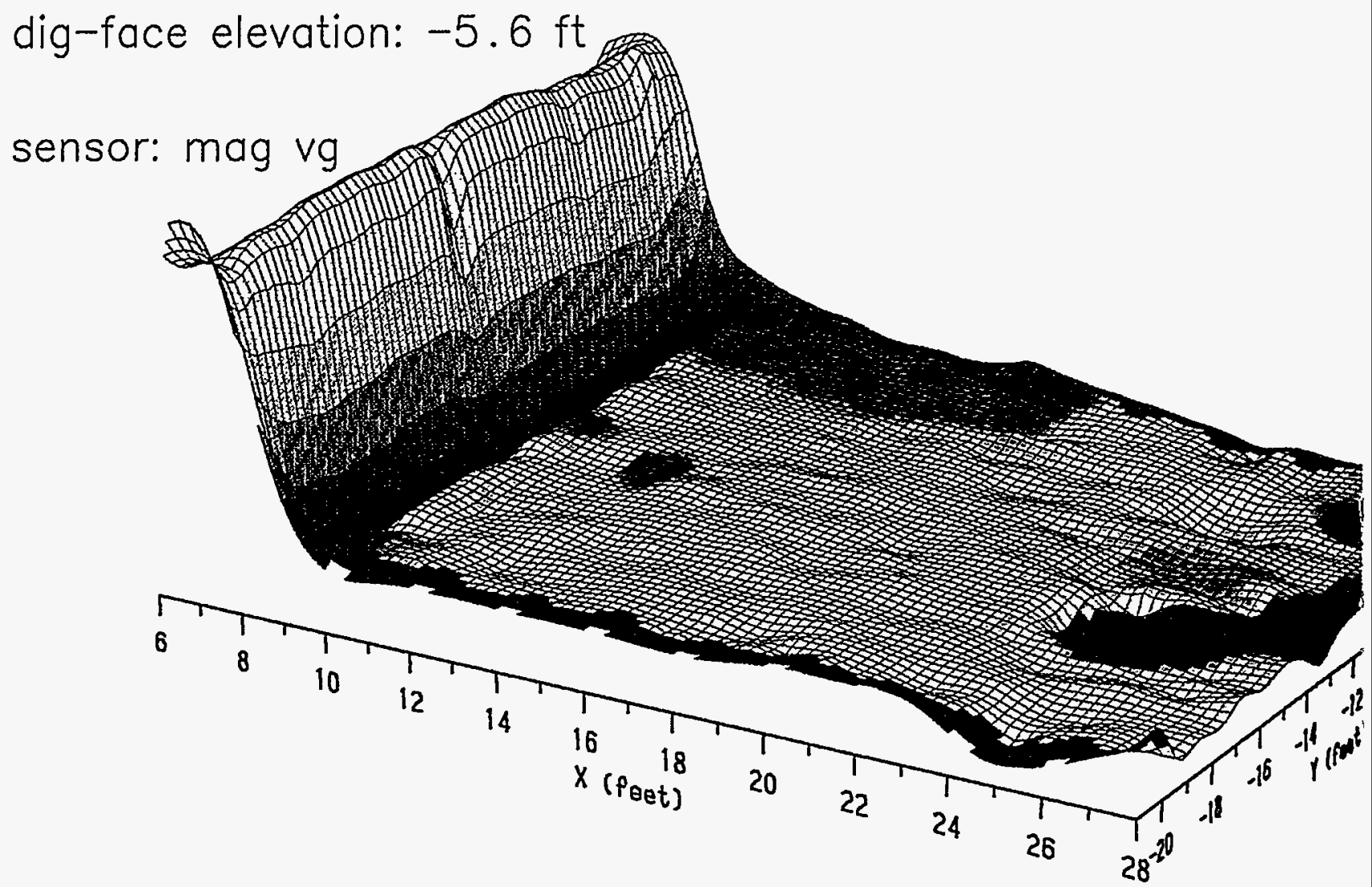

Figure 16 (continued). 

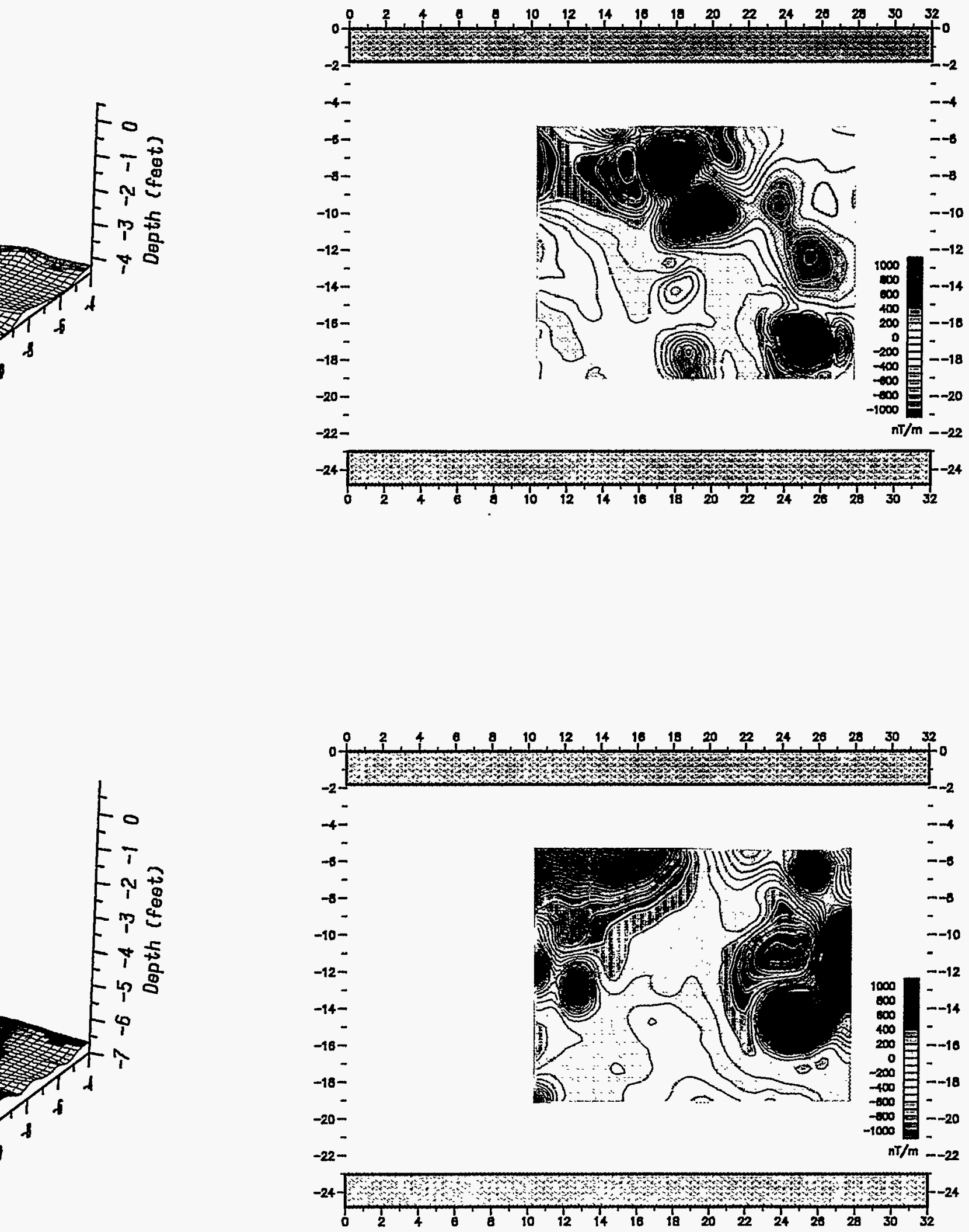


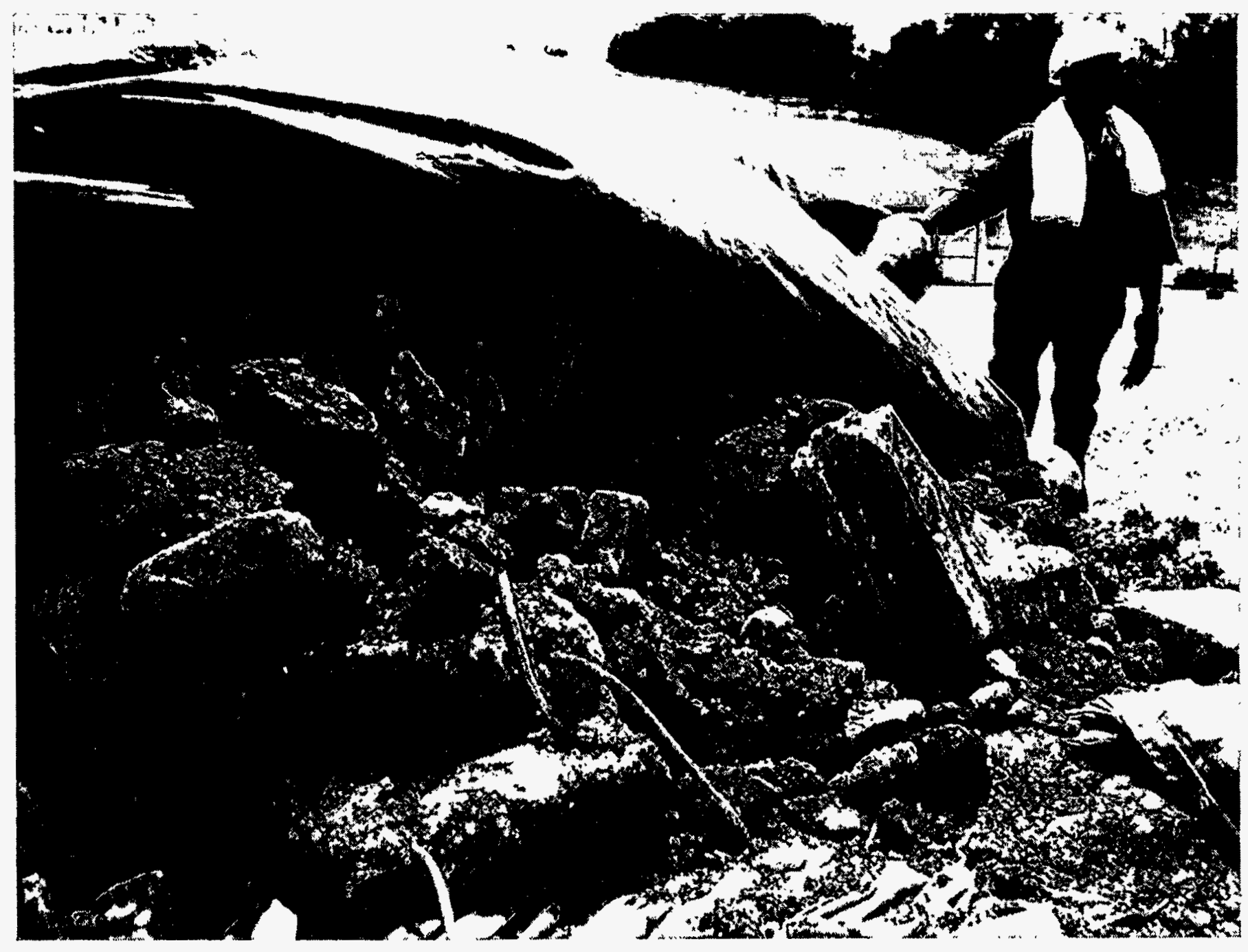

Figure 17. Photograph of concrete debris removed during the second excavation lift. The debris was thought to be a remnant of the concrete septic tank. 
improvement in anomaly resolution with increasing depth, as observed in the Area 7 magnetic data, could be important under different circumstances.

\section{Radiation Measurements: Detecting and Mapping Radioactive Contamination}

The sequence of radiation measurements made during the Area 7 excavation produced the most interesting examples of the capabilities of in situ monitoring. At each excavation level, the GNM was used to map gross radiation fields that would indicate the presence of subsurface contamination. The Ge-spectrometer was then deployed at key points within the measured radiation fields to determine the identity of the gamma radiation emitters. The combination of these tools provided a clear picture of the plan view distribution of radioactive contamination at Area 7 as well as some insight into the depth distribution.

\section{Level 1 Radiation Measurements: Ground Elevation $=0.0 \mathrm{ft}$}

The Level 1 data were collected at the ground surface existing at the time the trolley was set up, i.e., after the overburden removal stage (see Figure 7). Plots of the Level 1 GNM data are presented in Figure 18a. Upon completion of the GNM measurements at the first level, in situ gamma-ray spectra were measured at four positions with the Ge-spectrometer. Four $\sim 20$-g soil samples were taken at the same positions and assayed with the Ge-spectrometer using the calibrated sample counting geometry. Figure 19a summarizes the GNM data and shows the sample locations. The only radionuclide detected above natural radioactivity at this first level was ${ }^{232} \mathrm{Th}$.

Figure 18a shows a high gamma radiation area trending across the excavation site near $x=20$. The high gamma field zone is seen to be narrow and approximately linear. Peak values reach above 10,000 counts/sec (cps), over 10 times background radiation. The majority of the scan area in Figure 18a shows background level radiation, suggesting that ${ }^{232} \mathrm{Th}$ contamination is very localized, perhaps in its original disposal configuration.

\section{Level 2 Radiation Measurements: Ground Elevation $=-1.5 \mathrm{ft}$}

After excavating approximately $11 / 2$ feet of soil from between the trolley tracks, a new measurement sequence was begun. GNM data from the Level 2 scan are presented in Figure $18 \mathrm{~b}$. High gamma fields were observed along the same trend identified to contain ${ }^{232} \mathrm{Th}$ based on the Level 1 data. The high radiation field area had broadened and increased in intensity. The Level 2 data give a clear impression that the excavation has advanced closer to (or further into) the center of the ${ }^{232}$ Th contamination plume. The GNM sensor saturated at the $10,000 \mathrm{cps}$ level over the central portion of the plume, so the highest radiation fields were not measured. No other high radiation areas were observed.

Upon completion of the Level 2 GNM measurements, the Ge-spectrometer was deployed to make an in situ measurement at one point within the high field area. A grab sample was also taken at this point (L2-1, Figure 19b). This position is near the projected center of the 


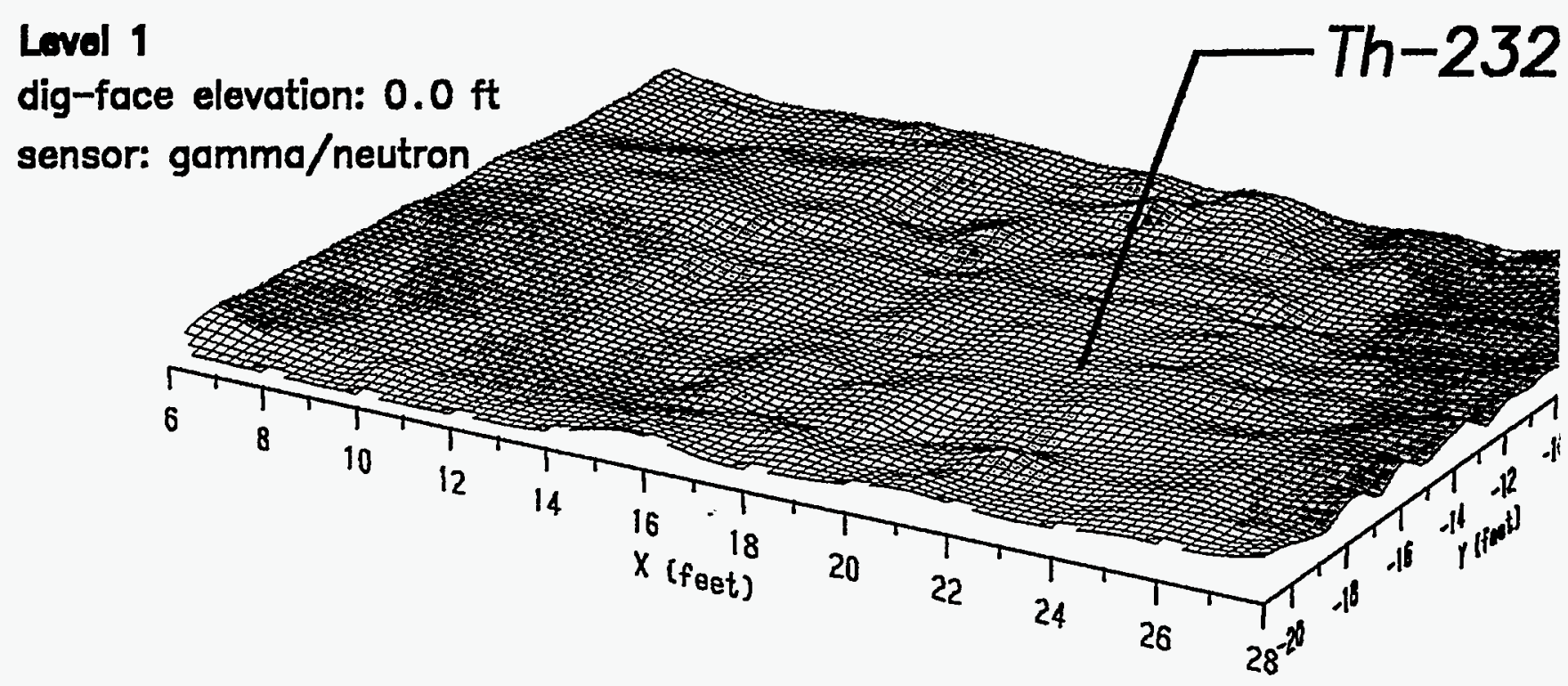

Lovel 2

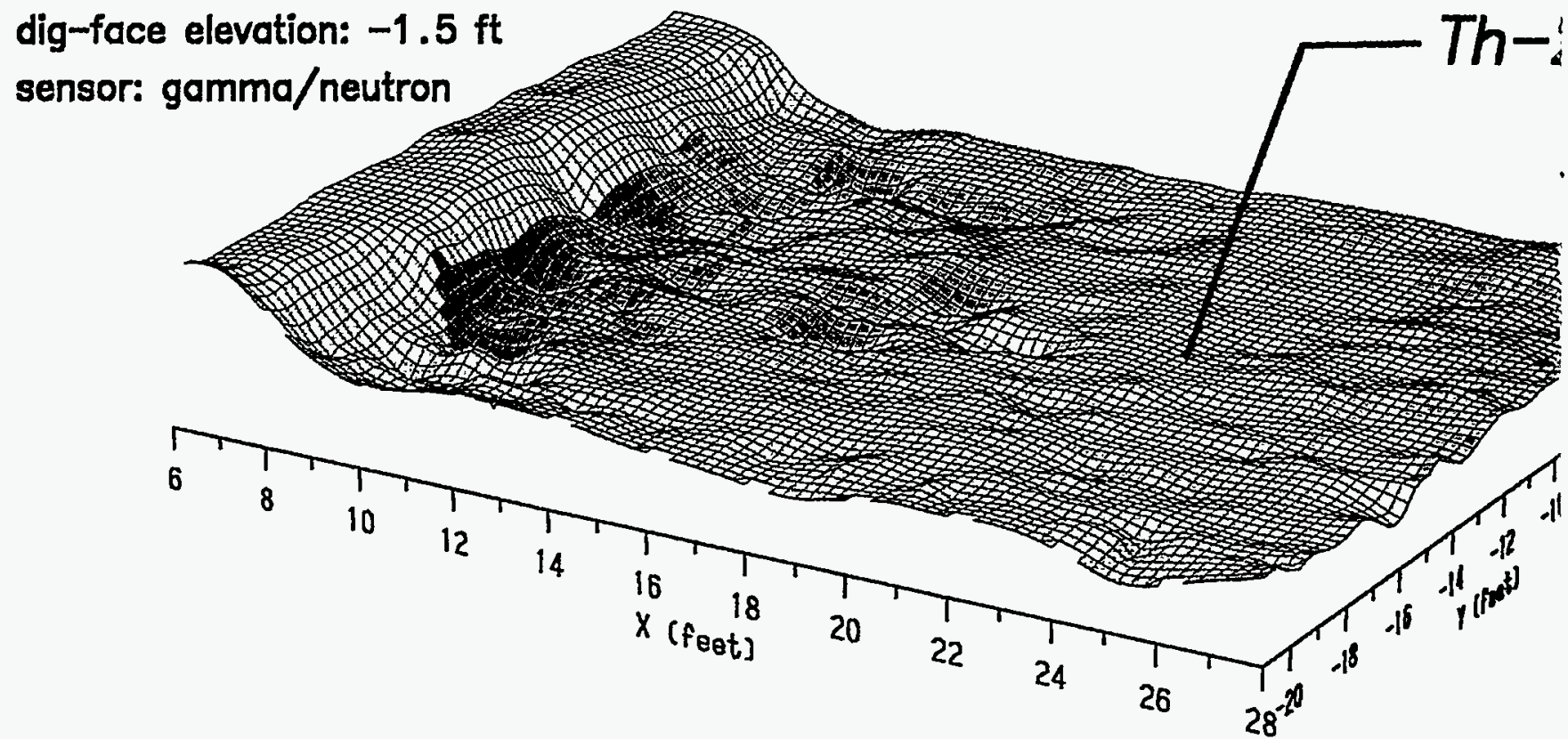

Figure 18. Gamma radiation data from Levels 1-4 (a-d) dig-face scans. See text for discussion. 


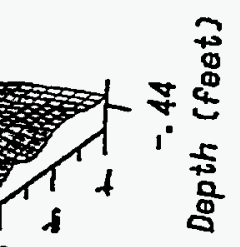
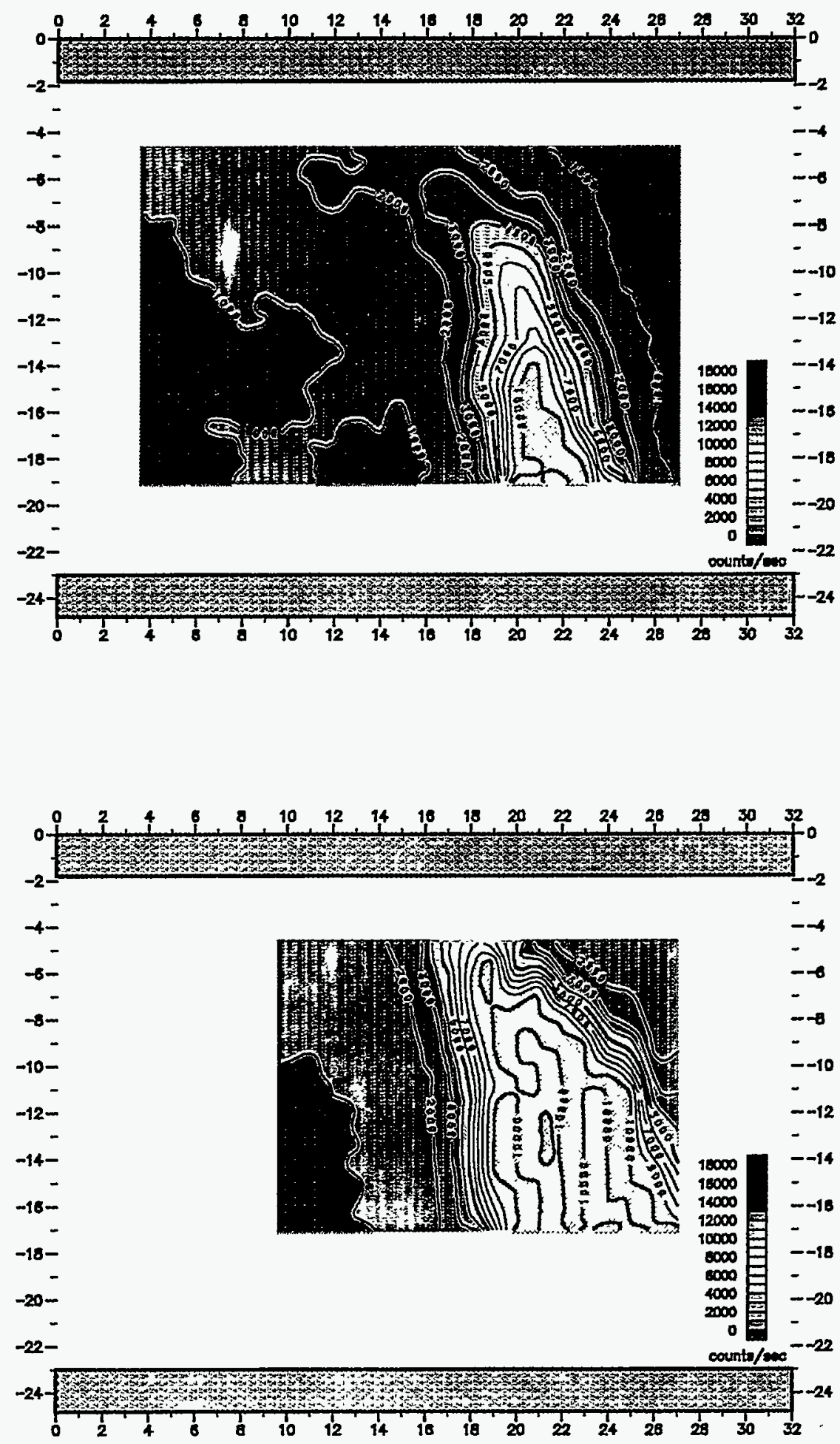


\section{Lovel 3}

dig-face elevation: $-3.5 \mathrm{ft}$ sensor: gamma/neutron

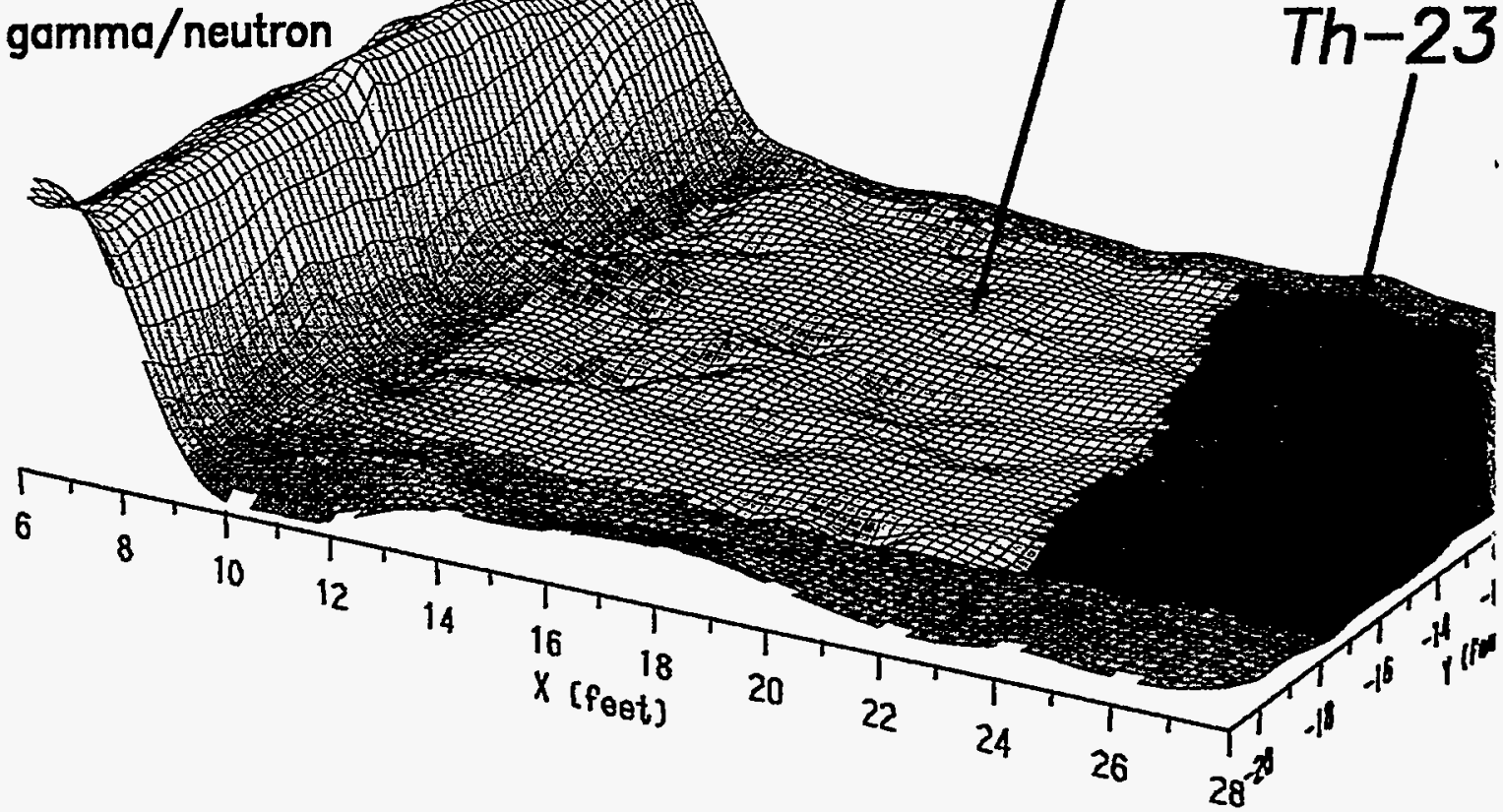

\section{Loval 4}

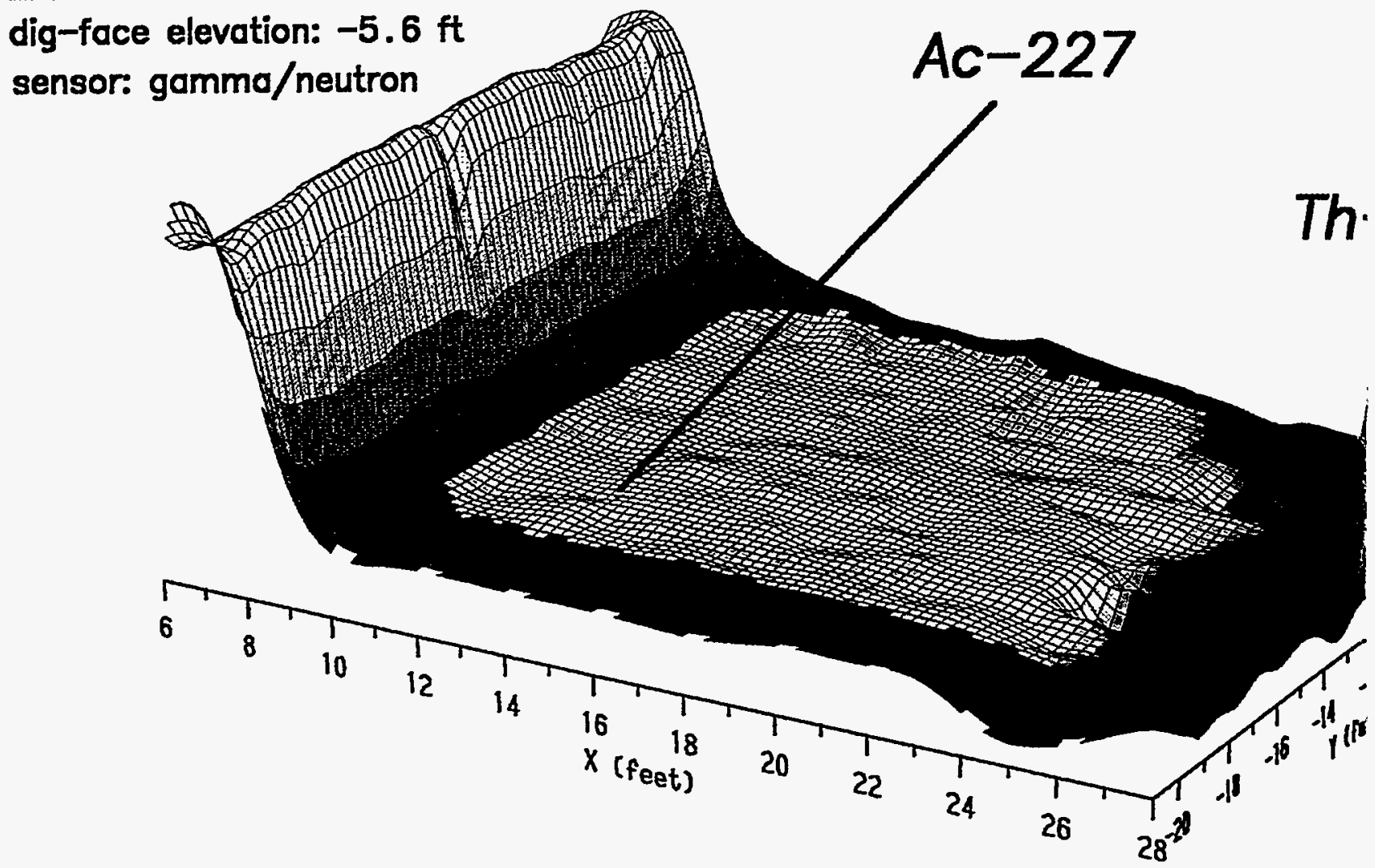

Figure 18 (continued). 

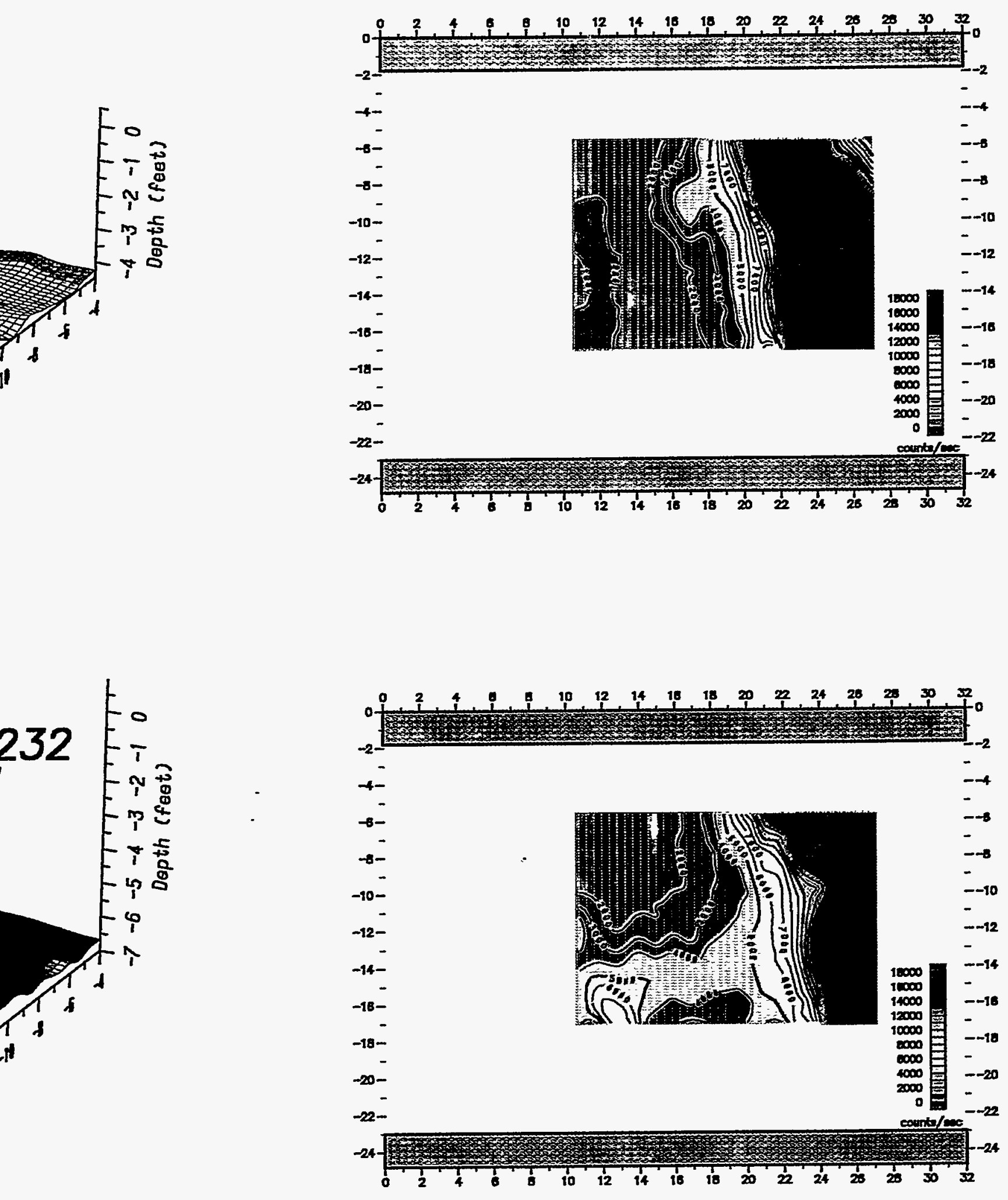

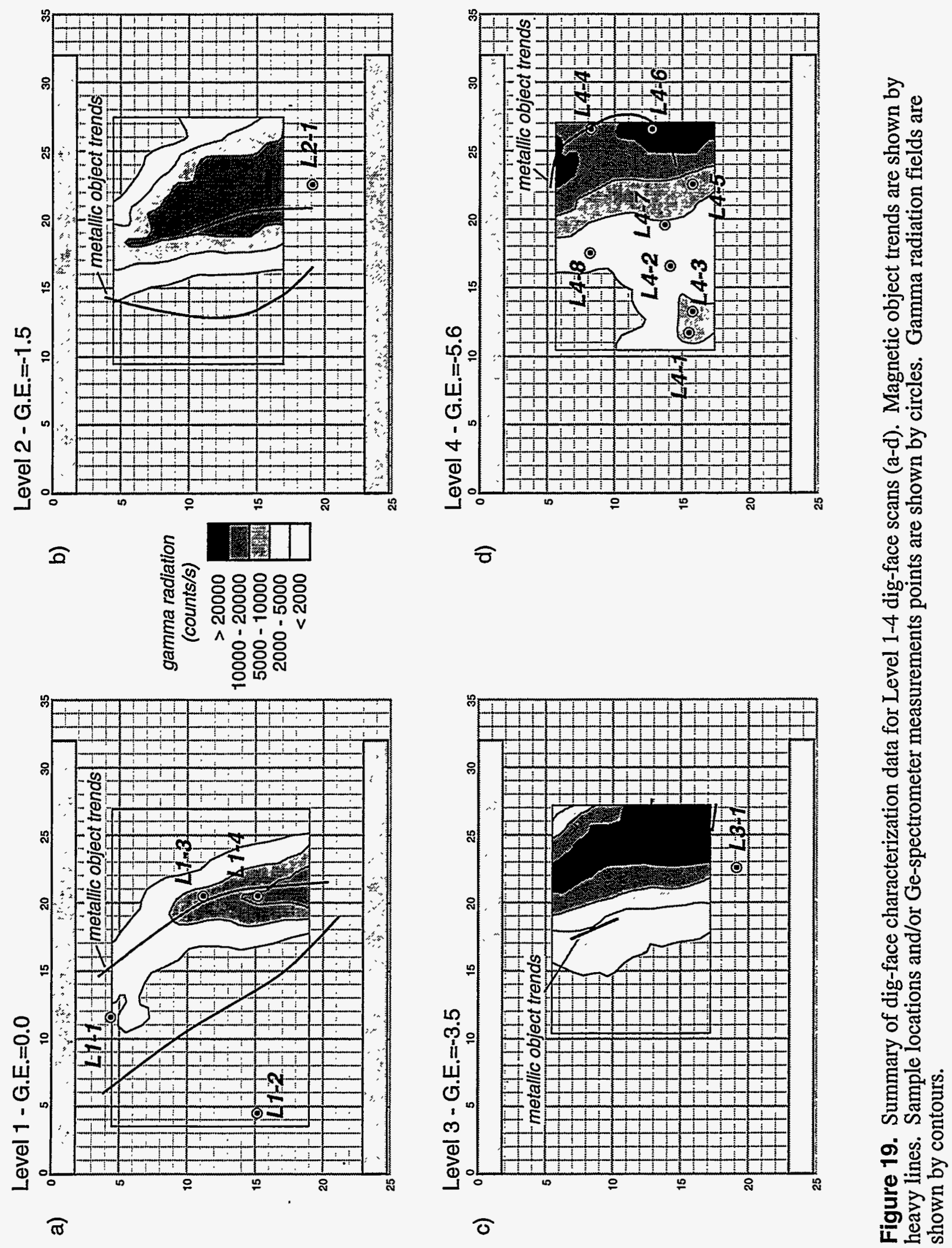
$10,000 \mathrm{cps}$ saturated portion of the radiation field and is presumed to be near the center of the ${ }^{232} \mathrm{Th}$ contamination (Figure 19b). Again, only ${ }^{232} \mathrm{Th}$ was detected above background levels.

\section{Level 3 Radiation Measurements: Ground Elevation $=\mathbf{- 3 . 5} \mathrm{ft}$}

The site was excavated approximately two additional feet, and the Level 3 sequence of radiation measurements were made. Level 3 GNM data are shown in Figure 18c. During this excavation, several large pieces of concrete were removed that appeared to have been part of a concrete structure, possibly a tank. No in situ Ge-spectrometer measurements were made at this level, but one sample was collected (L3-1, Figure 19c). A sample was also scraped from a piece of concrete debris after it was removed from the pit.

The Level 3 GNM data show continued evidence of the ${ }^{232} \mathrm{Th}$ plume with the plume centerline shifted several feet toward the $+x$ end of the pit. The GNM range was increased to $20,000 \mathrm{cps}$ before the Level $3 \mathrm{scan}$, but the measured radiation fields still saturated the sensor along the plume centerline. A separate small anomalous radiation field area $(4,000-5,000 \mathrm{cps})$ is visible near position $\mathrm{x}=17, \mathrm{y}=-9$ in Figure 18c. No spectral measurements were made in the vicinity of this feature. It is not known if the feature represents a satellite distribution of ${ }^{232} \mathrm{Th}$ or if it resulted from a different radionuclide.

\section{Level 4 Radiation Measurements: Ground Elevation $=\mathbf{- 5 . 6} \mathbf{f t}$}

The site was again excavated approximately two feet. The Level 4 GNM data are presented in Figure 18d. The Level 4 data show further shifting of the ${ }^{232} \mathrm{Th}$ plume in the $+\mathrm{x}$ direction, but no increase in the levels of radiation. In fact, the ${ }^{232} \mathrm{Th}$ plume radiation fields appear to have decreased slightly from Level 3 , suggesting that contamination levels are no longer increasing and may be decreasing. The Figure $18 \mathrm{~d}$ maps also show unmistakable evidence of a second contamination area, centered near the lower left corner of the map area and trending at nearly right angles to the ${ }^{232} \mathrm{Th}$ plume. Eight in situ Ge-spectrometer measurements were made at Level 4 (Figure 19d). Grab samples were no longer easily obtainable due to the inaccessibility of the bottom of the excavation.

Analysis of the in situ spectral measurements revealed that the gamma radiation field of Figure $18 \mathrm{~d}$ was caused by two separate radionuclides in the subsurface. The main plume contains only ${ }^{232} \mathrm{Th}$, and is continuous with the contamination zone seen in previous levels. A significant volume of this plume was already excavated by Level 4 . The second plume, with highest concentrations occurring near $x=13, y=16$, contains ${ }^{227}$ Ac. Level 1-3 GNM data show no evidence of this second contamination area, suggesting that the Level 4 dig-face occurred close to the top of its distribution. Subsequent excavation recovered ${ }^{227}$ Ac-contaminated soil throughout the area around and beneath the high field area mapped by the GNM. No other ${ }^{227} \mathrm{Ac}$ contamination areas were found during the subsequent excavation.

\section{Interpretation of the ${ }^{232}$ Th Contamination Area}

The sequence of radiation field maps in Figure 18 give a clear impression that the radioactive contamination plumes within the Area 7 pit are discrete bodies with relatively narrow distributions and well-defined edges. The exact edges of contamination are not easily derived 
from the maps since they depend on factors such as the sensor view angle and the thickness of the contaminated zone that, at present, are poorly understood. For example, the GNM sensor detects radiation from a contaminated soil zone before it comes into a position directly over the zone, causing the mapped radiation areas to be larger than the actual area of contamination. Even with this smearing effect, the ${ }^{232} \mathrm{Th}$ and ${ }^{227} \mathrm{Ac}$ plumes at Area 7 clearly occupy a relatively small volume of the excavated soil.

Figure 20 shows an attempt to reconstruct the ${ }^{232} \mathrm{Th}$ contamination zone encountered during the dig-face operations at Mound. This reconstruction is possible because of the multiple views of the plume that were acquired during the course of the excavation. Figure 20a shows centerlines of ${ }^{232} \mathrm{Th}$ radiation areas plotted for each dig-face level. The centerlines migrate further toward the end of the pit after each increment of excavation because the contamination seam has stratigraphic dip in the $+x$ direction. Figure $20 \mathrm{~b}$ shows this configuration in cross-sectional view. This view was constructed by projecting the 5000-cps and 10,000-cps contours into cross section and connecting them. The actual volume of contamination is somewhere within the projected contours. One explanation for the observed contaminant distribution is that the ${ }^{232} \mathrm{Th}$ soils were originally dumped on a slope.

\section{Quantifying Radiation Measurements: In Situ Radionuclide Concentrations}

The in situ concentration of a radioactive contaminant is of considerable interest to operators of a remedial activity such as Mound Area 7 because it relates directly to the sequence of decisions that must be made for each bucket of excavated soil. How should the material be handled to ensure worker safety? Does the material require treatment or regulated storage? What sort of treatment or storage is required? These decisions depend on the extent and the level of contamination as specified in federal and state regulations. Normally, the required information for making these decisions is obtained by collecting and analyzing small samples of the excavated materials. However, the quality of information from this method of acquiring radioassay data depends upon the number and locations of the samples analyzed and assumes that each sample is representative of its location.

In this section, the dig-face radiation measurements from the GNM and from grab samples and in situ measurements with the Ge-spectrometer are converted into estimates of the in situ radionuclide concentration ( $\mathrm{pCi} / \mathrm{g}$ ) as a function of location. This effort represents a small first step toward devising methods that can be used for quantitative assay of buried waste. All reported activity concentrations should be regarded as semi-quantitative values with uncertainties (one estimated standard deviation) of at least $100 \%$.

Many factors influence the relationship between the radiation fields measured by the dig-face radiation sensors and the corresponding concentration of contaminants in the ground. These factors can differ for each type of sensor, for each different radionuclide, and can depend on the geometry of deployment. For the GNM and Ge-spectrometer, the key factors that convert from counts per second to $\mathrm{pCi} / \mathrm{g}$, are the detector efficiency, the effective area viewed by the detector, the effective depth, and the density of the material (soil) being excavated. Some of 
a)

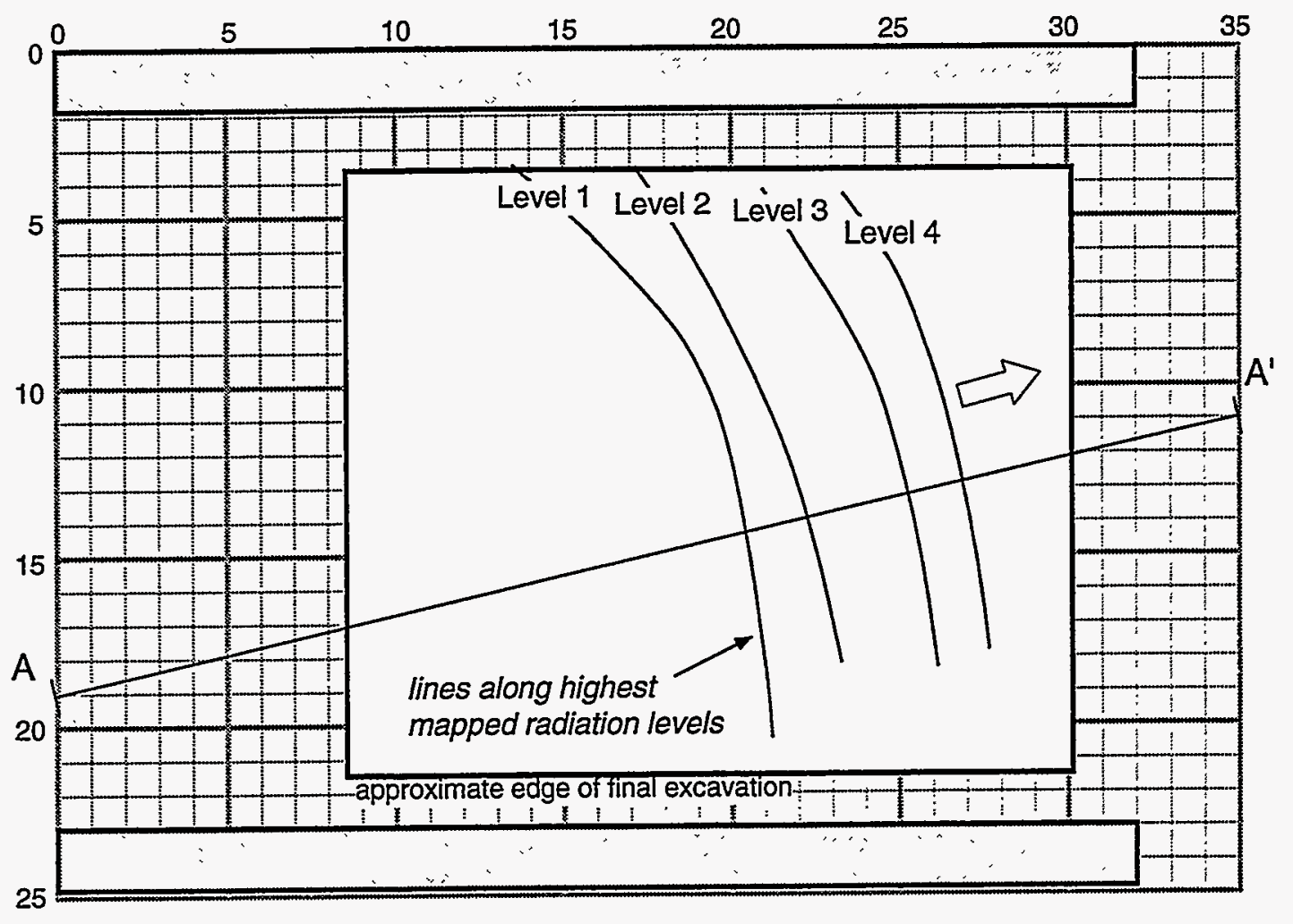

b)

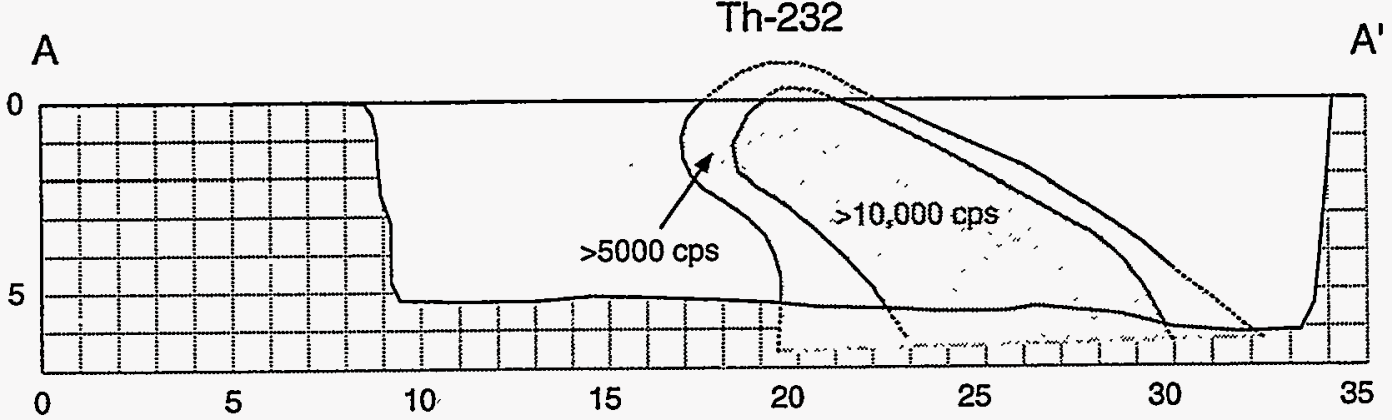

Figure 20. Interpreted geometry of ${ }^{232} \mathrm{Th}$ plume at Area 7. Lines in a) show the location of peak radiation for each Level. The interpreted depth distribution is shown in b). 
these parameters can be easily measured or estimated (e.g., the density); less easily quantified are the depth and field of view.

When a measured in situ count rate or activity can be correlated to a measured activity concentration obtained from a grab sample or known from other measurements (e.g., the natural thorium activity concentration), the conversion factor, $\mathrm{K}$, can be determined directly, as shown in Equation 1.

$K=A C$

where

$$
\begin{aligned}
& \mathrm{K}=\text { conversion factor } \mathrm{K}_{\mathrm{M}},=(\mathrm{c} / \mathrm{s}) /(\mathrm{pCi} / \mathrm{g}) \text { or } \mathrm{K}_{\mathrm{G}}=(\mathrm{pCi}) /(\mathrm{pCi} / \mathrm{g}) \\
& \mathrm{A}=\text { counts per second, } \mathrm{A}_{\mathrm{M}} \text {, or }=\text { activity }(\mathrm{pCi}), \mathrm{A}_{\mathrm{G}} \\
& \mathrm{C}=\text { activity concentration }(\mathrm{pCi} / \mathrm{g})
\end{aligned}
$$

for the GNM and the Ge-spectrometer, ${ }^{b}$ respectively. This direct calibration approach will form the basis for the quantitative work presented below. Because the effective depth of the in situ measurements differs for ${ }^{232} \mathrm{Th}$ and ${ }^{227} \mathrm{Ac}$, and because sample-detector distances changed for the in situ measurements at level $L 4$, different values of $\mathrm{K}_{M}$ and $\mathrm{K}_{\mathrm{G}}$ are required. The development of the $\mathrm{K}_{\mathrm{M}}$ and $\mathrm{K}_{\mathrm{G}}$ factors is summarized in the following sections. Appendix A provides more detailed discussion.

\section{Conversion of Data to Activity Concentrations}

In situ radionuclide concentrations were measured at 14 locations over the L1, L2, L3, and LA excavation elevations (Figure 19). For each location, up to three separate concentrations were measured using (a) GNM data, (b) in situ Ge-spectrometer data, and (c) 20-g samples counted by the Ge-spectrometer.

GNM Conversion Factors. The GNM activity concentrations for the ${ }^{232} \mathrm{Th}$ (and daughters) plume were converted from counts per second from the contour plots to $\mathrm{pCi} / \mathrm{g}$ using the deduced conversion factor $K_{M}(T h)$ (see Appendix A). The conversion factor $K_{M}(T h)=$ $253.34(\mathrm{c} / \mathrm{s}) /(\mathrm{pCi} / \mathrm{g})$, which applies only for ${ }^{232} \mathrm{Th}$ (and daughters), was deduced from the natural thorium activity concentration of the soil (estimated to be $1.5 \mathrm{pCi} / \mathrm{g}$ ) at the trolley parking area (position L1-2, Figure 19) and from the GNM count rate $(800 \mathrm{c} / \mathrm{s})$ in this location with the contribution (420 c/s) from K-40 subtracted (Equation 2).

b. The units for $\mathrm{K}_{\mathrm{M}},(\mathrm{c} / \mathrm{s}) /(\mathrm{pCi} / \mathrm{g})$, are different than those for $\mathrm{K}_{\mathrm{G}},(\mathrm{pCi}) /(\mathrm{pCi} / \mathrm{g})$. 
$A=\left(A_{M}-B\right) /\left[K_{M}(T h)\right]$

where

$$
\begin{array}{ll}
B & =\text { background count rate due to } \mathrm{K}-40 \\
A_{M} & =\text { count rate }(\mathrm{c} / \mathrm{s}) \\
\mathrm{K}_{\mathrm{M}}(\mathrm{Th}) & =\text { conversion factor }(\mathrm{c} / \mathrm{s}) /(\mathrm{pCi} / \mathrm{g}) .
\end{array}
$$

This factor is strictly valid only for ${ }^{232} \mathrm{Th}$ distributed uniformly throughout the volume of investigation of the GNM.

Adjustments to the GNM conversion factor $\mathrm{K}_{\mathrm{M}}(\mathrm{Th})$ are required for the measurement of ${ }^{227} \mathrm{Ac}$ activity concentrations owing to the lower average energy, $\mathrm{E} \gamma(\mathrm{Ac})=281 \mathrm{keV}$, of its emitted gamma-rays and the difference in the total number of emitted gamma-rays per 100 decays, to yield a conversion factor $\mathrm{K}_{\mathrm{M}}(\mathrm{Ac})=93.0(\mathrm{c} / \mathrm{s}) /(\mathrm{pCi} / \mathrm{g})$. Further correction of the conversion factor was required because the size of the ${ }^{227} \mathrm{Ac}$ plume is clearly smaller than the detector's field of view (Figure 18). Based on an estimated 3.3 times reduction in the field of view, the final $\mathrm{K}_{\mathrm{M}}(\mathrm{Ac})$ value for converting GNM measurements to activity concentration was set at $28.0(\mathrm{c} / \mathrm{s}) /(\mathrm{pCi} / \mathrm{g})$.

No adjustments to $K_{M}(T h)$ and $K_{M}(A c)$ were made for variations in height of the GNM sensor above ground, which ranged from about 6 to 12 inches.

Ge-Spectrometer In Situ Conversion Factors. The conversion factor $\mathrm{K}_{\mathrm{G}}(\mathrm{Th})$ was determined by the same approach used for the GNM, i.e., from an in situ measurement made in a background ${ }^{232} \mathrm{Th}$ area located near the trolley parking location (L1-2, Figure 19). Again, ${ }^{232} \mathrm{Th}$ was assumed to be present at $1.5 \mathrm{pCi} / \mathrm{g}$. Measured activity using the Ge-spectrometer was $1.78 \times 10^{5} \mathrm{pCi}$, yielding a $\mathrm{K}_{\mathrm{G}}(\mathrm{Th})=118,667 \mathrm{pCi} /(\mathrm{pCi} / \mathrm{g})$. This value of $\mathrm{K}_{\mathrm{G}}(\mathrm{Th})$ was used for all conversions from measured Ge-spectrometer activities $(\mathrm{pCi})$ to ${ }^{232} \mathrm{Th}$ activity concentrations (pCi/g).

Laboratory calibration of the Ge-spectrometer produced an efficiency curve that incorporates the gamma-ray attenuation of the soil. The calibration spans a broad range of gamma-ray energies, including the major peaks for both ${ }^{232} \mathrm{Th}$ and ${ }^{227} \mathrm{Ac}$. Because the Ge-spectrometer analysis package automatically corrects in situ measurements based on this efficiency curve, $K_{G}$ dependence on gamma-ray energy and depth of investigation is effectively eliminated. If it is assumed that the area of investigation for ${ }^{227} \mathrm{Ac}$ is similar to that for ${ }^{232} \mathrm{Th}$, the factor $\mathrm{K}_{\mathrm{G}}(\mathrm{Ac})$ becomes identical to $\mathrm{K}_{\mathrm{G}}(\mathrm{Th})$. In fact, because of the relatively small investigation area of the Ge-spectrometer (compared with the GNM), no area adjustment was made, and $\mathrm{K}_{\mathrm{G}}(\mathrm{Ac})=\mathrm{K}_{\mathrm{G}}(\mathrm{Th})$ was taken to be $118,667 \mathrm{pCi} /(\mathrm{pCi} / \mathrm{g})$.

Ge-Spectrometer Grab Samples. Ge-spectrometer measurements made on 20-g soil samples are directly converted to activity concentrations based on laboratory efficiency curves and known sample mass. The conversion for sample measurements requires no assumptions for 
volume of investigation since the position and size of the samples is accurately known. Deduced activity concentrations for the $20 \mathrm{-g}$ grab samples are by far the most accurate of the three types of quantitative estimates made at Mound. The only question regarding the value of the sample analysis estimates is whether or not they represent in situ conditions. This is a fundamental shortcoming of sample-based approaches.

\section{Application of Conversion Factors to In Situ Measurements}

Table 2 summarizes the results from estimating in situ radionuclide activity concentrations at the 14 locations shown in Figure 19. In compiling GNM values for Table 2, the appropriate conversion factor was determined based on identification of either ${ }^{227} \mathrm{Ac}$ or ${ }^{232} \mathrm{Th}$, using the Ge-spectrometer. Otherwise, the Table values were calculated by straightforward application of the conversion factors discussed above.

Table 2. Summary of estimated radionuclide activity concentrations based on dig-face radiation sensor measurements.

\begin{tabular}{|c|c|c|c|c|c|}
\hline $\begin{array}{l}\text { Sample } \\
\text { ID }\end{array}$ & Position & $\begin{array}{l}\mathrm{GNM}^{\mathrm{a}} \\
(\mathrm{pCi} / \mathrm{g})\end{array}$ & $\begin{array}{c}\text { In situ } \\
\text { Ge-spec }^{b} \\
(\mathrm{pCi} / \mathrm{g})\end{array}$ & $\begin{array}{c}\text { 20-g sample } \\
\text { (pCi/g) }\end{array}$ & $\begin{array}{c}\text { Activity ratio } \\
\text { 238:583:911:2614 }\end{array}$ \\
\hline L1-1 & $11.7,-4.2$ & $7.0 \mathrm{Th}$ & $6.9 \mathrm{Th}$ & $16 \mathrm{Th}$ & 125:100:117:59 \\
\hline L1-2 & $4.7,-15.2$ & $1.5 \mathrm{Th}$ & 1.5 Th & $3 \mathrm{Th}$ & 128:100:-:57 \\
\hline L1-3 & $20.7,-11.2$ & $22.0 \mathrm{Th}$ & $2.4 \mathrm{Th}$ & 13.7 Th & 52:100:148:393 \\
\hline L1-4 & $20.7,-15.2$ & $>37.8 \mathrm{Th}$ & $32.0 \mathrm{Th}$ & $116 \mathrm{Th}$ & $53: 100: 112: 154$ \\
\hline L2-1 & $22.6,-19.3$ & $>37.8 \mathrm{Th}$ & 412. $\mathrm{Th}$ & $302 \mathrm{Th}$ & $102: 100: 82: 52$ \\
\hline L3-1 & $22.6,-19.3$ & $\sim 37.8 \mathrm{Th}$ & - & $43 \mathrm{Th}$ & - \\
\hline LA-1 & $11.7,-15.3$ & 199. Ac & $\begin{array}{l}\text { 1.9 Th } \\
\text { 189. Ac }\end{array}$ & - & -:100:125:130 \\
\hline LA-2 & $16.7,-14.3$ & 14.1 Th? ${ }^{c}$ & - & - & - \\
\hline L4-3 & $13.2,-15.8$ & 199. Ac & $\begin{array}{l}\text { 4.2 Th } \\
\text { 202. Ac }\end{array}$ & - & 一:100:96:82 \\
\hline L4-4 & $25.7,-8.3$ & $71.1 \mathrm{Th}$ & $21.0 \mathrm{Th}$ & - & 72:100:118:139 \\
\hline IA-5 & $22.7,-15.8$ & $24.0 \mathrm{Th}$ & $3.5 \mathrm{Th}$ & - & -:100:186:317 \\
\hline L4-6 & $26.7,-12.8$ & $>77.3 \mathrm{Th}$ & 843. Th & - & $125: 100: 71: 30$ \\
\hline LA-7 & $19.7,-13.8$ & 16.1 Th & $9.0 \mathrm{Th}^{\mathrm{d}}$ & - & 111:100:92:71 \\
\hline LA-8 & $17.7,-8.3$ & $8.2 \mathrm{Th}$ & $1.5 \mathrm{Th}$ & - & $82: 100: 134: 215$ \\
\hline \multicolumn{6}{|c|}{$\begin{array}{l}\text { a. } \mathrm{K}_{\mathrm{M}}(\mathrm{Th})=253.4(\mathrm{c} / \mathrm{s}) / \mathrm{pCi} / \mathrm{g} \text { for }{ }^{232} \mathrm{Th} ; \mathrm{K}_{\mathrm{M}}(\mathrm{Ac})=28.0(\mathrm{c} / \mathrm{s}) /(\mathrm{pCi} / \mathrm{g}) \text { for }{ }^{227} \mathrm{Ac} \text {. } \\
\text { b. } \mathrm{K}_{\mathrm{G}}(\mathrm{Th})=118,667(\mathrm{pCi}) / \mathrm{pCi} / \mathrm{g} \text { for }{ }^{232} \mathrm{Th} ; \mathrm{K}_{\mathrm{G}}(\mathrm{Ac})=118,667(\mathrm{pCi}) /(\mathrm{pCi} / \mathrm{g}) \text { for }{ }^{227} \mathrm{Ac} \text {. } \\
\text { c. }{ }^{232} \mathrm{Th} \text { is assumed at this position based on } \mathrm{GNM} \text { map data, but was not verified by Ge-spectrometer. } \\
\text { d. The presence of }{ }^{223} \mathrm{Ra} \text { at } 270 \mathrm{keV} \text { is indicated by the width of the } 270 \mathrm{keV} \text { peak and its high relative } \\
\text { intensity compared with other locations. }\end{array}$} \\
\hline
\end{tabular}


In addition, the in situ measurement taken at L4-7 indicates the possible presence of ${ }^{223} \mathrm{Ra}$, a daughter of ${ }^{227}$ Ac. Unfortunately, lack of statistics prevented a quantitative measurement. This observation helps to explain the connecting contour lines between the ${ }^{227} \mathrm{Ac}$ plume and the ${ }^{232} \mathrm{Th}$ plume.

Radiation Measurement Results. From an inspection of Table 2, it is observed that the activity concentrations from all three measurements agree within about a factor of 4 , with some exceptions. Two of the exceptions, L2-1 and L4-6, occur at locations where the GNM was saturated and the calculated GNM activity concentrations give only minimum values. At two other locations, L1-3 and L4-5, all activity concentrations are low, and some of the discrepancy between the calculated values may be attributed to the method of calibration (i.e., subtraction of an assumed constant K- 40 background). Despite the scatter, the three methods show general agreement in identifying high versus low concentration areas and show no tendency to produce highly spurious concentration estimates (i.e., more than an order of magnitude). Considering the relatively simplistic methods used to calibrate the instruments, this basic agreement is considered encouraging.

Scatter in the Table 2 data may also reflect the more fundamental factor of effective sample size. The GNM has a large volume of investigation compared with the Ge-spectrometer. The Ge-spectrometer in turn has a large volume of investigation compared with the 20-g sample analyses. For each analysis method, the calculations assume that radioactive contaminants are uniformly distributed throughout the volume of investigation. This assumption becomes increasingly precarious as the volume of investigation increases.

The GNM gives a bulk concentration estimate and shows smoothly changing concentrations even if the radionuclide distribution is heterogeneous on a small scale. Although detailed concentration changes are not detected, large-scale changes are accurately mapped. The Ge-spectrometer detects smaller-scale concentration changes than the GNM. Because the two instruments are looking at different volumes of soil, some variation in concentration estimates is expected (unless the radionuclides are very evenly distributed). The $20 \mathrm{~g}$ sample method detects even smaller-scale changes and creates more variation in concentration estimates. The bulk estimates produced by the GNM may be most valuable for rapidly determining the fate of large volumes of excavated soil. Alternatively, the Ge-spectrometer measurements or sample collection must be conducted on much tighter grids to avoid bias from local concentration spikes.

Although the quantitative results achieved at Mound are encouraging, further improvements in the instrumentation and in the analysis protocol are necessary before the in situ measurements can be given the same weight as laboratory assays from a good sampling protocol. Methods to define the field of view and the effective depth need to be developed when the plume is not well-defined. However, the experience gained from this investigation indicates that, with further improvements in the methodology and operational procedures, many operational decisions could be made with the on-site use of the GNM, in situ Ge-spectrometer, and the support grab sample Ge-spectrometer.

Relative Activity Concentrations. The relative activity concentrations for the 238-, 583-, 911-, and 2614-keV Thorium gamma-rays as measured with the in situ Ge-spectrometer are also listed in Table 2. These values, within their uncertainties, should be constant and equal to 100. 
Deviation from 100 is an indication that the activity distribution is not evenly distributed in three dimensions within the detector's field of view. Note that the deviations from 100 are greatest for measurements in the vicinity of a steep gradient in the activity concentration.

Summary and Lessons Learned. Continuous mapping of a radioactive plume during a remedial excavation in combination with spot in situ measurements to identify specific radionuclides and their activity concentrations could be a powerful decision making tool for operations personnel. Lessons learned from the Mound Area 7 experience offer an opportunity to provide greater value to future cleanup activities employing the dig-face characterization philosophy.

Foremost, the simplified analytical techniques used at Mound need further development. The lack of experience in making in situ measurements became obvious during the process of analyzing the AREA 7 data from the GNM and the in situ radiation sensors. Before using the in situ radiation sensors at another remediation site, the principles used in the calibration of in situ Ge-spectrometers should be better understood. These principles are detailed in several references, including Beck et al. (1972) and ICRS (1994). Application of in situ measurements is best applied where the topography of the remediation site allows it. In situ measurements are easiest to apply when, as at Mound, scan surfaces are relatively flat, interference from the excavation walls is minimal, the composition and density of the excavated matrix is relatively constant, and the contamination plumes are not complex. However, it is believed that the combination of radiation measurements made at Mound can go far in interpreting even complex plumes at complex sites. The following specific lessons were learned from the Mound Area 7 experience:

1. The Ge-spectrometer must be used to track the GNM measurements for purposes of radionuclide identification.

2. In the process of developing analysis methods, grab samples should be taken whenever possible at every position at which an in situ Ge-spectrometer measurement is made.

3. Grab samples should be taken directly below each Ge-spectrometer measurement at a depth of $-5 \mathrm{~cm}$ to most closely approximate the effective volume observed by the Ge-spectrometer and to reduce the chance of collecting a nonrepresentative sample.

4. The curve relating the effective area (volume) and associated detector efficiency as a function of detector height should be measured for the GNM and the Ge-spectrometer to allow for variations in detector height at the excavation.

5. The curve relating the effective investigation volume as a function of the energy should be measured for the GNM and the Ge-spectrometer.

6. The shielding surrounding the Ge-spectrometer should be enhanced to better define the field of view of the instrument and to reduce the amount of radiation from oblique angles that penetrates the shield. 
In addition, several improvements in the hardware are needed. The following lists those hardware problems of greatest concern:

1. The noise from the trolley causing the loss of energy resolution by the Ge-spectrometer must be identified and eliminated.

2. The analog readout of the GNM must be changed to prevent count rate saturation resulting from the limits of the analog-to-digital conversion circuit.

3. The count rate capability of the GNM should be improved so that it will operate at $10^{6} \mathrm{c} / \mathrm{s}$, with no more than $10 \%$ counting loss.

4. The stability of the dual-energy pulser circuit on the Ge-spectrometer must be improved to ensure proper tracking of the gamma-ray spectrum.

5. The cabling associated with the Ge-spectrometer must be simplified with the data transferred to the computer by way of RF Ethernet.

\section{A Comparison of Dig-face Radiation Data with Sampling and Analysis Plan Sampling Results}

At Mound, as in most radioactive soil remediation efforts, a formal Sampling and Analysis Plan (SAP) was followed to direct the handling and final disposition of excavated soil. Health Physics conducted gamma surveys of each excavator bucket. If the surveys showed high gamma radiation, samples were collected before the soil was placed in $30 \mathrm{cu}-\mathrm{ft}$ boxes. The results from analysis of these samples formed the hard record of contamination at Area 7. Figure 21 summarizes these results.

The detailed sample inventory for Compartments 1 and 2 in Figure 21 show that the majority of samples contained levels of ${ }^{232} \mathrm{Th}$ below cleanup levels $(15 \mathrm{pCi} / \mathrm{g})$. However, the position of discrete hot zones within these excavation compartments could not be determined from the SAP work because the original location of the hot samples was unrecoverable. One would suspect that the hot ${ }^{232} \mathrm{Th}$ samples were all collected along the linear gamma-radiation anomaly mapped by the dig-face GNM sensor (see Figure 18). If so, a significant portion of the soil disposed in the first 191 boxes (i.e., before encountering ${ }^{227} \mathrm{Ac}$ in Compartment 3 ) probably contained less than cleanup levels of both ${ }^{227} \mathrm{Ac}$ and ${ }^{232} \mathrm{Th}$.

A grid of 16 samples was collected on the pit floor at the conclusion of the dig-face characterization-supported phase of the excavation (i.e., after excavation of Compartment 3 ) in an effort to obtain sample-based spatial information on the relative positions of the ${ }^{232} \mathrm{Th}$ and ${ }^{227} \mathrm{Ac}$ plumes. The sample grid results directly compare to the Level 4 dig-face radiation measurements. Figures 22 and 23 compare the ${ }^{227} \mathrm{Ac}$ and ${ }^{232} \mathrm{Th}$ plume distributions as reconstructed from the sample analysis and from the dig-face radiation measurements. These figures provide both a plan view comparison based on the 16 sample grid, and a cross section comparison, based on the full suite of SAP samples. 


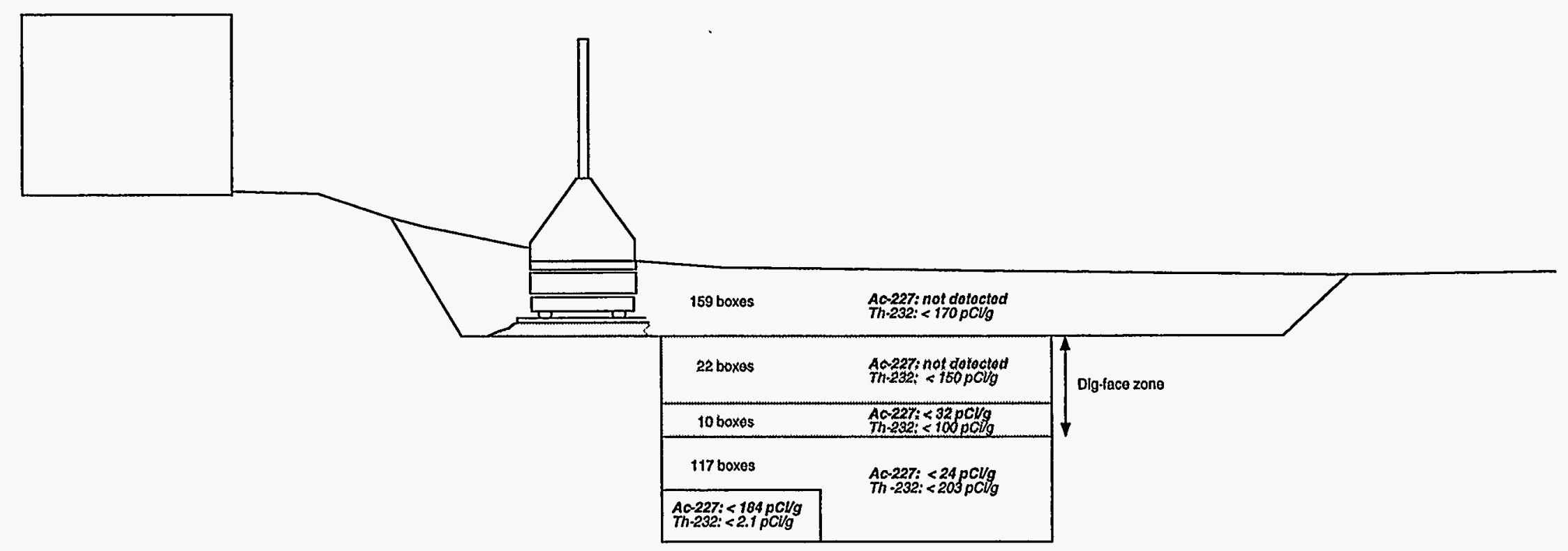

Figure 21. Contamination levels for various compartments of the Area 7 excavation based on results from routine sampling. 


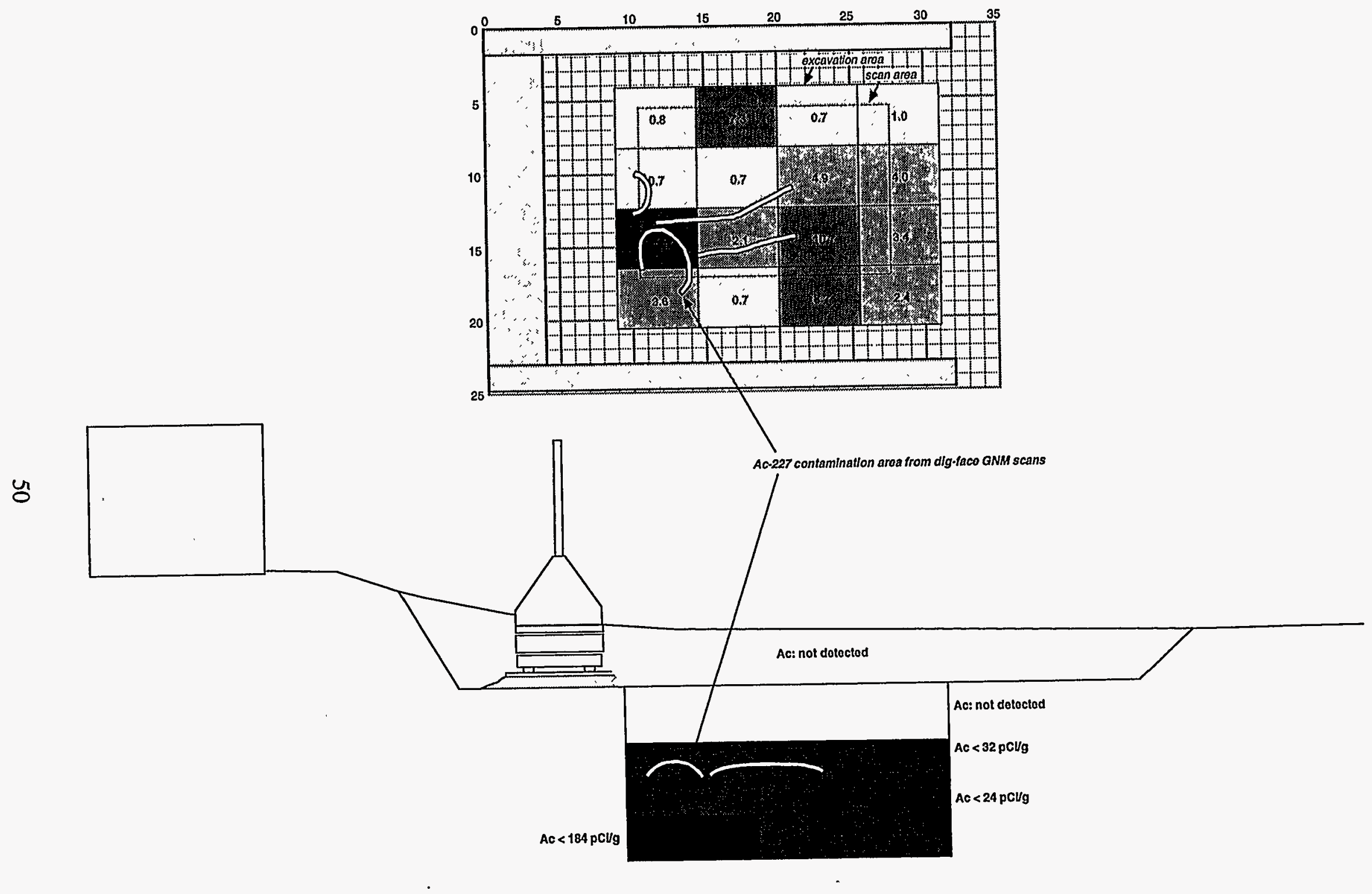

Figure 22. Comparison between ${ }^{227} \mathrm{Ac}$ contamination geometry as reconstructed from routine sample analysis versus dig-face scanning. Upper drawing shows the comparison at Level 4. Lower drawing shows a generalized cross section view. 


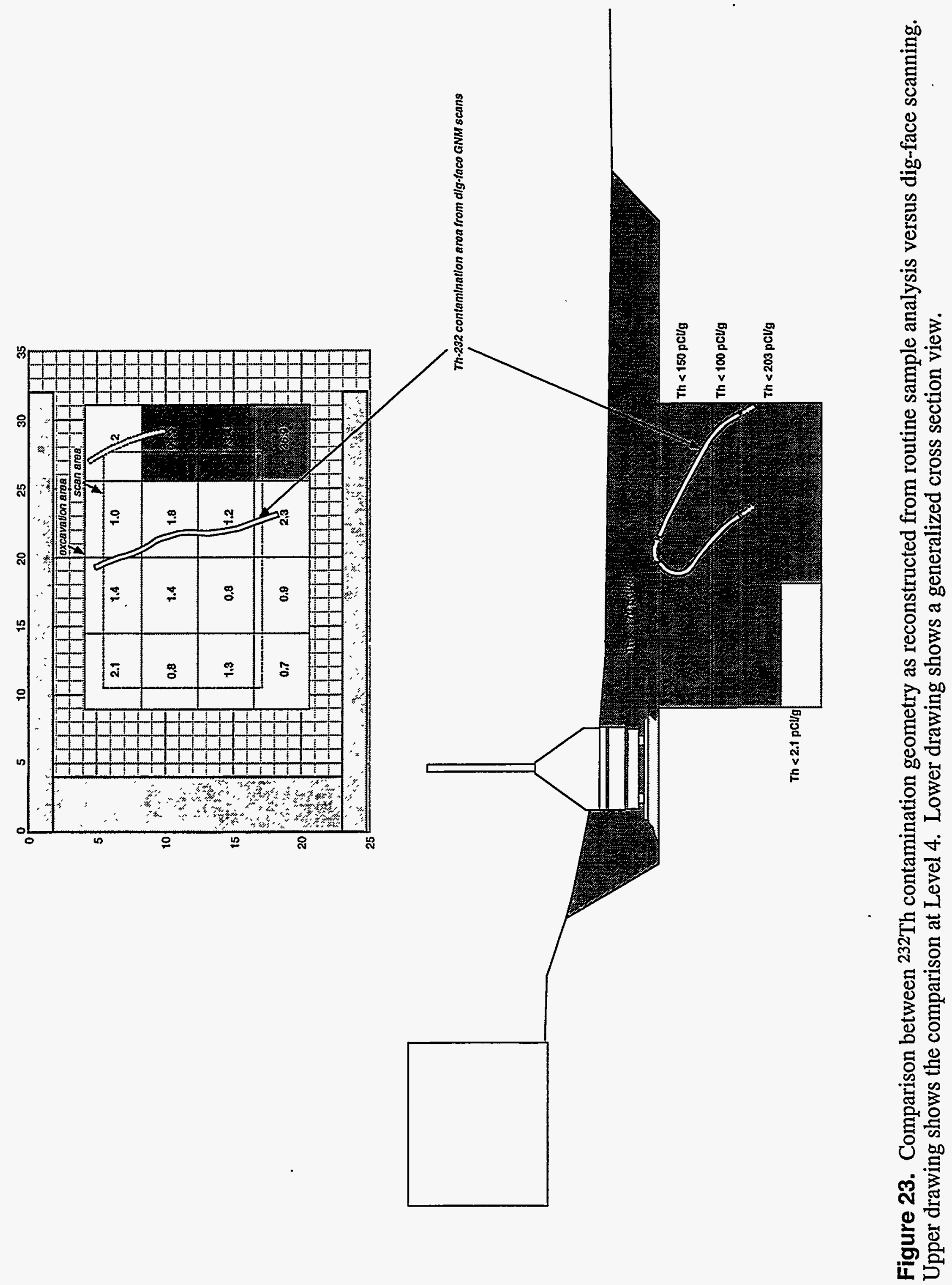


The images of plume geometry generated by the two alternate methods agree in their basic points. For example, both methods detect the onset of Th and Ac contamination in the vertical (depth) direction near the bottom of Compartments 1 and 3, respectively. ${ }^{c}$ Also, both systems locate the centers of the Th and Ac contamination areas at $+x$ and $-x$ ends of the pit, respectively. ${ }^{d}$ However, the dig-face radiation measurements provide a much higher fidelity spatial image of the plume geometries. Two factors account for the difference. First, the dig-face radiation measurements generate superior data point density through the formal scanning sequence conducted over the entire dig-face. Second, the dig-face sensors perform bulk measurements of relatively large soil volumes and thus avoid biases caused by small-scale heterogeneities in the contaminant plume. Such heterogeneities may be easily created by the normal moving and mixing of soils during excavation.

\section{Potential for Waste Minimization and Cost Savings}

The high-fidelity spatial information generated by the dig-face radiation sensors at Area 7 suggest that it may be possible in the future to use in situ monitoring to support preliminary waste separation at the dig-face. Such separation would be aimed at waste minimization, e.g., replacing clean soils directly back into the excavation. Of course, quantitative information regarding contamination levels is of paramount importance for defending such an approach in a regulated setting. This might initially be accomplished through modified direct sampling procedures guided by dig-face radiation measurements. If economic incentive is strong, it should also be possible to develop accurate and reliable real-time quantitative estimation methods based on the dig-face radiation measurements themselves.

Consider the contamination conditions in Compartments 1 and 2 of the Area 7 excavation. Based on interpretation of the GNM sensor data, it is conservatively estimated that only about $15 \%$ of this volume contained ${ }^{232} \mathrm{Th}$ above cleanup levels. Had it been possible to separate the clean soils and replace them in the ground, only about 29 soil boxes would have required packaging, handling, and shipping to engineered storage facilities, rather than 191 . At $\$ 5,000$ per box, the cost savings would have approached $\$ 800,000$.

\section{Operations Issues}

The sensors, trolley, and data acquisition system used for the Area 7 excavation were considered highly successful, if only because they functioned reliably as designed under difficult conditions. The weather during the excavation routinely exceeded 90 degrees, and the humidity exceeded $90 \%$. Two heavy thunderstorms soaked the equipment without mishap.

c. Daily sample logs show that ${ }^{232} \mathrm{Th}$ was not detected until the last day of the Compartment 1 excavation, indicating the plume began near the bottom of the Compartment 1 volume.

d. The 16 sample grid gives strong evidence for the ${ }^{232}$ Th position but is somewhat unclear for the ${ }^{227} \mathrm{Ac}$. Detection of high ${ }^{227} \mathrm{Ac}$ (and very $10 \mathrm{w}{ }^{232} \mathrm{Th}$ ) in the bottom of the excavation after the dig-face characterization system had been disassembled provides the best sample-based evidence for the ${ }^{227} \mathrm{Ac}$ position. 
Despite the excellent system performance, it would be incorrect to call the Area 7 operation routine. Improvements may be accomplished both in basic system function and in the area of system integration with excavation activities. This section presents brief observations that could lead to future improvements in system function and integration.

\section{Trolley Scan Footprint}

The effective scan area of the trolley-based dig-face characterization system became progressively smaller as the excavation advanced (Figure 24). Scan area corresponds to the range of sensor motion, which depends on the sensor dimensions and the location of impediments such as the excavation sidewalls.

The initial excavation area must preserve adequate support for the trolley track, causing the loss of several feet of work area on each side. For deep, unshored holes, more space must be allowed. As the excavation deepens, unshored sidewalls tend to slope inward and further reduce sensor range. For large sensors, such as the GNM, blind zones as large as 4 to $6 \mathrm{ft}$ on each side develop at relatively moderate depths $(3$ to $5 \mathrm{ft})$.

The loss of scan area appears to be a fundamental attribute of a trolley-based deployment system. Unless a deployment system can be designed that is not supported from the sides, the loss of scan area must be accommodated by use of a suitably oversized trolley.

\section{Portability}

Perhaps the major limitation of the trolley deployment system is its lack of portability. The trolley approach is well suited for extending an excavation in the track direction, but is not easily adaptable to extensions in the bridge direction. This shortcoming follows directly from the need to support the trolley's weight from the side. At Area 7, the dig-face characterization system could have continued to contribute to the ${ }^{227} \mathrm{Ac}$ excavation below the 5-ft depth level. Unfortunately, there was no way to reposition it over a new area of interest.

\section{Trolley Function}

The trolley functioned very well under remote control, minimizing the need for entry into the excavation exclusion zone. Entry into the exclusion zone was required, however, in order to set $x$ - and $y$ - limits for sensor scans at the beginning of each new Level. The limit settings were chosen through trial and error, by moving the trolley small increments in each direction until the sensor nearly contacted the excavation walls.

In future excavations, especially when exclusion zone entrance is more severely restricted, it will be necessary to determine scan limits remotely. Topography data (e.g., from the laser rangefinder) may serve for this purpose if the sidewall dropoffs can be mapped. Remote video may also work. 

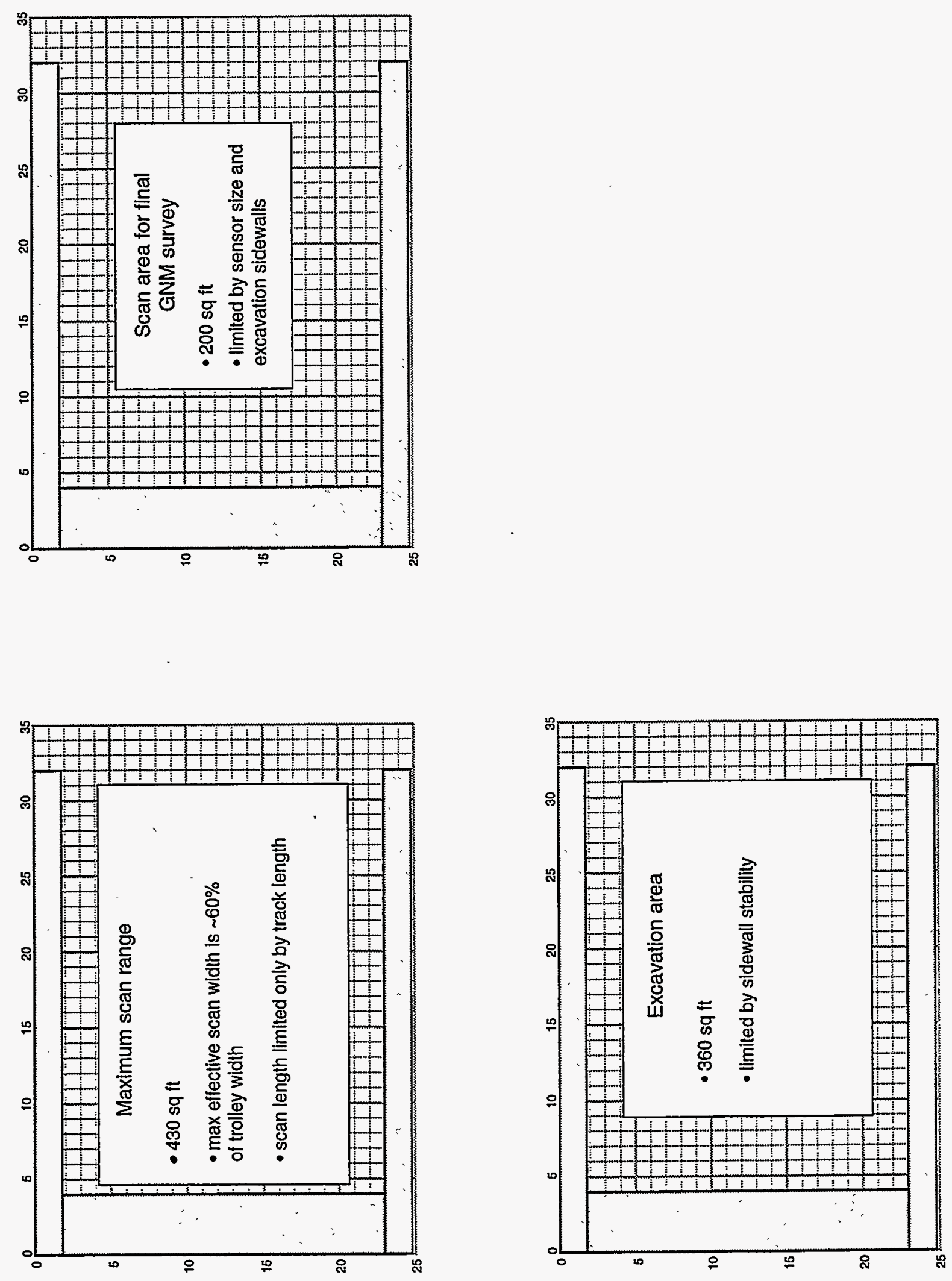


\section{Projected Cost for a Routine Dig-Face Characterization Operation}

The total investment for a functional trolley type dig-face characterization system depends mainly on sensor costs. It is estimated that the system taken to Mound could be duplicated, including sensors, for less than $200 \mathrm{~K}$. The equipment can be shipped by flatbed truck. Setup time takes less than a day. Actual operation of the system for routine scanning can be scheduled to create minimal standby time for the excavation operation. Scanning takes about 15 minutes per sensor, and could be performed at night.

In looking forward to the routine use of dig-face characterization for monitoring hazardous excavations, it is necessary to consider the cost of the operation. The operation at Mound was conducted comfortably with a three-person crew. It is reasonable to assume that the crew size can be reduced to two once operations are streamlined. The crew could function much like a well logging crew in the oil field service industry, with an equipment/software engineer and a professional data analyst. Table 3 gives some very preliminary estimates for the cost of operating a dig-face characterization system as a commercial venture.

Table 3. Cost estimate for operation of a dig-face characterization system as a commercial venture.

\begin{tabular}{lll}
\hline \multicolumn{1}{c}{ Item } & \multicolumn{1}{c}{ Basis } & Cost \\
\hline System cost & Mound prototype, including sensors & $<200 \mathrm{~K}$ \\
Shipping & Idaho to Ohio (one way) & $2 \mathrm{~K}$ \\
Setup & 1 day, 3 person crew ${ }^{\mathrm{a}}+$ heavy equip & $<2 \mathrm{~K}$ \\
Daily operation & 2-person crew & $0.5 \mathrm{~K}$ \\
1-month operation & 2-person crew, 30 days + travel, per diem & $22 \mathrm{~K}$ \\
6-month operation & 2-person crew, 180 days + travel, per diem & 130K \\
\hline \multirow{2}{*}{ Crew cost based on \$30/hr, unburdened. } & \\
\hline
\end{tabular}




\section{SOME COMMENTS FROM USERS}

The dig-face system was operated at Mound amidst the ongoing work of Mound environmental restoration managers, health physicists, union and nonunion hazardous waste workers, and federal regulators. In a sense, these groups are the dig-face characterization system users. If the system provides no benefit to them, from either a safety or cost savings standpoint, it misses the point. This section provides a collection of comments obtained from some of these groups during and after the Mound operation.

\section{ER Personnel}

According to Mssrs. Bob Stanley and Keith MacMahan (EG\&G Mound), Area 7 Environmental Restoration managers, the chief benefit of the dig-face operation was the system's ability to establish a clear, spatially registered picture of ${ }^{232} \mathrm{Th}$ and ${ }^{227} \mathrm{Ac}$ contamination area. The dig-face radiation measurements showed the contamination plumes to be confined and separate. Stanley and MacMahon said that they could not have developed the same detailed picture based on their sample analysis program. The dig-face results were instrumental in planning the final phase of excavation aimed at removing the main ${ }^{227} \mathrm{Ac}$ contamination. The dig-face results also initiated further consideration of the ${ }^{232} \mathrm{Th}$ problem at Area 7.

Stanley and MacMahan would have requested dig-face support for the final phase of their operation had it been capable of relocating over the ${ }^{227} \mathrm{Ac}$ contamination area. They pointed out that the immobility of the current system is in some ways self-defeating. The need to adjust an excavation plan based on in situ monitoring results is likely to be a common occurrence. If the dig-face system cannot adapt, it "works itself out of a job."

The potential for waste minimization using in situ monitoring data was not lost on Mound environmental restoration management. They believed, however, that this possibility raised regulatory issues, which they cannot control.

\section{Health Physics}

Mr. Henry Robinson (EG\&G Mound) was the lead health physicist during the Area 7 work. He commented that the dig-face system's ability to map and identify radioactive contaminants in real time was a significant achievement when compared with the time required to collect and analyze even a small number of samples. He did not say how or if this capability provided any benefit to his work as a health physicist.

As an experienced radiation measurements professional, Mr. Robinson had some questions concerning the effects of radioactive materials in the excavation walls. A radiation sensor's response to sources located above or to the side of a sensor is a condition referred to as bleed over. It is certain that ${ }^{232} \mathrm{Th}$ remained in the excavation walls as the hole was deepened. What contribution did the associated radiation fields have on the dig-face system maps? 


\section{Remediation Workers}

Mr. Mark Daubenmire was the labor coordinator and field manager for the Area 7 work. Mr. Daubenmire spent time in the excavation pit and in the exclusion zone handling excavated materials. He expressed notable interest in the dig-face data as they were output on the data acquisition screen and in the paper plots that were made on site.

Mr. Daubenmire stated that, at a minimum, the progressive views of the contamination areas as the excavation advanced provided the workers with a clear sense of their progress and success in removing the contaminated soil. Also, commenting on the question of safety and radiation exposure, Mr. Daubenmire made it clear that he never felt unsafe during the operation, for himself or for the work crew. He did say that "what they normally do on faith they could do based on reality, and (they) didn't have to conjure up an image of where and how big the contamination area was."

\section{Regulators}

Ms. Kathy Lee Fox (EPA-Region 9) visited the Area 7 site during the dig-face operation and attended a meeting of regional DOE organizations and the EPA where the preliminary Area 7 results were presented. Ms. Fox believed the system had relevance to both worker safety and waste minimization issues. She expressed the general opinion that it is time to seriously address the sampling philosophies that are used to support operations such as Area 7, in the interest of decreasing costs. Ms. Fox noted that any new system involved in health and safety or cleanup level decisions needed regulatory validation. From the EPA point of view, this process is easier when case histories such as Mound Area 7 exist. 


\section{REFERENCES}

Akers, D. W., R. J. Gehrke, and D. R. Staples, 1993, Dig-face Chemical and Radiation Sensor Assay System, EGG-WM-11034, EG\&G Idaho, Inc., Idaho Falls, ID.

Beck, H. L., J. DeCampo, and C. Gogolak, 1972, In-Situ Ge(Li) and NaI(Tl) Gamma-Ray-Spectrometry, Health and Safety Laboratory, U.S. Atomic Energy Commission Report HASL-258, TID-4500.

Collins, H. D., 1994, High Resolution Imaging of Buried Waste Using Holographic Impulse Radar Array, RI34002, Pacific Northwest Laboratories, Richland, WA.

Debertin, K. and R. G. Helmer, 1988, Gamma- and X-Ray Spectrometry with Semiconductor Detectors, Horth-Holland publishing Co., Amsterdam, Oxford, New York, Tokyo.

Gehrke, R. J., R. S. Lawrence and R. J. Pawelko, 1995, Results of Performance Tests on Chemical and Radiation Measurement Systems For Use at the Dig-face, INEL-95/0036, Lockheed Idaho Technologies Company, Inc., Idaho Falls, ID.

Gehrke, R. J., R. S. Lawrence, L. G. Roybal, J. M. Svoboda, D. J. Harker, D. N.Thompson, M. V. Carpenter, and N. E. Josten, 1995, Results of the Gamma-Neutron Mapper Performance Test on 55-Gallon Drums at the RWMC, INEL-95/0302, Lockheed Idaho Technologies Company, Inc., Idaho Falls, ID.

Graebner, P., 1993, Preliminary Data Processing and Data Analysis Concepts, Final Report for Subcontract C93-120493, EG\&G Idaho, Inc. Idaho Falls, ID.

Graebner, P., 1994, Dig-face Acquisition, Processing, and Analysis Concepts, Final Report for Subcontract C93-120493, EG\&G Idaho, Inc. Idaho Falls, ID.

Harthill, N. and A. A. Kaufman, 1993, Conceptual Design of an Optimized Electromagnetic Profiling System for Shallow Penetration Dig-face Characterization, Final Report for Subcontract P036563, RUST Geotech Inc., Grand Junction, CO.

ICRS (International Commission on Radiation Units and Measurements), 1994, Gamma-Ray Spectrometry in the Environment, ICRU Report 53, International Commission on Radiation Units and Measurements.

Josten, N. E., S. T. Marts, and G. S. Carpenter, 1991, Use of Noninvasive Geophysical Techniques for the In Situ Vitrification Program, EGG-WTD-9432 Volume 2, EG\&G Idaho, Inc., Idaho Falls, ID.

Josten, N. E., 1992, Preliminary Design For a Safe Step Remediation System, EGG-EELS-002, EG\&G Idaho, Inc., Idaho Falls, ID. 
Josten, N. E., and L. G. Roybal, 1993, Test Plan for Dig-face Characterization Performance Testing, EGG-WTD-10766, EG\&G Idaho, Inc., Idaho Falls, ID.

Josten, N. E., 1994, Test Plan for FY-94 Dig-face Characterization Field Experiments, EGG-WTD-11424, EG\&G Idaho, Inc., Idaho Falls, ID.

Josten, N. E., 1995, Progress on Development of the Dig-face Characterization Technology, INEL-95/0093, Lockheed Idaho Technologies Company, Inc., Idaho Falls, ID.

Svoboda, J. M. and R. A. Callow, 1994, Dig-face Characterization Development Plan, EGG-WTD-11062, EG\&G Idaho, Inc., Idaho Falls, ID. 


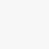


Appendix A

Radiation Sensor Calibration 
A-2 


\section{Appendix A}

\section{Radiation Sensor Calibration}

Both the GNM and the Ge-spectrometer were used to estimate the activity concentrations present in the ${ }^{232} \mathrm{Th}$ and the ${ }^{227} \mathrm{Ac}$ plumes. In order to do this, it was necessary to develop a calibration factor for the GNM and the in situ Ge-spectrometer. The GNM calibration factor, $\mathrm{K}_{\mathrm{M}}$, converts counts per second to $\mathrm{pCi} / \mathrm{g}$; the in situ Ge-spectrometer calibration factor, $\mathrm{K}_{\mathrm{G}}$, converts $\mathrm{pCi}$ to $\mathrm{pCi} / \mathrm{g}$. The following sections describe the empirical methods used to calibrate these detectors.

\section{GNM Efficiency Calibration}

Accurate efficiency calibration of a gross counter usually requires duplication of the expected working conditions, including the radionuclide(s) and source distribution. The efficiency is a major element of the conversion factor used to convert gross counter measurements into estimates of activity concentration.

At Mound, ${ }^{227} \mathrm{Ac}$ was believed to be of primary concern. The GNM was efficiency calibrated for a plane distributed source of ${ }^{227}$ Ac. However, the amount by which this efficiency for a plane distributed source is changed by a source evenly distributed over a volume depends on the volume of investigation of the GNM, which was not accurately determined by simple laboratory procedures. Rather than estimate the effective volume being detected by the GNM, it was decided to use on-site measurements of natural ${ }^{232} \mathrm{Th}$ for calibration. Measuring the GNM response for (assumed) uniformly distributed natural ${ }^{232} \mathrm{Th}$ at (assumed) known levels permitted a calibration that incorporates effects from both volume of investigation and radionuclide specificity. Based on additional assumptions, the ${ }^{232} \mathrm{Th}$ conversion factor was scaled to produce an ${ }^{227} \mathrm{Ac}$ conversion factor. The following sections describe this process of determining the ${ }^{232} \mathrm{Th}$ and ${ }^{227} \mathrm{Ac}$ conversion factors.

\section{Deduced Conversion Factor, $K_{M}(T h)$, for ${ }^{232} T h$ (and daughters)}

The presence of a relatively high-activity plume of ${ }^{232} \mathrm{Th}$ distributed over a large volume of the Mound excavation site was not expected. No laboratory measurements had been made to determine appropriate conversion factors for ${ }^{232} \mathrm{Th}$. By necessity, the GNM was efficiency calibrated at Mound by taking advantage of the natural thorium present in the soil away from the contamination plume.

Natural thorium activity concentration for soils ranges from $\sim 0.5$ to $4 \mathrm{pCi} / \mathrm{g}$. The natural background level ${ }^{232} \mathrm{Th}$ activity concentration at the Area 7 excavation site was estimated to be $1.5 \mathrm{pCi} / \mathrm{g}$. This value is based on typical measured values at Mound. Another radionuclide naturally present in soil is ${ }^{40} \mathrm{~K}$. It has a higher natural activity concentration in most soils $(8$ to $20 \mathrm{pCi} / \mathrm{g})$ and can be further elevated owing to the application of fertilizer or ice melt. An average ${ }^{40} \mathrm{~K}$ activity concentration of $43 \mathrm{pCi} / \mathrm{g}$ was measured with the Ge-spectrometer from 20-g soil samples taken during the Area 7 excavation at Levels 1 and 2 . The contribution of natural uranium was considered negligible. 
Although natural ${ }^{40} \mathrm{~K}$ has a higher activity concentration in soil than natural ${ }^{232} \mathrm{Th}$ and its daughters, only $10.5 \%$ of ${ }^{40} \mathrm{~K}$ decays emit a detectable $\gamma$-ray at $1460 \mathrm{keV}$ (Browne and Firestone 1986). On the other hand, summing all $\gamma$-rays emitted in the decay of ${ }^{232} \mathrm{Th}$ and its daughters results in $>223 \%$ total emission probability (Browne and Firestone 1986) of detectable $\gamma$-rays per decay (i.e., Ey $2238 \mathrm{keV})$. Hence, $[\Sigma \mathrm{P}(\mathrm{Th}) / \Sigma \mathrm{P}(\mathrm{K})]=21.2$. Since the $\gamma$-ray energy of monoenergetic ${ }^{40} \mathrm{~K}$ is $1460 \mathrm{keV}$, and the average $\gamma$-ray energy for ${ }^{232} \mathrm{Th}$ and its daughters (weighted by the $\gamma$-ray intensities) is $-970 \mathrm{keV}$, relative differences in the detector efficiency for ${ }^{232} \mathrm{Th}$, its daughters, and ${ }^{40} \mathrm{~K}$ reduce the fraction of ${ }^{40} \mathrm{~K}$ counts detected by another $\sim 20 \%$, that is $\left[1-\mathrm{e}^{-\mu(\mathrm{Th})^{*} \rho(\mathrm{Th})^{*} t}\right] /\left[1-\mathrm{e}^{-\mu(\mathrm{K})^{*} \rho^{*} t}\right]=1.2$, where $\mu(\mathrm{Th})$, and $\mu(\mathrm{K})$ are the mass absorption coefficients for the average $\gamma$-ray energy of thorium and potassium, respectively, $\rho(s)$ is the density of soil, and $t$ is the effective thickness. When measuring total natural background in the vicinity of the trolley parking area, ${ }^{40} \mathrm{~K}$ contributes $-52 \%$ or $420 \mathrm{c} / \mathrm{s}$ of the GNM total gross count rate.

Solving Equation $A 1$ for $\mathrm{K}_{\mathrm{M}}$, with a total background count rate of $800 \mathrm{c} / \mathrm{s}$, a ${ }^{40} \mathrm{~K}$ background contribution of $420 \mathrm{c} / \mathrm{s}$, and an activity of $1.5 \mathrm{pCi} / \mathrm{g}$ of ${ }^{232} \mathrm{Th}, \mathrm{K}_{\mathrm{M}}(\mathrm{Th})$ equals $253.34(\mathrm{c} / \mathrm{s}) /(\mathrm{pCi} / \mathrm{g})$.

$A=\left(A_{M}-B\right) / K_{M}$,

where

$\begin{array}{ll}\mathrm{B} & =\text { background count rate }(\mathrm{c} / \mathrm{s}) \text { due to }{ }^{40} \mathrm{~K} \\ \mathrm{~A}_{M} & =\text { count rate }(\mathrm{c} / \mathrm{s}) \\ \mathrm{K}_{\mathrm{M}}(\mathrm{Th}) & =\text { conversion factor for }{ }^{232} \mathrm{Th}(\mathrm{c} / \mathrm{s}) /(\mathrm{pCi} / \mathrm{g}) .\end{array}$

No attempt was made to correct for differences from count-to-count in the effective area or depth of the ${ }^{232} \mathrm{Th}$ contamination plume observed by the GNM.

\section{Deduced Conversion Factor for ${ }^{227} \mathrm{AC}$ (and daughters)}

The conversion factor for the GNM differs for each radionuclide owing to differences in the average energy of the emitted $\gamma$-rays and the total number of $\gamma$-rays per 100 decays. Equation A2 modifies the value of the conversion factor $\mathrm{K}_{\mathrm{M}}(\mathrm{Th})$ for these differences to yield a conversion factor, $\mathrm{K}_{\mathrm{M}}(\mathrm{Ac})$, for ${ }^{227} \mathrm{Ac}$ :

$\mathrm{K}_{\mathrm{M}}(\mathrm{Ac})=\mathrm{K}_{\mathrm{M}}(\mathrm{Th}) * \mathrm{C}_{1}{ }^{*} \mathrm{C}_{2} /\left[\sum \mathrm{P}(\mathrm{Th}) / \sum \mathrm{P}(\mathrm{Ac})\right]^{\mathrm{a}}$

where

$\mathrm{K}_{\mathrm{M}}(\mathrm{Th})=$ the conversion factor for ${ }^{232} \mathrm{Th}$ (and daughters)

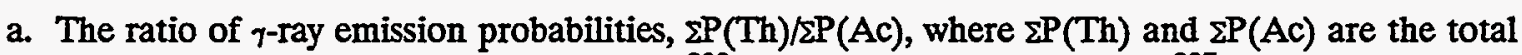
emission probabilities per 100 decays for all ${ }^{232} \mathrm{Th}$ and daughter, and for all ${ }^{227} \mathrm{Ac}$ and daughter $\gamma$-rays, respectively. The $y$-ray emission probabilities are from Browne and Firestone (1986). 


$$
\begin{aligned}
& \mathrm{K}_{\mathrm{M}}(\mathrm{Ac})=\text { the conversion factor for }{ }^{227} \mathrm{Ac} \text { (and daughters) } \\
& \mathrm{C} 1=\left[1-\mathrm{e}^{-\mu(\mathrm{Ac})^{*} \tau^{*} t}\right] /\left[1-\mathrm{e}^{-\mu(\mathrm{Th})^{*} \mathrm{p}^{*} t}\right]=1.53 \text {, a ratio of the percent absorption } \\
& \text { in the plastic scintillator by the average energy of the } \boldsymbol{\gamma} \text {-rays emitted } \\
& \text { by }{ }^{227} \mathrm{Ac} \text { and by }{ }^{232} \mathrm{Th} \\
& \mathrm{C}_{2} \quad=\left[\mathrm{e}^{-\mu(\mathrm{Ac})^{*} \mathrm{r}^{*} \mathrm{~d}}\right] /\left[\mathrm{e}^{-\mu(\mathrm{Th})^{*} \rho^{*} \mathrm{~d}}\right]=0.71 \text { for } \mathrm{d}=15 \mathrm{~cm} \text { and }=0.62 \text { for } \mathrm{d}=30 \\
& \mathrm{~cm} \text {, a ratio of the percent transmission out of the soil by the average } \\
& \text { energy } \gamma \text {-rays emitted by }{ }^{227} \mathrm{Ac} \text { and by }{ }^{232} \mathrm{Th} \\
& {[\Sigma \mathrm{P}(\mathrm{Th}) / \Sigma \mathrm{P}(\mathrm{Ac})]=2.75}
\end{aligned}
$$

Since $C_{2}$ is slowly varying as a function of depth, a value of $C_{2}=0.66$ is chosen. The parameters $\mu(\mathrm{Ac})$ and $\mu(\mathrm{Th})$ are the mass absorption coefficients for ${ }^{227} \mathrm{Ac}$ and ${ }^{232} \mathrm{Th}$, respectively. The $\mu$ used to determine $C_{1}$ are for plastic, and the $\mu$ used to determine $C_{2}$ are for soil; $\rho(i)$ is the matrix density where $i=p$ is for plastic and $i=s$ is for soil; $t$ is the thickness of the plastic scintillator; and $d$ is the thickness of soil viewed by the detector. Combining terms yields $\mathrm{K}_{\mathrm{M}}(\mathrm{Ac})$ $=93.0(\mathrm{c} / \mathrm{s}) /(\mathrm{pCi} / \mathrm{g})$ for a plume extended at least to the edge of the detector's view. A smaller plume requires a decrease in the value of $\mathrm{K}_{\mathrm{M}}(\mathrm{Ac})$.

For the ${ }^{227} \mathrm{Ac}$ plume at Level 4 , the $\mathrm{K}_{\mathrm{M}}(\mathrm{Ac})$ value was reduced by a factor of 3.3 owing to the small size of the plume (i.e., it occupies only a portion of the field of view of the GNM, which is estimated to be $\left.\sim 5940 \mathrm{~cm}^{2}\right)$. Hence, $\mathrm{K}_{\mathrm{M}}(\mathrm{Ac})=28.0(\mathrm{c} / \mathrm{s}) /(\mathrm{pCi} / \mathrm{g})$ was used to estimate the activity concentration of the ${ }^{227} \mathrm{Ac}$ plume.

\section{Ge-Spectrometer Efficiency Calibration}

As indicated in the text, the Ge-spectrometer was used in two modes: (a) for counting soil in situ at distances of $\sim 15 \mathrm{~cm}$ from the center of the detector or $-30 \mathrm{~cm}$ from the center of the detector, and (b) for counting $\sim 20 \mathrm{-g}$ soil samples at a distance of $1.0 \mathrm{~cm}$ from the detector housing. Measurements at the first through third excavation levels were made with the Ge-spectrometer support assembly resting on the ground (i.e., $\sim 15 \mathrm{~cm}$ from the center of the detector). Measurements at the fourth excavation elevation were made at a distance of $\sim 30 \mathrm{~cm}$ from the center of the detector.

\section{In Situ Efficiency Calibration}

By removal of a bottom piece from the side of the bismuth shield, the Ge-spectrometer can be used to count an exposed ground surface in situ, as shown in Figure A1. The efficiency of the Ge detector was measured using a mix of standardized radionuclides $\left({ }^{109} \mathrm{Cd},{ }^{57} \mathrm{Co},{ }^{139} \mathrm{Cd}\right.$, ${ }^{113} \mathrm{Sn},{ }^{54} \mathrm{Mn}$, ${ }^{88} \mathrm{Y},{ }^{65} \mathrm{Zn}$, and ${ }^{60} \mathrm{Co}$ ). A checkerboard distribution of point sources of this mixed radionuclide standard solution was deposited on two sheets of plastic to simulate a plane source covering an area of $\sim 774 \mathrm{~cm}^{2}$ and dried. The dried activity was covered with polyester tape. The efficiency curve resulting from counting this standard represents a source extending in the $x, y$ plane with no extension in the $z$ direction (i.e., depth). This efficiency curve was then modified to represent a source 

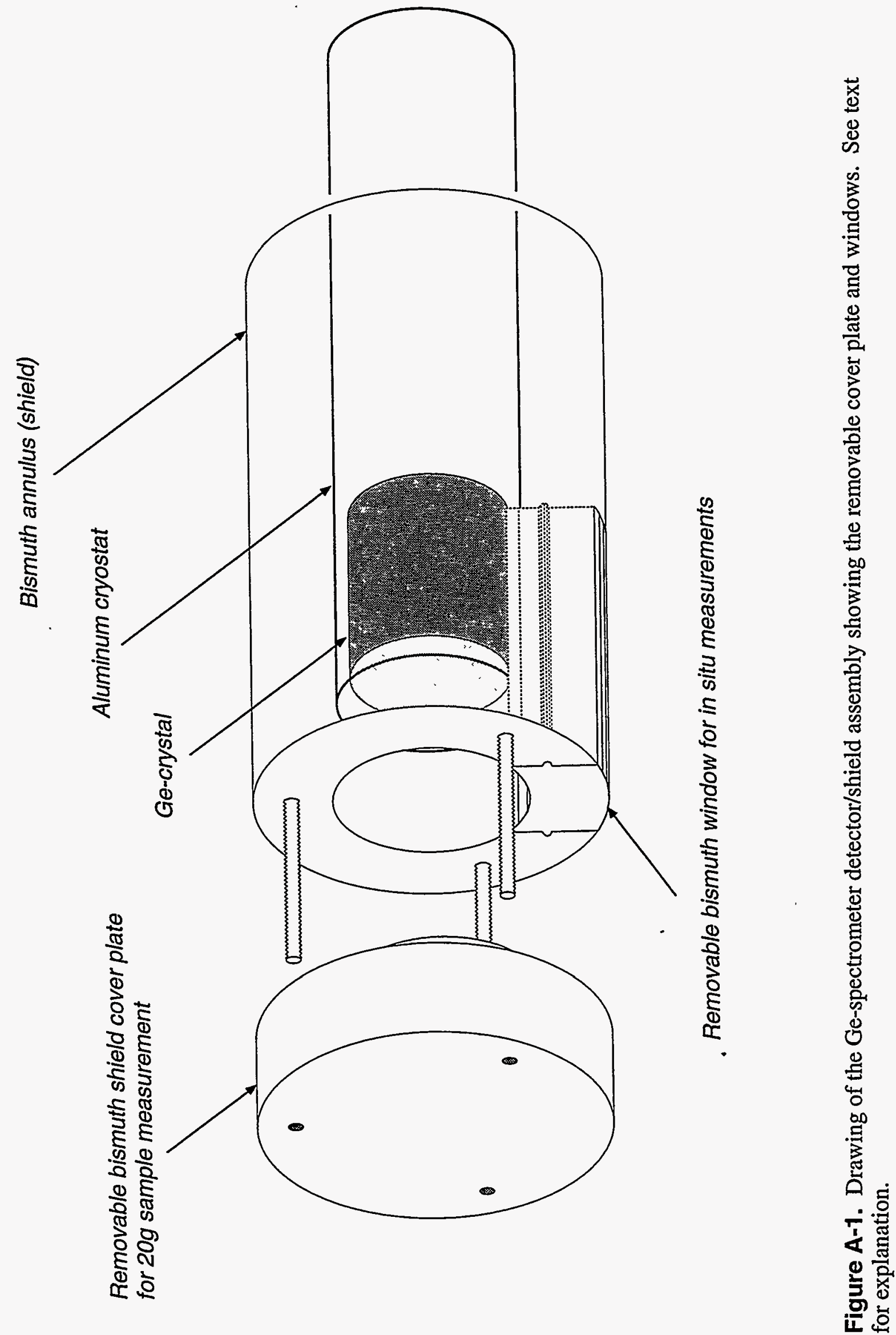
distributed in the soil over a depth of $30 \mathrm{~cm}$ by including the attenuation from such a distributed source.

We also obtained a long count of a 30 -cm-thick concrete floor where the detector efficiency measurements were being made. This floor contains natural thorium and uranium distributed uniformly throughout. A relative efficiency curve was developed from this count by using the relative $\boldsymbol{\gamma}$-ray emission probabilities of the daughters comprising the natural thorium and uranium chains. No $\gamma$-ray peaks associated with the natural radioactivity from the concrete were measured below $238 \mathrm{keV}$. The relative efficiency curve from the cement floor was then normalized at $\sim 238 \mathrm{keV}$ to the modified efficiency curve measured with a mixed radionuclide standard. This additional step was performed to normalize the efficiency to an absolute full-energy peak efficiency because the activity concentration of ${ }^{232} \mathrm{Th}$ in the concrete slab was not known.

The Ge-spectrometer $\gamma$-ray efficiency was used to convert the net peak area count rates from analysis of the Ge-spectrometer $\boldsymbol{\gamma}$-ray spectrum to yield activity in $\mathrm{pCi}$. These activity values were then divided by $\mathrm{K}_{\mathrm{G}}(\mathrm{Th})=\mathrm{K}_{\mathrm{G}}(\mathrm{Ac})$ to yield the in situ activity concentration in $\mathrm{pCi} / \mathrm{g}$. Since the Ge-spectrometer efficiency corrects the net peak area count rate for each $\gamma$-ray separately and the spectral analysis program corrects for $P$ (the number of $\gamma$-rays per decay), a separate conversion factor for ${ }^{227} \mathrm{Ac}$ is not required.

\section{Efficiency Calibration for Samples}

The Ge-spectrometer was efficiency calibrated with $20 \mathrm{~g}$ soil samples loaded into a pancake-shaped plastic container 7- $\mathrm{cm}$ in diameter by $8-\mathrm{mm}$ in height with inside dimensions of 6.5-cm diameter by 5-mm deep, as shown in Figure A2. The soil was homogeneously spiked with a distribution of mixed standardized radionuclides $\left({ }^{109} \mathrm{Cd},{ }^{57} \mathrm{Co},{ }^{139} \mathrm{Cd},{ }^{113} \mathrm{Sn},{ }^{54} \mathrm{Mn},{ }^{88} \mathrm{Y}\right.$, ${ }^{65} \mathrm{Zn}$, and ${ }^{60} \mathrm{Co}$ ). This efficiency was measured in the standard manner. 


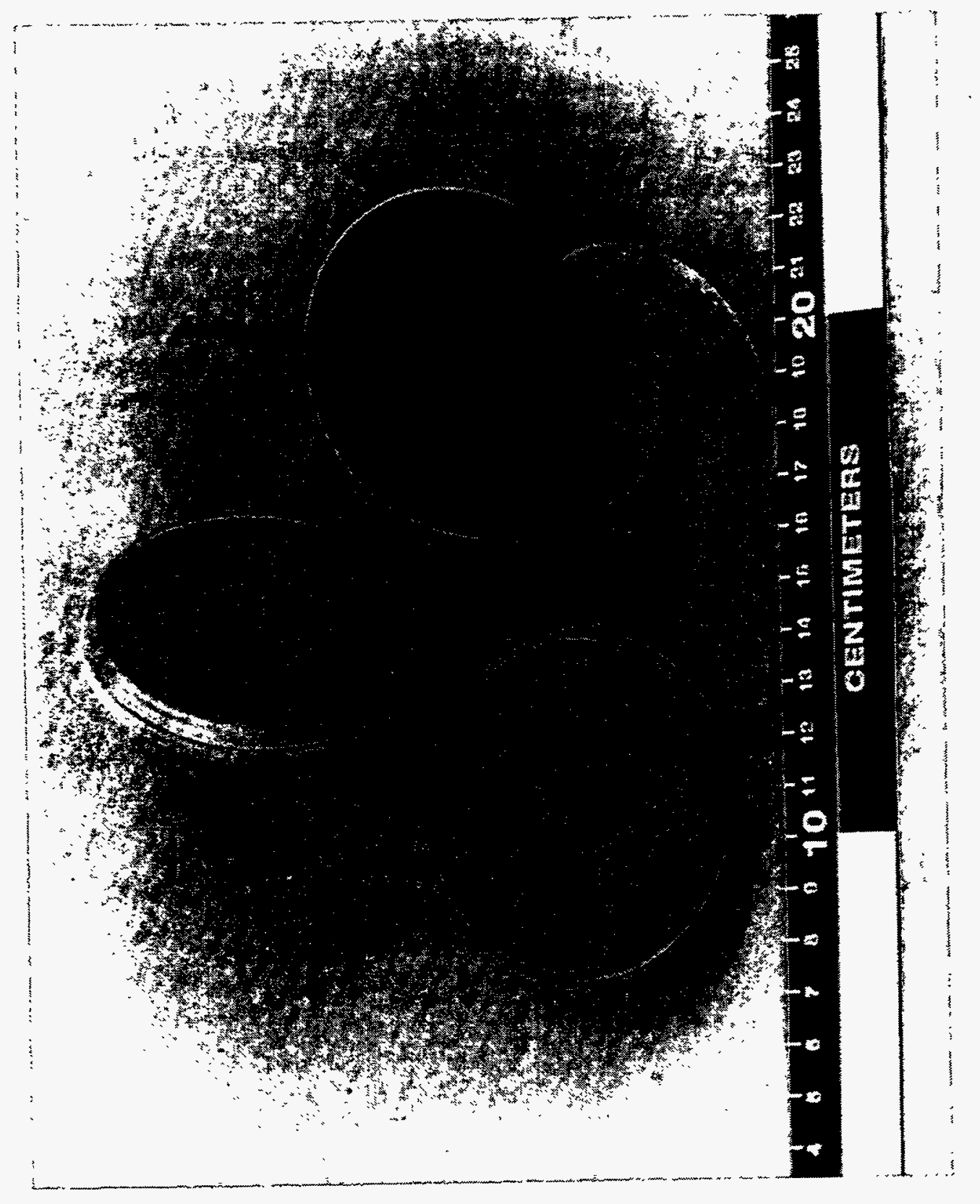




\section{APPENDIX A REFERENCES}

Browne, E. and R. B. Firestone, Table of Radioactive Isotopes, ed. V. S. Shirley (Wiley, New York) 1986. 
